\title{
Evolução ponderal de gestantes clientes de serviço público de pré-natal: influência de fatores socieconômicos, reprodutivos e comportamentais
}

\author{
Silvia Cristina Konno
}

Dissertação apresentada ao Programa de PósGraduação em Saúde Pública da Universidade de São Paulo para obtenção do título de Mestre em Saúde Pública

Área de Concentração: Nutrição

Orientadora: Maria Helena D'Aquino Benicio

São Paulo

2005 
Autorizo, exclusivamente para fins acadêmicos e científicos, a reprodução total ou parcial desta dissertação, por processos fotocopiadores.

\section{Assinatura:}

Data:

$$
4|c, 837| 20 \times 54 x
$$




\section{Agradecimentos}

À Profa. Maria Helena D'Aquino Benício pela dedicada orientação, e pelo aprendizado que tem me proporcionado ao longo deste anos.

Ao Prof. Aluisio D. J. Barros pelas sugestões na análise multinivel.

Ao Prof. José Maria Pacheco de Souza pela grande ajuda na realização do modelo multinivel.

Ao Prof. Wolney Conde pelo incentivo e amizade desde os tempos da Graduação.

Aos meus pais pelo incentivo e apoio ao longo destes anos.

Ao James, meu amor, pelo apoio, incentivo e carinho.

A todos que participaram da realização do projeto de gestantes, sem vocês este trabalho não seria possivel. 


\section{ÍNDICE}

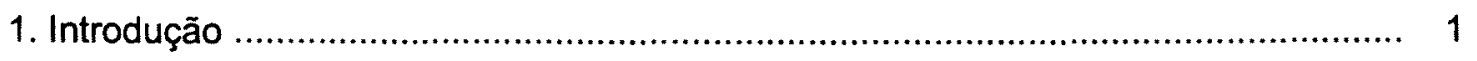

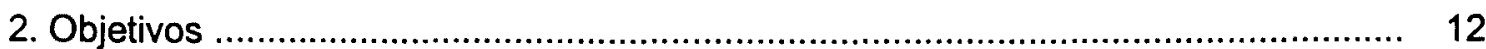

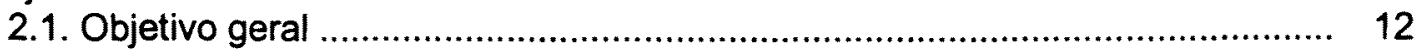

2.2. Objetivos especificos ...................................................................... 12

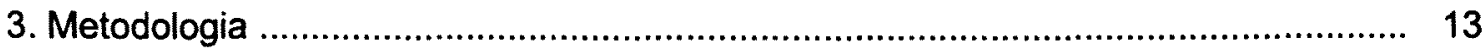

3.1. Delineamento do estudo ...................................................................... 13

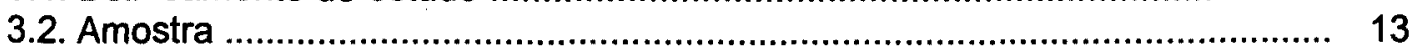

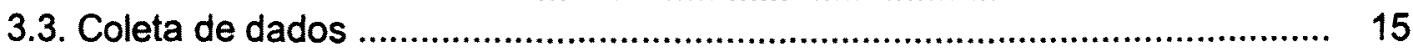

3.4. Variáveis de estudo ................................................................................. 16

3.4.1. Evolução da gordura corporal e pregas cutâneas triciptal e subescapular durante a gestação ................................................... 16

3.4.2. Evolução do peso corporal .......................................................... 17

3.4.2.1. Variável resposta $\quad 17$

3.4.2.1. Variáveis independentes ................................................ 17

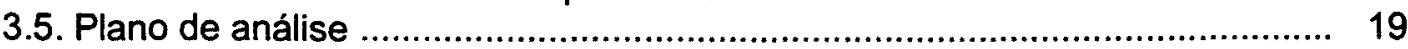

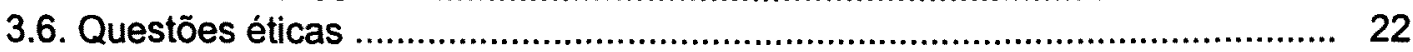

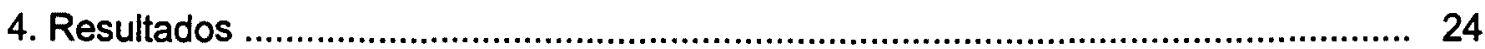

4.1. Descrição das gestantes ...................................................................... 24

4.2. Mudanças longitudinais de peso, gordura corporal e pregas cutâneas
triciptal e subescapular durante a gestação ............................................... 26

4.3. Influência de fatores socioeconômicos, reprodutivos e comportamentais sobre a evolução do peso gestacional ................................................ 30

4.3.1. Análise exploratória inicial ........................................................... 30

4.3.2. Análise bivariada .................................................................. 31

4.3.3. Análise multivariada ............................................................. 42

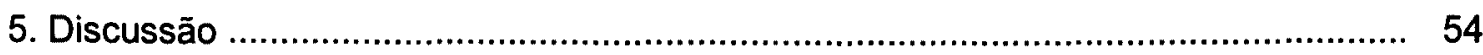

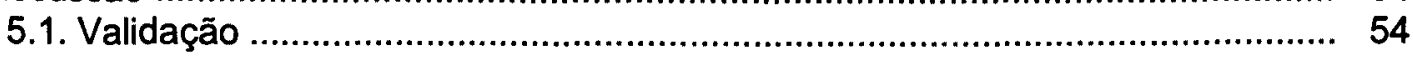

5.2. Caracteristicas das gestantes .............................................................. 55

5.3. Mudanças longitudinais na gordura corporal e nas medidas de pregas cutâneas triciptal e subescapular durante a gestação ................................. 57

4.3. Influência de fatores socioeconômicos, reprodutivos e comportamentais sobre a evolução do peso gestacional ................................................... 60

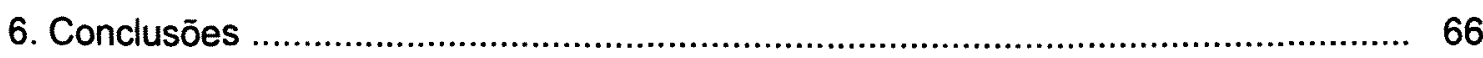

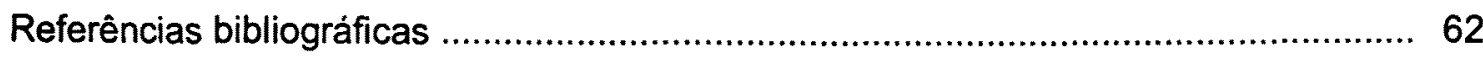

Anexos 


\section{LISTA DE TABELAS}

Tabela 1 Distribuição das gestantes da coorte, segundo características socioeconômicas, demográficas, estado nutricional inicial, história reprodutiva e hábito de fumar. São Paulo, março/1997 a outubro/1998

Tabela 2 Distribuição das gestantes da coorte, segundo características antropométricas e idade gestacional no inicio do segumento. São Paulo, março/1997 a outubro/1998

Tabela 3 Mudanças no peso corporal, na gordura corporal e nas pregas cutâneas triciptal e subescapular. São Paulo, março/1997 a outubro/1998

Tabela 4 Análise bivariada para predição da evolução do peso durante a gestação. São Paulo, março/1997 a outubro/1998

Tabela 5 Análise linear multinivel hierarquizada para predição da evolução do peso durante a gestação. São Paulo, março/1997 a outubro/1998

Tabela 6 Ganho ponderal estimado segundo estado nutricional inicial, nível de escolaridade, situação marital e paridade. São Paulo, março/1997 a outubro/1998 


\section{LISTA DE FIGURAS}

Figura 1 Gestantes incluídas na coorte, número e razões das perdas

Figura 2 Marco teórico para a investigação de determianantes individuais do ganho de peso gestacional

Figura 3 Evolução do peso e da gordura corporal ao longo da gestação. São Paulo, março/1997 a outubro/1998

Figura 4 Evolução das pregas cutâneas triciptal e subescapular durante a gestação. São Paulo, março/1997 a outubro/1998

Figura 5 Evolução do peso corporal gestacional estimado segundo idade gestacional. São Paulo, março/1997 a outubro/1998 


\section{RESUMO}

Konno SC. Evolução ponderal de gestantes clientes de serviço público de prénatal: influênica de fatores socioeconômicos, reprodutivos e comportamentais. São Paulo, 2005 [Dissertação de Mestrado - Faculdade de Saúde Pública da Universidade de São Paulo].

Introdução: No Brasil, altas prevalências de obesidade são observadas, principalmente na população feminina. Estudos têm apontado o ganho de peso excessivo durante a gestação como um dos fatores associados à obesidade em mulheres.

Objetivos: Neste estudo avaliou-se a influência de fatores socioeconômicos, reprodutivos e comportamentais sobre a evolução do peso durante a gestação.

Metodologia: Estudou-se uma coorte de 225 gestantes inscritas em serviço público de pré-natal de baixo risco do municipio de São Paulo, no período de março de 1997 a março de 1998. Os dados foram obtidos a partir de entrevistas e avaliação antropométrica mensal, com início anterior a $16^{\mathrm{a}}$ semana de gestação. A influência dos fatores de estudo sobre a evolução do peso gestacional foi avaliada mediante análise multinivel linear hierarquizada para medidas repetidas.

Resultados: $A$ análise multinivel mostrou associação estatisticamente significativa da evolução ponderal com as variáveis IMC inicial, escolaridade, paridade e hábito de fumar. As equações obtidas permitiram identificar o efeito individualizado de cada um dos fatores estudados. Escolaridade $\geq 5$ anos, ausência de companheiro e primiparidade elevam o ganho médio de peso durante a gestação em $2,2 \mathrm{~kg}, 1,5 \mathrm{~kg}$ e $2,0 \mathrm{~kg}$ respectivamente. Observou-se que estas condições são freqüentes na coorte: $70 \%$, um quarto e mais da metade, respectivamente.

Conclusão: $O$ conjunto dos resultados obtidos ressaltam a importância do monitoramento do peso gestacional, que constitui uma estratégia fundamental para o aconselhamento nutricional com vistas um ganho ponderal gravídico adequado. Assim, devem receber maior atenção as gestantes com maior escolaridade, as primiparas e as sem companheiro.

Descritores: Ganho de peso. Gestação. Análise multinivel. Medidas repetidas. 


\section{SUMMARY}

Konno SC. Ponderal evolution of pregnants customers of public health prenatal service: the influence of socioeconomic, reproductive and behavioral factors. São Paulo, 2005 [Master degree thesis - School of Public health of the University of São Paulo].

Introduction: A high prevalence of obesity is observed in Brazil, especially in the female population. Studies have indicated excessive weight gain during gestation as one of the factors associated with obesity in women.

Objectives: The objective of this study is to assess the influence of socioeconomic, reproductive and behavioral factors on the evolution of weight during gestation.

Methodology: The study group consisted of 225 pregnant women enrolled in a public low risk pre-natal service from the city of São Paulo, between March 1997 and March 1998. The data was obtained with a basis on interviews and monthly anthropometric evaluation, starting prior to the $16^{\text {th }}$ week of gestation. The influence of the study factors on the evolution of gestational weight was evaluated by means of linear multilevel analysis hierarchicized for repeated measures.

Results: The multilevel analysis demonstrated a statistically significant association of ponderal evolution with the following variables: initial BMI, academic level, parity and smoking habit. The equations that were obtained permitted the identification of the individualized effect of each one of the studied factors. Academic level $\geq 5$ years, absence of spouse and primiparity cause the average weight to rise during pregnancy by $2.2 \mathrm{~kg}, 1.5 \mathrm{~kg}$ and $2.0 \mathrm{~kg}$ respectively. It was observed that these conditions are frequent in the group: $70 \%$, one fourth and more than half, respectively.

Conclusion: The set of results obtained emphasize the importance of gestational weight monitoring, which constitutes an essential strategy for nutritional counseling aiming at an adequate gestational weight gain. Hence pregnant women with a higher academic level, those given birth for the first time and those without a spouse should receive more attention.

Descriptors: Weight gain. Pregnancy. Multilevel analysis. Repeated measures. 


\section{INTRODUÇÃO}

A obesidade é atualmente um dos principais problemas de saúde de pública em paises desenvolvidos. Em alguns paises em desenvolvimento, a prevalência da obesidade vem aumentando dramaticamente, representando um problema emergente para estes países (Popkin, 1994). O Brasil apresenta elevadas taxas de obesidade (Índice de Massa Corporal maior ou igual a 30,0 $\mathrm{kg} / \mathrm{m}^{2}$ ), principalmente na população feminina. A prevalência da obesidade nas mulheres brasileiras é de $12,5 \%$ enquanto que na população masculina é de $6,9 \%$. A análise dos dados de três inquéritos nutricionais de abrangência nacional realizados em 1975, 1989 e 1997 revela um aumento estatisticamente significante do risco de obesidade entre as mulheres com mais de 20 anos no periodo de 1975-89 e um aumento significante do risco de obesidade em mulheres urbanas de baixa renda e mulheres da área rural de categorias intermediárias de renda no período de 1989 a 1997 (Monteiro, 2000).

A obesidade provoca inúmeras alterações metabólicas, contribui para a patogênese de várias doenças crônicas e também está associada com aumento do risco de morbidade e mortalidade. No sexo feminino, o excesso de peso pode causar redução da fertilidade, câncer de endométrio e, ainda, estar associado com prejuízos da saúde mental, que se expressa através de depressão, transtornos alimentares, baixa auto-estima e insatisfação corporal 
(Gunderson \& Abrams, 1999; World Health Organization, 1998).

Durante a gestação, a obesidade $\left(\mathrm{IMC} \geq 25,0 \mathrm{~kg} / \mathrm{m}^{2}\right)$ tem sido associada com aumento dos riscos gravidicos. Um estudo com 287.213 mulheres mostrou que durante a gravidez a obesidade associa-se a diabetes mellitus gestacional, pré-eclampsia, proteinúria, indução prematura ao trabalho de parto, cesáreas de emergência, hemorragia no pós-parto, infecção do trato genital, infecção do trato urinário, infecção de ferimentos, recém-nascidos grandes para a idade gestacional, e morte intrauterina. O estudo conclui que a obesidade materna acarreta riscos tanto para a mãe quanto para o feto (Sebire et al, 2001).

O balanço energético (diferença entre o consumo e gasto energético) é fator determinante da obesidade, isto é, quanto mais freqüente e intensamente o consumo de energia exceder o dispêndio do indivíduo (balanço energético positivo), maior o risco de se tornar obeso (Monteiro, 1998). Transformações que estão ocorrendo nos paises em desenvolvimento como a adoção de uma dieta rica em gorduras saturadas, açúcares e alimentos refinados e a redução da atividade física favorecem o balanço energético positivo (Martorell et al, 1998; Popkin, 1994). A gestação é um momento no qual se orienta o aumento do consumo de energia, 300 kcal extras por dia, ou um aumento acumulativo total de $80000 \mathrm{kcal}$. Esta recomendação é baseada supondo que a mulher deposita $3,3 \mathrm{~kg}$ de gordura corporal durante a gestação, equivalente a aproximadamente $32000 \mathrm{kcal}$ ou metade do custo acumulativo total da 
gestação (Abrams \& Selvin, 1995; Koop-Hoolihan, 1999; Ministério da Saúde, 2000).

Estudos enfocando a obesidade severa em mulheres têm apontado a retenção de peso que ocorre após a gestação como uma das causas da obesidade (Gunderson \& Abrams, 1999). Evidências de estudos observacionais têm associado a excessiva taxa de ganho de peso gestacional e o IMC prégestaciional com acelerados e persistentes incrementos de peso no pós-parto (Feig \& Naylor, 1998).

Recente revisão sistemática da literatura acerca da epidemiologia do ganho de peso durante a gestação e seu impacto sobre o risco de obesidade indica que tanto o ganho excessivo de peso como a mudança de estilo de vida após o nascimento do bebê influem sobre a obesidade em mulheres em idade fértil. Existem evidências que sugerem que a gestação pode aumentar o peso corporal no pós-parto para alguns subgrupos de mulheres, principalmente aquelas que apresentaram elevados ganhos de peso gestacional (Gunderson \& Abrams, 1999).

Harris et al (1997), ao estudarem 3507 mulheres multíparas inglesas, apontam que o ganho de peso excessivo durante a gestação pode estar associado com permanentes aumentos no peso corporal materno, simplesmente porque este é um período em que ocorre um balanço energético positivo, no qual algumas mulheres ganham peso excessivamente. 
Os resultados do estudo de Smith et al (1994) sugerem que após a primeira gestação, a mulher apresenta mudanças no seu peso corporal e na distribuição de gordura, e que estas mudanças são persistentes e são mais intensas que aquelas provocadas pelo fator idade isolado.

Os resultados observados por Soltani et al (2000) mostram que a tendência do desenvolvimento da obesidade central em mulheres obesas é fator possivelmente associado à retenção de peso após a gestação.

O ganho de peso durante a gestação expressa o aumento dos estoques maternos de gordura e nutrientes, o crescimento fetal, a expansão de tecidos maternos (placenta, tecido adiposo, útero) e seios, aumento de líquido extracelular e do volume sangüíneo e formação de líquido amniótico (WHO, 1997; Institute of Medicine, 1990). Um ganho de peso gestacional adequado propicia um crescimento fetal favorável e estoques de gordura materna no pósparto suficientes para a lactação. As grandes variações encontradas no ganho de peso gravídico em mulheres saudáveis com gestação única parecem ser determinadas por diferenças nas características maternas como estado nutricional pré-gestacional, idade, paridade, origem étnica, condição sócioeconômica, uso de drogas e atividade física (Institute of Medicine, 1990). Além dos determinantes biológicos, o ganho de peso gestacional pode ser influenciado por fatores sociais e psicológicos (Lederman et al, 1997).

Estudo realizado por Scholl et al (1995) em mulheres de baixa renda, 
indicam que excessivos ganhos de peso tendem a ocorrer em mulheres jovens e em primíparas.

Strychar et al (2000) estudaram 115 gestantes com o objetivo de determinar os fatores psicossociais e de estilo de vida associados ao ganho de peso gestacional (insuficiente e excessivo). Foram investigados: atitudes frente a recomendação de ganho de peso, conhecimentos sobre saúde, conhecimento sobre o ganho de peso, consulta com médico ou nutricionista sobre ganho de peso, uso de tabaco ou álcool, consumo de alimentos e características demográficas. Os resultados mostram que mulheres com ganhos excessivos de peso apresentaram IMC pré-gestacional mais elevados, relataram ter menos atitudes favoráveis sobre o ganho de peso, e eram menos informadas a respeito da importância de não ganhar peso em demasia durante a gestação $(p<0,05)$. As gestantes que ganharam peso de acordo com a recomendação apresentaram melhor compreensão acerca dos resultados de ganhos de peso adequados: crescimento intra-uterino favorável e o retorno ao peso prégestacional de forma mais fácil $(p<0,05)$.

Na etapa de transição nutricional na qual o Brasil se encontra, têm sido relatados ganhos de peso gestacional elevados. Paralelamente ao já mencionado aumento da prevalência da obesidade, verifica-se estabilidade do baixo peso ao nascer ou até mesmo uma elevação em municípios das Regiões Sudeste e Sul (Monteiro et al, 2000). Neste panorama, o impacto do ganho de 
peso gestacional na retenção de peso no pós-parto é mais pronunciado e direto do que no peso ao nascer. Não existem evidências de que o aumento do tecido adiposo materno em mulheres com estado nutricional normal ou com sobrepeso no início da gestação proporcione benefícios para o crescimento fetal. Pelo contrário, mulheres com sobrepeso que tiveram elevados ganhos de peso apresentam um risco aumentado de conceberem recém-nascidos pretermo e de baixo peso (Muscati et al, 1995).

Schieve et al (1999), em estudo envolvendo 266172 mulheres de baixo nível sócio-econômico, observaram que tanto baixos quanto elevados ganhos de peso materno são fatores de risco para partos prematuros.

Estudo de Young \& Woodmansee (2002) mostrou que em mulheres nuliparas de classe média no setor privado o ganho excessivo de peso gestacional exerce um efeito estatisticamente significante nas taxas de parto por cesárea primária.

A partir de meados do século passado, a recomendação de ganho de peso gestacional vem aumentando consideravelmente, sempre com base no beneficio potencial para a saúde do bebê. Em 1940 e 1950, vigorou nos USA a prática de restringir o ganho de peso total durante a gestação a menos de 9,0 $\mathrm{kg}$, com a intenção de reduzir os riscos de toxemia e distócias fetais que acreditavam ocorrer mais freqüentemente em bebês grandes. Em 1970, o Comitê de Nutrição Materna recomendava ganhos de peso mais elevados 
durante a gestação - 10,9 kg - a partir de evidências de que a restrição de peso materno resultava em efeitos deletérios para o bebê, como prematuridade e baixo peso ao nascer. Em 1990, a recomendação de ganho de peso gestacional passou a ser de 11,4 a 15,9 kg, após a publicação de estudos mostrando que ganhos de peso materno adequados reduziam as taxas de baixo peso ao nascer. A Academia Americana de Ciências recomenda ganhos de peso gestacional diferenciados de acordo com o estado nutricional prégestacional: valores mais elevados para as desnutridas e menores para as mulheres com sobrepeso ou obesidade no inicio da gestação (Institute of Medicine, 1990; Gunderson \& Abrams, 1999; Feig \& Naylor, 1998). Idealmente, estas recomendações foram estabelecidas com o objetivo de restabelecer os estoques de gordura corporal em mulheres desnutridas e minimizar os ganhos de gordura em mulheres obesas (Lederman et al, 1997). Recomendações que também são preconizadas pelo Colégio Americano de Obstetrícia e Ginecologia, pela Organização Mundial de Saúde (OMS) e pelo Ministério da Saúde (WHO, 1995; Ministério da Saúde, 2000).

É importante destacar que a recomendação de ganhos de peso de aproximadamente $15 \mathrm{~kg}$ vigentes no período de 1960 a 1980 coincidem com aumentos de 50 a $100 \%$ na prevalência de sobrepeso em mulheres norte americanas em idade reprodutiva neste período (Gunderson \& Abrams, 1999). 
Estudo conduzido por Parker \& Abrams (1993), em uma amostra de 1 129 mulheres americanas com IMC inicial inferior a $26 \mathrm{~kg} / \mathrm{m}^{2}$, mostrou que $35 \%$ destas tiveram ganhos de peso acima do limite superior recomendado pelo Institute of Medicine (IOM).

Carmichael et al (1997) estudou 4218 mulheres americanas com desfecho favorável da gestação (crianças nascidas vivas por parto vaginal e termo, com tamanho adequado para a idade gestacional, e com mães sem diabetes ou hipertensão). A média de peso dos recém-nascidos foi de $3404 \mathrm{~g}$. Observaram também que o total de peso gestacional excedeu a recomendação (IOM) em $49 \%$ das eutróficas, $70 \%$ das mulheres com sobrepeso e $57 \%$ das obesas.

Nucci et al (2001) realizaram um estudo de coorte retrospectiva em gestantes em seis capitais brasileiras de 1991 a 1995, envolvendo 3082 mulheres que foram assistidas pelo serviços de pré-natal do Sistema Único de Saúde. Verificaram que até a $40^{\mathrm{a}}$ semana de gestação $32,3 \%$ de todas as mulheres apresentaram ganhos superiores aos recomendados pela Academia Americana de Ciências.

Estudo de coorte prospectiva em 141 gestantes clientes de um serviço público de pré-natal do Municipio de São Paulo detectou alta freqüência (37,0\%) de ganho ponderal excessivo (Stubalch, 2003). 
O estudo de coorte de Lederman et al (1997) avaliou 196 gestantes com o objetivo de determinar a deposição de gordura durante a gestação. $O$ total de gordura corporal foi estimado a partir da avaliação de quatro compartimentos corporais (água total, peso, densidade e massa mineral óssea). Os resultados mostram que a maioria das mulheres ganham mais peso do que é recomendado durante a gestação; e que elevados ganhos de peso aumentam o ganho de gordura corporal. Por outro lado, as gestantes que apresentam ganhos de peso gravídicos de acordo com as recomendações do IOM não desenvolvem obesidade, pois o ganho de gordura corporal é adequado.

Resultados semelhantes foram encontrados em estudo que avaliou a composição corporal de nove mulheres americanas saudáveis. A avaliação foi realizada pelo mesmo método descrito no estudo anterior, e em três fases distintas: anterior, durante e pós-gestação (Kopp-Hoolihan, 1999).

Achados observados no estudo de Butte et al (2003) mostram que a retenção de gordura materna, 27 semanas após o parto, era significantemente maior em mulheres que ganharam peso acima da recomendação da IOM (1990) comparadas com aquelas que ganharam de acordo ou abaixo da recomendação.

Segundo a OMS, o monitoramento do ganho ponderal durante a gestação é um procedimento de baixo custo e de grande utilidade para o 
estabelecimento de intervenções nutricionais com vistas à redução de riscos maternos e fetais (WHO, 1995; Feig \& Naylor, 1998).

Conforme mencionado anteriormente, o acompanhamento do ganho de peso deve ser avaliado levando-se em consideração o estado nutricional inicial da gestante. No contexto de elevados ganhos de peso gestacional, particular ênfase deve ser dada as mulheres com sobrepeso ou obesidade. $O$ índice de massa corporal (IMC), indicador do estado nutricional amplamente recomendado para a avaliação de gestantes, é considerado como um representante acurado de indicadores de composição corporal (Institute of Medicine, 1990).

Poucos estudos tem examinado fatores que influenciam o ganho de peso gestacional (Abrams et al, 1995; Stevens-Simon \& McAnarney, 1992). Lederman et al (1997) ressaltam a necessidade de futuros estudos que examinem quais os fatores que predispõem gestantes a elevados ganhos de peso, e técnicas para assisti-las de modo que o ganho de peso restrinja-se as recomendações da OMS, uma melhor compreensão dos determinantes maternos pode sugerir estratégias de intervenções mais efetivas.

O propósito do presente estudo é investigar em uma coorte de mulheres clientes de serviço público de pré-natal a evolução do peso, gordura corporal e pregas cutâneas triciptal e subescapular durante a gestação. Pretende também avaliar os fatores socioeconômicos, reprodutivos e comportamentais que 
influenciam o ganho ponderal gravídico nesse grupo por meio de análise de dados longitudinais de peso corporal, coletados mensalmente. 


\section{OBJETIVOS}

\subsection{Objetivos gerais}

- Avaliar a evolução ponderal de gestantes clientes de serviço público de pré-natal e identificar fatores a ela associados.

\subsection{Objetivos específicos}

- Descrever as gestantes estudadas quanto a indicadores socioeconômicos, reprodutivos e estado nutricional no início da gestação.

- Descrever a evolução do peso corporal, gordura corporal e pregas cutâneas triciptal e subescapular durante a gestação.

- Estudar a influência de fatores socioeconômicos, reprodutivos e comportamentais sobre a evolução ponderal gravídica, levando em consideração o estado nutricional no início da gestação. 


\section{METODOLOGIA}

\subsection{Delineamento do estudo}

Foi estudada uma coorte prospectiva de gestantes atendidas pelo serviço de assistência pré-natal da Maternidade Amparo Maternal, entidade filantrópica que assiste mulheres de baixo nível socioeconômico do Município de São Paulo. Esta coorte é parte integrante do projeto de pesquisa: "Eficiência de Indicadores Antropométricos Maternos na Predição do Baixo Peso ao Nascer".

\subsection{Amostra}

Foram recrutadas mulheres saudáveis inscritas no serviço de prénatal de baixo risco da maternidade Amparo Maternal no período de março de 1997 a março de 1998. A rotina deste serviço não compreendia acompanhamento ou aconselhamento nutricional. Somente as gestantes que apresentavam ganhos de peso insuficientes eram encaminhadas à consulta nutricional.

Os critérios de inclusão do estudo foram: idade igual ou superior a 18 anos; início do pré-natal com idade gestacional menor ou igual a 16 semanas. 
Foram excluídas as mulheres com gestação múltipla, HIV positivo, e aquelas gestantes que abortaram e cujo parto resultou em natimorto.

Inicialmente, 260 mulheres foram recrutadas para o estudo. Destas, 33 foram consideradas não elegíveis (Figura 1). Das 227 gestantes elegíveis, 2 mulheres se recusaram a participar do estudo. Assim, foram consideradas 2 mulheres como perdas de seguimento $(0,9 \%)$. A amostra final ficou composta por 225 gestantes.

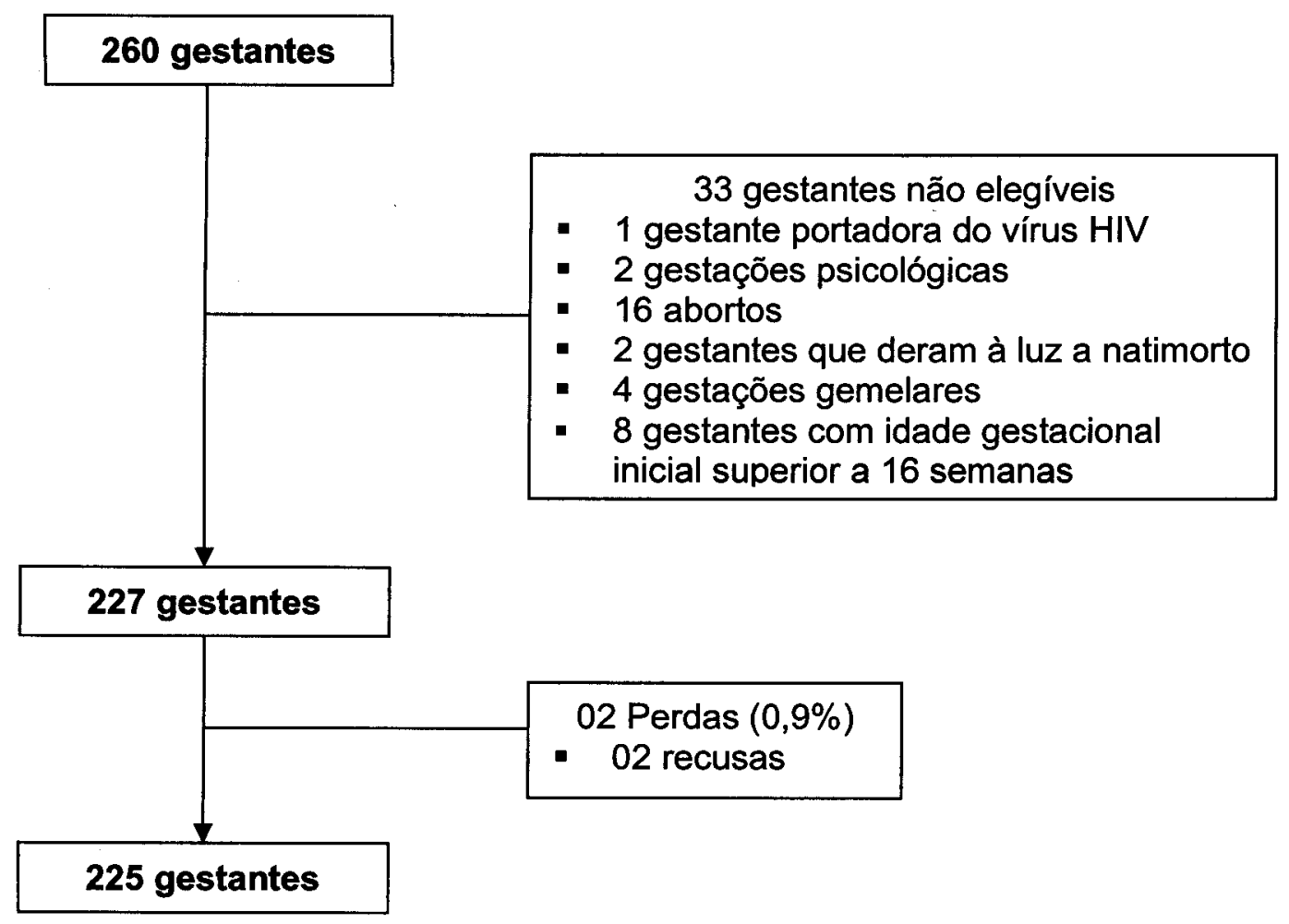

Figura 1: Gestantes incluidas na coorte, número de mulheres perdidas e razão das perdas 


\subsection{Coleta de dados}

Os dados foram obtidos a partir de entrevistas com as gestantes mediante a aplicação de questionários pré-testados em três momentos da gestação. Informações referentes a identificação da gestante, escolaridade, situação marital, características socioeconômicas, antecedentes obstétricos e morbidade foram abordadas no Questionário 1 (Anexo 1). As informações referentes ao tabagismo foram obtidas através da aplicação do Questionário 3 (Anexo 2).

As medidas antropométricas (altura, peso e prega cutânea triciptal e subescapular) foram coletadas mensalmente por ocasião das consultas de pré-natal em diversas idades gestacionais.

A equipe de campo era formada por três entrevistadoras devidamente treinadas para a aplicação do questionário e duas antropometristas treinadas segundo técnica descrita em Lohman et al (1988) e Jelliffe e Jelliffe (1989) e padronizadas segundo técnica recomendada por Habicht (1978).

Com o objetivo de se captar precocemente as gestantes, implantou-se uma estratégia, na qual todas as mulheres atendidas pelo serviço e com teste de gravidez positivo eram encaminhadas para as entrevistadoras da pesquisa. Neste primeiro encontro, aplicava-se o primeiro questionário, coletava-se medidas antropométricas e eram solicitados exames de rotina do pré-natal. As demais entrevistas e os exames antropométricos aconteceram no mesmo dia das demais consultas de pré-natal. 


\subsection{Variáveis do Estudo}

\subsubsection{Evolução da gordura corporal e pregas cutâneas triciptal e subescapular}

- Gordura corporal: obtida pela multiplicação do peso corporal pela porcentagem de gordura. Expressa em $\mathrm{kg}$.

- Porcentagem de gordura: calculada como percentagem do total do peso corporal a partir da densidade corporal pela equação de Siri (1956). A densidade corporal é o logaritmo da soma de duas pregas cutâneas: triciptal e subescapular (Durnin \& Womersley, 1974).

Porcentagem de gordura corporal (\%gordura):

$\%$ gordura $=(4,95 /$ densidade corporal $-4,50) \times 100$

\section{Densidade corporal (D):}

Mulheres de 17 a 19 anos: $D=1,1468-(0,0740 \times \log$ (triciptal + subescapular)

Mulheres de 20 a 29 anos: $D=1,1582-(0,0810 \times \log$ (triciptal + subescapular)

Mulheres de 30 a 39 anos: $D=1,1356-(0,0680 \times \log$ (triciptal + subescapular)

Mulheres de 40 a 49 anos: $D=1,1230-(0,0635 \times \log$ (triciptal + subescapular) 
- Pregas cutâneas triciptal e subescapular: medidas mensalmente, utilizando-se calibrador de pregas cutâneas Holtain com precisão de 0,2 $\mathrm{mm}$.

- Idade gestacional: expressa em meses de gestação. Obtida pela divisão da idade gestacional em semanas por 4,44 . Este número é resultado da divisão de 40 semanas de gestação (tempo médio de duração da gestação) por 9 meses. Ou seja, 1 mês de gestação têm em média 4,44 semanas (Abrams et al, 1995).

\subsubsection{Evolução do peso corporal durante a gestação}

\subsubsection{Variável resposta}

- Peso corporal da gestante: medidas mensais de peso corporal da gestante, utilizando-se balança digital portátil ("Soehnle") com precisão de $100 \mathrm{~g}$ e capacidade até $150 \mathrm{~kg}$.

\subsubsection{Variáveis independentes}

- Idade gestacional: definida por algoritmo baseado em três parâmetros Data da Última Menstruação (DUM), exame de ultrassonagrafia realizado 
antes da $20^{\mathrm{a}}$ semana de gestação e/ou pelo método de Capurro (exame físico ao nascimento). Diferenças inferiores a $\pm 1,5$ semanas considerouse a idade gestacional obtida pelo DUM; para diferenças superiores a $\pm 1,5$ semanas utilizou-se a idade gestacional calculada pela ultrassonografia, e expressa em semanas de gestação.

As informações de US, Capurro e DUM não são completas para todas as gestantes da amostra. Para evitar perdas e melhorar a qualidade da aferição desta variável optou-se por utilizar os três parâmetros, uma vez que todos os métodos utilizados para o cálculo da idade gestacional apresentam um certo grau de imprecisão.

- Índice de Massa Corporal inicial: obtido pela divisão do peso inicial pela altura ao quadrado. Adotou-se níveis de corte proposto pela OMS para indivíduos adultos (1997). Classificado em três categorias: baixo peso $\left(\leq 18,5 \mathrm{~kg} / \mathrm{m}^{2}\right)$, peso adequado $\left(18,6-24,9 \mathrm{~kg} / \mathrm{m}^{2}\right)$ e sobrepeso/obesidade $\left(\geq 30 \mathrm{~kg} / \mathrm{m}^{2}\right)$.

- Altura: medida realizada apenas no primeiro exame antropométrico, utilizando estadiomêtro portátil, com precisão de $0,1 \mathrm{~cm}$.

- Escolaridade: anos completos de estudo. Na análise, utilizou-se variável em duas categorias: $\leq 4$ anos e $>4$ anos de escolaridade.

- Situação marital: companheiro residindo com a gestante, variável dicotômica: sim ou não.

- Idade: considerada em anos completos. Variável expressa em três categorias: $\leq 19 ; 20$ a 29 e $\geq 30$ anos. 
- Paridade: número de filhos nascidos vivos. Expressa de forma dicotômica: primíparas e multíparas.

- Hábito de fumar: considerou-se fumantes as gestantes que fizeram uso de cigarros durante a gestação. Variável dicotômica: sim ou não.

\subsection{Plano geral da análise}

Primeiramente foi realizada uma descrição das gestantes quanto a características sócioeconômicas, demográficas, reprodutivas e comportamentais.

Em seguida, realizou-se a descrição do peso, da gordura corporal, e das pregas cutâneas triciptal e subescapular ao longo dos nove meses de gestação.

A análise descritiva (médias, freqüências e intervalos de confiança) da coorte foi realizada utilizando-se software SPSS versão 11 (Norusis, 2001).

A influência dos fatores de estudo sobre a evolução ponderal gestacional foi avaliada mediante análise multinivel (Snijders \& Bosker, 1999) (Anexo 3). Adotou-se este tipo de análise em função da variável resposta - múltiplas observações de peso corporal de gestantes. Uma das vantagens apresentadas por este tipo de análise é não exigir o mesmo número de observações para todos os indivíduos da amostra, reduzindo o número de perdas ao se analisar os dados. 
Considerando a estrutura hierárquica de dados repetidos, observamse dois niveis hierárquicos neste estudo: a ocasião da medidas são as unidades de nivel 1 e as gestantes como unidades de nivel 2. O software utilizado para a análise estatística do modelo linear multinivel foi o MlwiN (Yang et al 2001).

A significância estatística de cada variável no modelo multinível foi analisada pelo teste de Wald, no qual comparam-se as estimativas de máxima verossimilhança do coeficiente, em relação à estimativa de seu erro padrão (SE). Quando essa razão $W=\beta / S E$ for superior a dois, significa que o coeficiente é significativo.

$\mathrm{Na}$ primeira etapa da análise multinivel foram realizados modelos bivariados, no qual examinou-se a associação entre cada fator de estudo e a evolução ponderal. A modelagem iniciou-se com a introdução da variável idade gestacional. Modelos alternativos com idade gestacional quadrática e cúbica foram testados, utilizando-se teste de razão de verossimilhança para identificar o que apresenta melhor ajuste (Barros, 2004). A seguir inclui-se cada uma das variáveis explanatórias do nivel 2 como um termo independente com o objetivo de avaliar o efeito da variável no intercepto do modelo. Na seqüência adicionou-se a interação do fator de estudo com a variável idade gestacional (nível 1), interação essa que expressa o efeito da variável explanatória na inclinação da curva. Neste caso, foram igualmente testados modelos contendo a interação entre cada fator de estudo e a variável idade gestacional de forma linear, quadrática e cúbica. A interação 
com a idade gestacional foi mantida no modelo, independente de sua significância estatística, sempre que a interação com o termo quadrático tenha sido significante, e assim sucessivamente.

A seguir, procedeu-se à construção do modelo de regressão linear múltipla, utilizando a estratégia de modelagem hierarquizada (Victora et al, 1997). O modelo teórico hierarquizado dos fatores que influenciam o peso gestacional materno estão apresentados na Figura 2. As variáveis encontram-se agrupadas em cinco blocos hierárquicos seguindo a procedência temporal de sua determinação: 1-IMC no início da gestação e altura; 2-escolaridade; 3-situação marital; 4-idade e paridade; 5-hábito de fumar. As variáveis IMC no início da gestação e altura foram incluídas no primeiro bloco, uma vez que o ganho esperado de peso na gravidez varia de acordo com o estado nutricional inicial e a estatura (WHO, 1995). As variáveis escolaridade e situação marital (planos 2 e 3), além de exercerem influência direta sobre a variável resposta, teriam influência sobre as variáveis dos blocos subsequentes. As variáveis de cada bloco, que conservaram significância estatística $(p<0,20)$ dentro do bloco respectivo, foram mantidas no modelo subsequente, que inclui a variável do bloco mais próximal. 


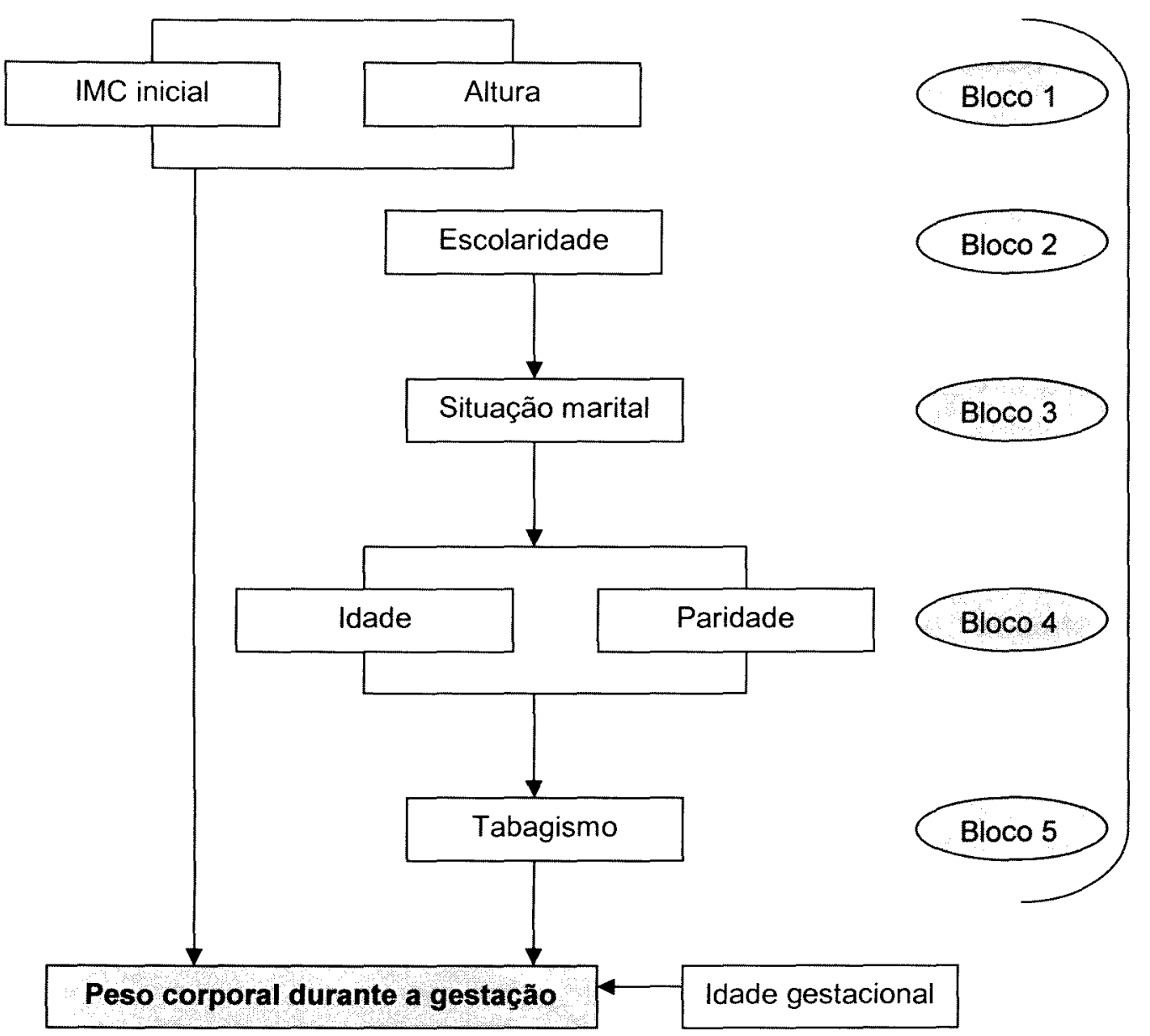

Figura 2: Marco teórico para a investigação dos fatores associados ao ganho de peso durante a gestação

\subsection{Questões Éticas}

Este projeto foi aprovado pelo Comitê de Ética em Pesquisa da Faculdade de Saúde Pública da Universidade de São Paulo (FSP/COE) (Anexo 4). 
O estudo não oferece riscos à saúde e adota métodos não invasivos, e supõe-se que os benefícios suplantem o eventual incômodo de responder às questões e de se submeter à avaliação antropométrica.

O início do projeto é anterior à constituição do referido Comitê, por isso não foi obtido o termo de consentimento por escrito. No entanto, a justificativa e os objetivos do estudo, bem como os procedimentos que foram utilizados na pesquisa foram explicados oralmente às gestantes, em linguagem compreensível. Foi garantida a liberdade da gestante de se recusar a participar ou de retirar seu consentimento, em qualquer momento da pesquisa, sem penalização alguma e sem prejuízo em seu cuidado. Foi igualmente garantida a privacidade, confidencialidade e anonimato das participantes da pesquisa. 


\section{RESULTADOS}

\subsection{Descrição das gestantes}

As características socioeconômicas, demográficas, reprodutivas e nutricionais das 225 gestantes participantes do estudo estão apresentadas nas tabelas 1 e 2 .

Observou-se as seguintes características na coorte de gestantes:

- Cerca de $32 \%$ das mulheres possuem um baixo nivel de escolaridade ( 0 a 4 anos);

- Três quartos das gestantes residiam com seus respectivos companheiros na ocasião do estudo;

- A idade variou de 18 a 42 anos, sendo que a maior parte (70\%) encontrase na faixa de 20 a 29 anos;

- A primeira consulta de pré-natal ocorreu em média na décima segunda semana de gestação;

- Aproximadamente metade $(53,8 \%)$ das mulheres que participaram do estudo são primíparas;

- $35 \%$ das gestantes da coorte possuíam o hábito de fumar até o segundo trimestre de gestação;

- A altura média materna foi de $158,5 \mathrm{~cm}$, com valores mínimo e máximo iguais a $144,0 \mathrm{~cm}$ e a maior $172,0 \mathrm{~cm}$, respectivamente;

- O peso corporal da primeira consulta de pré-natal foi em média de 63,7 
$\mathrm{kg}$;

- O IMC inicial foi em média $23,7 \mathrm{~kg} / \mathrm{m}^{2}$;

- $68 \%$ das grávidas iniciaram o pré-natal com o peso adequado, de acordo com o IMC.

Tabela 1: Distribuição das gestantes da coorte, segundo características socioeconômicas, demográficas, estado nutricional no início da gestação, história reprodutiva e hábito de fumar. São Paulo, março/1997 a outubro/1998.

\begin{tabular}{|c|c|c|}
\hline Variável & $\mathbf{N}$ & $\%$ \\
\hline $\begin{array}{c}\text { Escolaridade } \\
\geq 4 \text { anos } \\
<4 \text { anos }\end{array}$ & $\begin{array}{c}69 \\
149\end{array}$ & $\begin{array}{l}31,7 \\
68,3\end{array}$ \\
\hline $\begin{array}{l}\text { Idade } \\
\qquad 20 \text { anos } \\
20 \text { a } 30 \text { anos } \\
\geq 30 \text { anos }\end{array}$ & $\begin{array}{c}33 \\
170 \\
30\end{array}$ & $\begin{array}{l}14,8 \\
71,7 \\
13,5\end{array}$ \\
\hline $\begin{array}{l}\text { Situação marital } \\
\text { Com companheiro } \\
\text { Sem companheiro }\end{array}$ & $\begin{array}{c}166 \\
57\end{array}$ & $\begin{array}{l}74,4 \\
25,6\end{array}$ \\
\hline $\begin{array}{l}\text { ÍMC inicial } \\
\text { Baixo peso } \\
\text { Peso adequado } \\
\text { Sobrepeso/obesidade }\end{array}$ & $\begin{array}{c}10 \\
154 \\
61\end{array}$ & $\begin{array}{c}4,4 \\
68,4 \\
27,1\end{array}$ \\
\hline $\begin{array}{l}\text { Paridade } \\
\text { Primípara } \\
\text { Multípara }\end{array}$ & $\begin{array}{l}120 \\
103\end{array}$ & $\begin{array}{l}53,8 \\
46,2\end{array}$ \\
\hline $\begin{array}{l}\text { Hábito de fumar } \\
\text { Sim } \\
\text { Não }\end{array}$ & $\begin{array}{c}71 \\
130\end{array}$ & $\begin{array}{l}35,3 \\
64,7\end{array}$ \\
\hline $\begin{array}{l}N^{0} \text { cigarros/dia } \\
0 \\
1 \text { a } 9 \\
10\end{array}$ & $\begin{array}{c}130 \\
44 \\
27\end{array}$ & $\begin{array}{l}64,7 \\
21,9 \\
13,4\end{array}$ \\
\hline
\end{tabular}


Tabela 2: Distribuição das gestantes da coorte segundo características antropométricas e idade gestacional no início do seguimento. São Paulo, março/1997 a outubro/1998.

\begin{tabular}{lccc}
\hline \multicolumn{1}{c}{ Variável } & N & $\begin{array}{c}\text { Média } \\
\text { e \% }\end{array}$ & IC 95\% \\
\hline Altura $(\mathrm{cm})$ & 225 & 158,5 & $157,7-159,3$ \\
IMC inicial $\left(\mathrm{kg} / \mathrm{m}^{2}\right)$ & 225 & 23,7 & $23,1-24,2$ \\
Peso inicial $(\mathrm{Kg})$ & 225 & 63,7 & $55,4-72,1$ \\
Gordura corporal inicial $(\mathrm{kg})$ & 222 & 18,5 & $16,6-20,4$ \\
Gordura corporal inicial $(\%)$ & 222 & 28,9 & $28,1-29,7$ \\
Idade gestacional na 1 ${ }^{\mathrm{a}}$ consulta de pré- & 225 & 11,6 & $11,2-12,0$ \\
natal & & & \\
\hline
\end{tabular}

\subsection{Mudanças longitudinais de peso, gordura corporal e pregas cutâneas triciptal e subescapular}

A Tabela 3 apresenta as mudanças absolutas do peso, da gordura corporal e das pregas cutâneas durante a gestação. Um padrão geral foi observado para as mudanças longitudinais das medidas de gordura corporal e pregas cutâneas triciptal e subescapular ao longo da gestação: aumento até o segundo trimestre e redução lenta no final da gestação (figuras 3 e 4).

O peso corporal aumenta progressivamente durante a gestação: a velocidade de ganho de peso no início da gestação é menor, no período intermediário se intensifica e no final esta velocidade reduz-se um pouco. 
A gordura corporal apresentou incrementos positivos no primeiro e segundo trimestre, 1,3 e $2,7 \mathrm{~kg}$ respectivamente. No sétimo e oitavo mês observa-se ainda acréscimos, porém menores $(0,4$ e 0,3 kg) e no último mês uma discreta redução de $0,5 \mathrm{~kg}$. No final da gestação, tem-se em média 4,2 $\mathrm{kg}$ a mais de gordura corporal do que no primeiro mês.

O peso e da gordura corporal aumentam concomitantemente até o oitavo mês de gestação. Entretanto, no último mês observou-se que o peso manteve o padrão ascendente, enquanto que a gordura corporal tem uma pequena redução (Figura 3).

As pregas cutâneas triciptal e subescapular apresentaram uma evolução semelhante à da gordura corporal, ou seja, aumentam até o segundo trimestre e mostram uma modesta redução no final da gestação. A dobra cutânea subescapular tem aumentos constantes no primeiro e segundo trimestre (2,6 e 2,1 mm, respectivamente) e no último uma redução de $1,9 \mathrm{~mm}$. A prega cutânea triciptal aumenta lentamente no primeiro trimestre $(0,5 \mathrm{~mm})$, no segundo trimestre este aumento chega a $1,0 \mathrm{~mm}$ e no terceiro um decréscimo de $1,2 \mathrm{~mm}$. No nono mês de gestação o valor médio da prega triciptal é semelhante a do início da gestação. Identifica-se maiores acréscimos na prega cutânea subescapular que aumenta em média $2,8 \mathrm{~mm}$ durante a gestação, expressando uma deposição de gordura nesta região como decorrência do processo gravídico. 
Tabela 3: Mudanças no peso corporal, na gordura corporal e nas pregas cutânea triciptal e subescapular durante a gestação. São Paulo, março/1997 a outubro/1998.

\begin{tabular}{|c|c|c|c|c|c|}
\hline $\begin{array}{c}\text { Idade } \\
\text { gestacional } \\
\text { (meses) }\end{array}$ & & $\begin{array}{l}\text { Peso } \\
\text { corporal } \\
(\mathrm{kg})\end{array}$ & $\begin{array}{l}\text { Gordura } \\
\text { corporal } \\
(\mathrm{kg})\end{array}$ & $\begin{array}{c}\text { Prega } \\
\text { cutânea } \\
\text { triciptal } \\
(\mathrm{mm})\end{array}$ & $\begin{array}{c}\text { Prega } \\
\text { cutânea } \\
\text { subescapular } \\
(\mathrm{mm})\end{array}$ \\
\hline 1 & $\begin{array}{c}n \\
\text { Media } \\
\text { IC } 95 \%\end{array}$ & $\begin{array}{c}26 \\
57,5 \\
54,4-60,7\end{array}$ & $\begin{array}{c}26 \\
16,6 \\
14,8-18,5\end{array}$ & $\begin{array}{c}27 \\
16,6 \\
14,7-18,5\end{array}$ & $\begin{array}{c}27 \\
17.6 \\
15,1-20,0\end{array}$ \\
\hline 2 & $\begin{array}{c}n \\
\text { Nedfa } \\
\text { IC } 95 \%\end{array}$ & $\begin{array}{c}124 \\
58,7 \\
56,9-60,6\end{array}$ & $\begin{array}{c}119 \\
16,9 \\
15,8-18,0\end{array}$ & $\begin{array}{c}123 \\
172 \\
16,1-18,3\end{array}$ & $\begin{array}{c}123 \\
19,0 \\
17,5-20,5\end{array}$ \\
\hline 3 & $\begin{array}{c}n \\
\text { Wodla } \\
\text { IC } 95 \%\end{array}$ & $\begin{array}{c}182 \\
60,0 \\
58,8-61,6\end{array}$ & $\begin{array}{c}176 \\
179 \\
17,0-18,8\end{array}$ & $\begin{array}{c}180 \\
16,9 \\
16,0-17,9\end{array}$ & $\begin{array}{c}180 \\
19,7 \\
18,5-20,9\end{array}$ \\
\hline 4 & $\begin{array}{c}n \\
\text { Media } \\
\text { IC } 95 \%\end{array}$ & $\begin{array}{c}177 \\
61,3 \\
59,8-62,8\end{array}$ & $\begin{array}{c}160 \\
18,3 \\
17,4-19,2\end{array}$ & $\begin{array}{c}164 \\
17,1 \\
16,2-17,9\end{array}$ & $\begin{array}{c}164 \\
20,2 \\
19,0-21,3\end{array}$ \\
\hline 5 & $\begin{array}{c}n \\
\text { IC } 95 \%\end{array}$ & $\begin{array}{c}170 \\
63,5 \\
62,0-65,1\end{array}$ & $\begin{array}{c}163 \\
19,5 \\
18,6-20,4\end{array}$ & $\begin{array}{c}165 \\
17,4 \\
16,6-18,3\end{array}$ & $\begin{array}{c}165 \\
21,2 .: \\
20,0-22,4\end{array}$ \\
\hline 6 & $\frac{n}{\text { Modia }}$ & $\begin{array}{c}153 \\
65,9 \\
64,3-67,5\end{array}$ & $\begin{array}{c}146 \\
20,6 \\
19,5-21,6\end{array}$ & $\begin{array}{c}147 \\
18,1 \\
17,1-19,1\end{array}$ & $\begin{array}{c}147 \\
22,0 \\
20,7-23,3\end{array}$ \\
\hline 7 & $\begin{array}{c}n \\
\text { Media } \\
\text { IC } 95 \%\end{array}$ & $\begin{array}{c}160 \\
672 \\
65,8-68,7\end{array}$ & $\begin{array}{c}151 \\
21,0 \\
20,1-21,9\end{array}$ & $\begin{array}{c}154 \\
17,8 \\
16,9-18,7\end{array}$ & $\begin{array}{c}154 \\
22,3 \\
21,1-23,5\end{array}$ \\
\hline 8 & $\begin{array}{c}n \\
\text { Wedla } \\
\text { IC } 95 \%\end{array}$ & $\begin{array}{c}144 \\
68,6 \\
67,0-70,2\end{array}$ & $\begin{array}{c}134 \\
21,3 \\
20,2-22,3\end{array}$ & $\begin{array}{c}138 \\
17,4 \\
16,4-18,4\end{array}$ & $\begin{array}{c}138 \\
21.5 \\
20,3-22,7\end{array}$ \\
\hline 9 & $\begin{array}{c}n \\
\text { Media } \\
\text { IC } 95 \%\end{array}$ & $\begin{array}{c}31 \\
69,0 \\
65,6-72,3\end{array}$ & $\begin{array}{c}30 \\
20,8 \\
18,7-22,9\end{array}$ & $\begin{array}{c}30 \\
16,6 \\
14,3-19,0\end{array}$ & $\begin{array}{c}30 \\
20,4 \\
18,3-22,5\end{array}$ \\
\hline
\end{tabular}



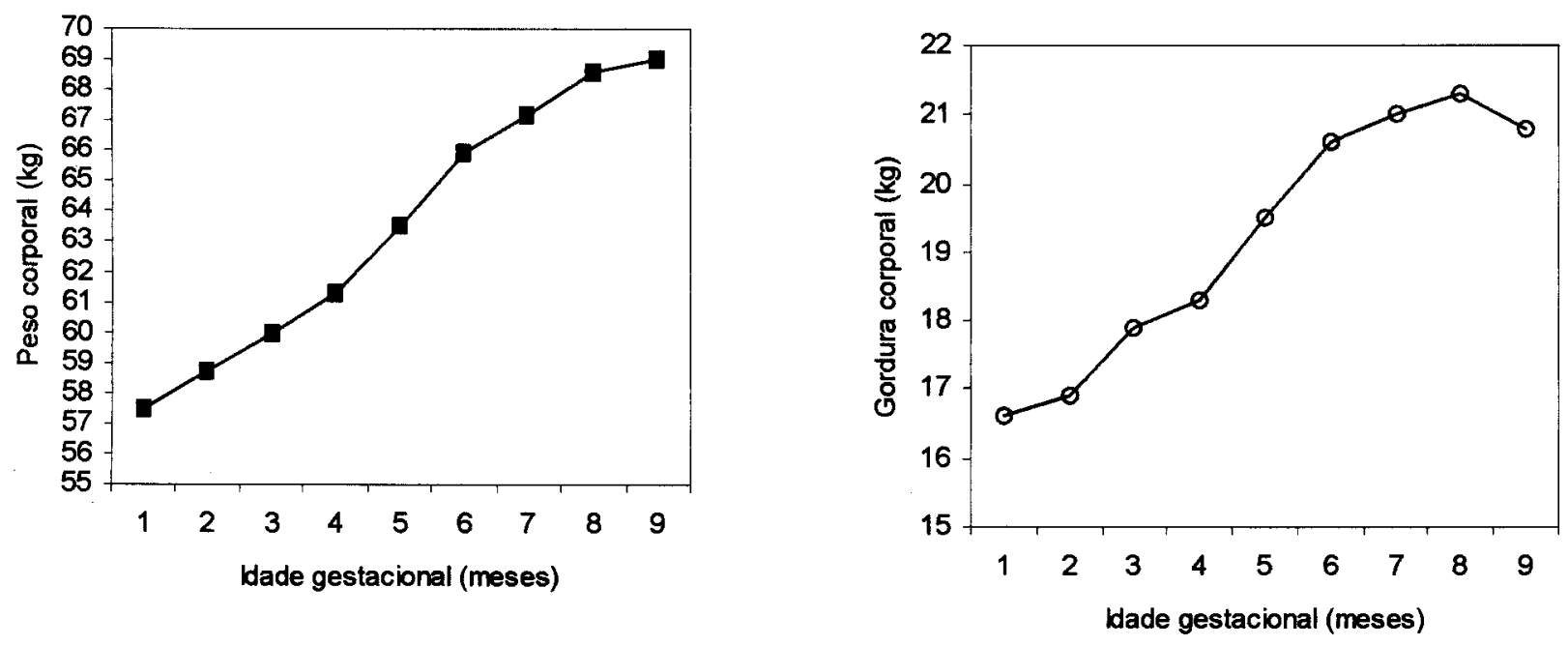

Figura 3: Evolução do peso e da gordura corporal ao longo da gestação. São Paulo, março/1997 a outubro/1998

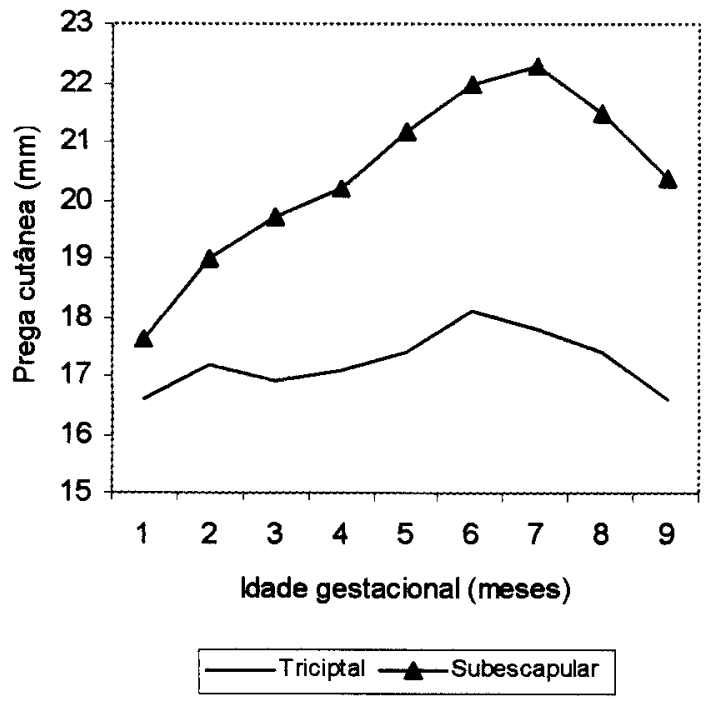

Figura 4: Evolução das pregas cutâneas triciptal e subescapular. São Paulo, março/1997 a outubro/1998 


\subsection{Influência de fatores socioeconómicos, reprodutivos e comportamentais sobre a evolução do peso gestacional}

\subsubsection{Análise exploratória inicial}

Foram realizadas 1340 medidas de peso corporal nas 225 gestantes estudadas. Esta medida antropométrica foi tomada mensalmente. Como o seguimento não é completo para todas as gestantes, tem-se gestantes com 11 medidas, como também gestantes com apenas uma medida de peso. Em média as gestantes da coorte foram medidas 7 vezes.

As tabelas em anexo apresentam a distribuição das gestantes segundo o número de medidas ao longo do estudo e o número de medidas de peso segundo cada idade gestacional em semanas (ANEXO 5). Como 0 número de observações de peso correspondente a idades gestacionais inferiores a sete semanas e superiores a quarenta semanas de gestação é pequeno ( $n<4$ medidas), optou-se por excluí-los da análise.

Foram identificados cinco valores aberrantes, que foram retirados da análise.

O número total de casos analisados é inferior ao total de medidas por gestante devido à presença de resultados faltantes para algumas variáveis explanatórias. 


\subsubsection{Análise multinível bivariada}

Primeiramente, foi considerado um modelo apenas com o intercepto.

Modelo vazio

$$
\begin{aligned}
& \text { pesoges }_{i j} \sim N(X B, \Omega) \\
& \text { pesoges }_{i j}=\beta_{0 i j} \text { Cons } \\
& \left.\beta_{0 i j}=842570739\right)+u_{0 j}+e_{0 i j} \\
& {\left[u_{0}\right] \sim N\left(0, \Omega_{u}\right): \Omega_{u}=[85.148(10.3606]} \\
& {\left[e_{0 i i}\right] \sim N\left(0, \Omega_{e}\right): \Omega_{e}=[1734807950]} \\
& -2 * \text { loglikelihood(IGLS) }=7080.781(1133 \text { of } 6120 \text { cases in use })
\end{aligned}
$$

A seguir, incluiu-se a variável idade gestacional (nível 1). Por uma questão de conveniência numérica, a variável igo, inicia em zero, que corresponde a idade gestacional de 7 semanas de gestação. Deste modo, o intercepto do modelo corresponde a esta idade gestacional (Modelo 1). 
Modelo 1: Variável do nível 1: idade gestacional

$$
\begin{aligned}
& \text { pesoges }_{i j} \sim N(X B, \Omega) \\
& \text { pesoges }_{i j}=\boldsymbol{\beta}_{0 i j} \text { cons }+0.427(0,000) \text { igo } \\
& \left.\beta_{0 i j}=5.1230 .764\right\}+u_{0 j}+e_{0 i j} \\
& {\left[u_{0,}\right] \sim N\left(0, \Omega_{u}\right): \Omega_{u}=[100,348(10.626)]} \\
& {\left[e_{0 i i}\right] \sim N\left(0, \Omega_{e}\right): \Omega_{e}=[2.413(0,111)]}
\end{aligned}
$$

$-2 *$ loglikelihood(IGLS) $=5206.651(1133$ of 6120 cases in use)

Para testar a linearidade, incluiu-se um termo quadrático e um termo cúbico para a idade gestacional (Modelos 2 e 3).

Modelo 2: Variável do nível 1: idade gestacional e termo quadrático para idade gestacional

$$
\begin{aligned}
& \text { pesoges }_{i j} \sim N(X B, \Omega) \\
& \text { pesoges }_{i j}=\beta_{0 i} \text { Cons }+0.357(0024) \mathrm{igO} 0_{i j}+0002(0001) \mathrm{ig} 0^{\wedge} 2_{i j} \\
& \beta_{0 i j}=5757(07760)+u_{0 j}+e_{0 i j} \\
& {\left[u_{0, j}\right] \sim N\left(0, \Omega_{u}\right): \Omega_{u}=[100.487(10.626)]} \\
& {\left[e_{0 i i}\right] \sim N\left(0, \Omega_{e}\right): \Omega_{e}=[23830111]} \\
& -2 * \text { loglikelihood(IGLS) }=5197.741(1133 \text { of } 6120 \text { cases in use })
\end{aligned}
$$


Modelo 3: Variável do nível 1: idade gestacional, termo quadrático e termo cúbico para idade gestacional

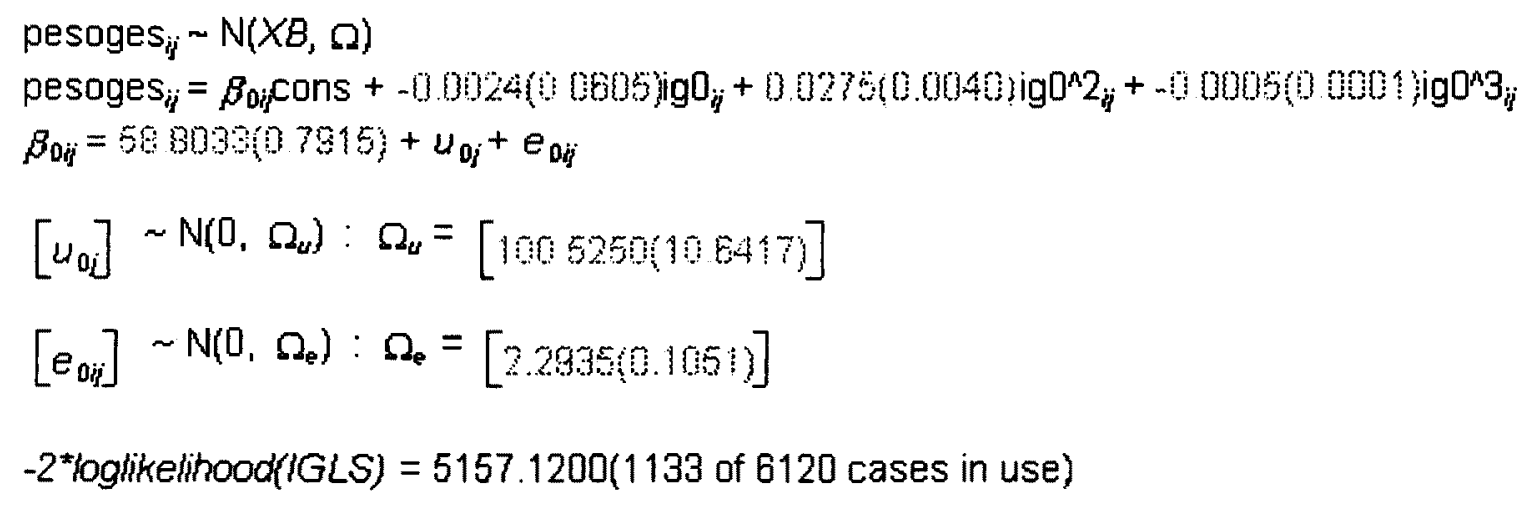

A introdução dos termos quadrático e cúbico para idade gestacional melhora o ajuste do modelo (Teste de Razão de Verossimilhança com $p<0,0001$ ), indicando que a evolução do peso ao longo da gestação não é essencialmente linear.

Após constatação pela análise dos resíduos de maior variabilidade nas idades gestacionais extremas (anexo 6), foi realizado o ajuste do modelo com variância simples no nível 2 e variância dependendo da idade gestacional no nivel 1 (Modelo 4a, Anexo 7). Testou-se, também, a variância do nível 2 dependendo da idade gestacional e variância simples no nível 1 (Modelo 4). 
Modelo 4: Modelo 3 com variância do nível 2 dependendo da idade gestacional

pesoges $_{i j} \sim N(X B, \Omega)$

pesoges $_{i j}=\beta_{0 i j}$ cons $+\beta_{1 j g 0}+0.0258(0.0022) i g 0^{n} 2_{i j}+.00005(00000)$ ig0 $3_{i j}$

$\beta_{0 i j}=506950107799+u_{0 j}+e_{0 i j}$

$\left.\beta_{1 j}=0.024500359\right)+u_{1 i}$

$\left[\begin{array}{l}u_{0 j} \\ u_{1 j}\end{array}\right] \sim N\left(0, \Omega_{u}\right): \Omega_{u}=\left[\begin{array}{ll}105.3230(11.1733) & \\ -0.32 ? 4(01243) & 0024(00026)\end{array}\right]$

$\left[e_{0 i j}\right] \sim N\left(0, \Omega_{e}\right): \Omega_{e}=[0.6813(0.0293)]$

-2 *oglikelihood(IGLS) $=4331.5630(1133$ of 6120 cases in use)

O modelo com a variância do nível 2 em função da idade gestacional (Modelo 4) foi o que apresentou em melhor ajuste $(p<0,0001)$. Os resíduos mostraram dispersão uniforme ao longo da idade gestacional (anexo 6).

Os fatores de estudo do nivel 2 (IMC inicial, altura, escolaridade, situação marital, idade, paridade e tabagismo) podem influenciar o intercepto do modelo, isto é, o peso na sétima semana de gestação, como também a magnitude da inclinação da curva (ganho de peso semanal). Para avaliar o primeiro efeito, incluiu-se a variável como um termo principal. O sobre a inclinação da curva foi verificado pela interação de cada variável explanatória com a idade gestacional e seus termos quadrático e cúbico.

A primeira variável a ser estudada foi o IMC no início da gestação. $\mathrm{Na}$ análise, fez-se a opção de utilizar a variável estado nutricional expressa em apenas duas categorias: peso adequado e sobrepeso/obesidade. As 
gestantes com sobrepeso e obesas foram agrupadas em uma única categoria por apresentarem características semelhantes e também pelo pequeno número de mulheres obesas observadas nesta coorte. As gestantes de baixo peso foram excluídas, por não serem o foco de atenção deste estudo (gestantes nesta condição devem apresentar maiores ganhos ponderais), e devido a baixa freqüência observada (4,4\%). Para a indentificação das gestantes de baixo peso até a $13^{a}$ terceira semana de gestação o nível de corte preconizado pela OMS para a população adulta (WHO, 1995). Niveis de corte ligeiramente superiores foram adotados para gestantes que entraram na coorte entre a $14^{\mathrm{a}}$ e a $16^{\mathrm{a}}$ semana de gestação, de acordo com o ganho esperado para este período, conforme pode-se observar no quadro a seguir:

\begin{tabular}{cc}
\hline $\begin{array}{c}\text { Idade gestacional } \\
\text { (semanas) }\end{array}$ & $\begin{array}{c}\text { IMC inicial } \\
\left(\mathrm{kg} / \mathrm{m}^{2}\right)\end{array}$ \\
\hline$\leq 13$ & 18,5 \\
14 & 18,6 \\
15 & 18,7 \\
16 & 18,8 \\
\hline
\end{tabular}


Modelo 5: Modelo 4 e variável do nível 2 - IMC inicial

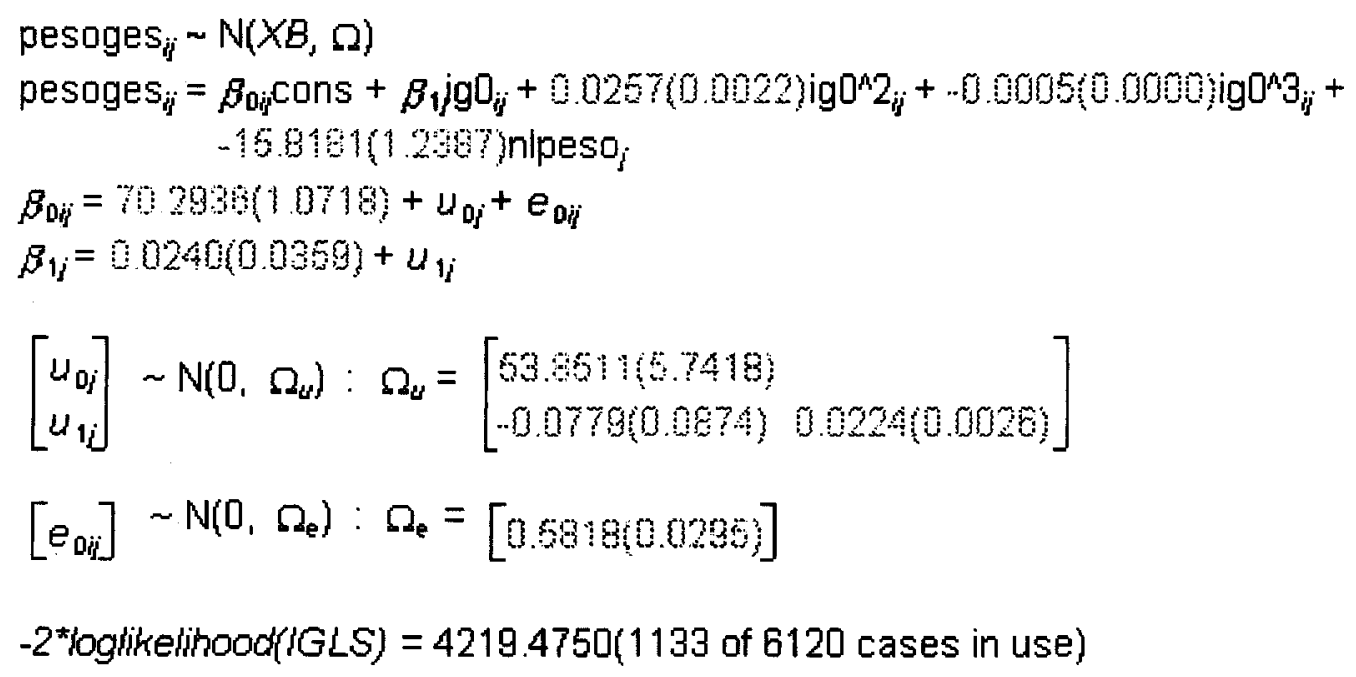

Modelo 6: Modelo 4 e variáveis do nível 2 - IMC inicial e termo de interação IMC inicial e idade gestacional

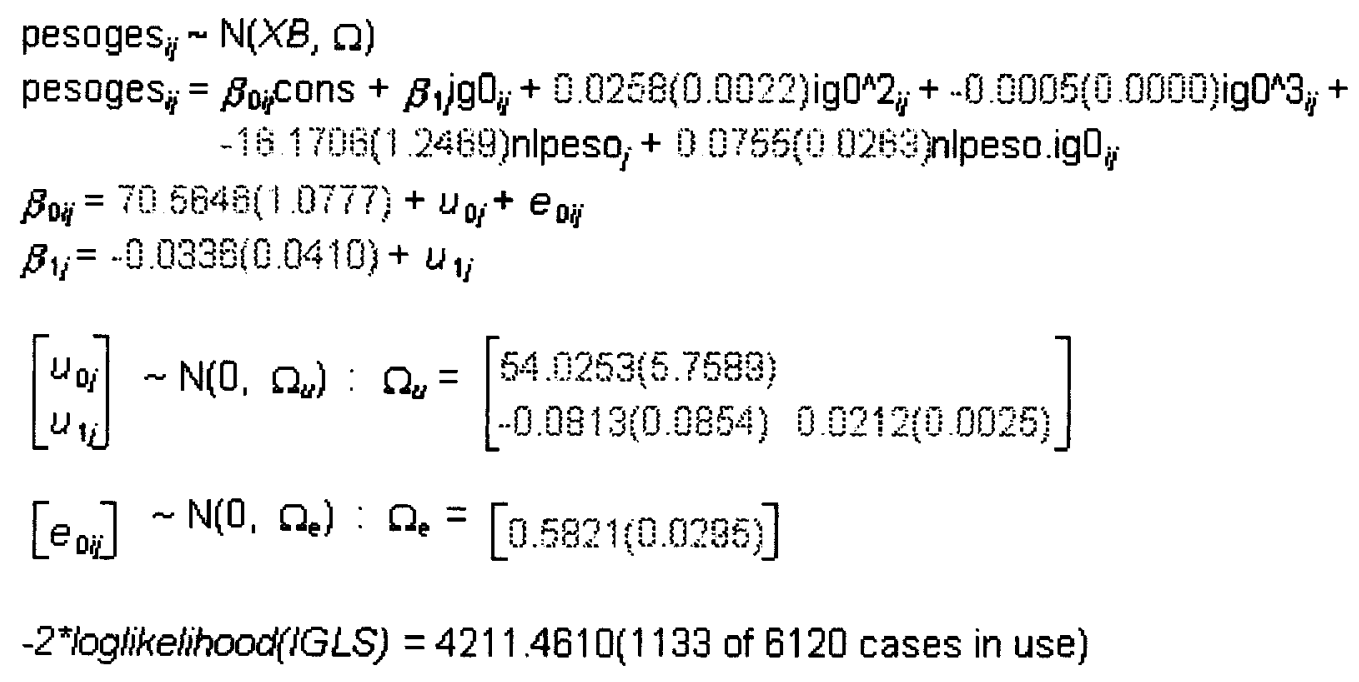

A variável altura (altura_c) foi incluída na modelagem na forma 
contínua. Para tanto, centralizou-se a variável (altura - média altura/desvio padrão da altura) (Modelo 8).

Modelo 7: Modelo 4 e variável do nível 2 - altura

$$
\begin{aligned}
& \text { pesoges }_{i j} \sim N(X B, \Omega) \\
& \text { pesoges } \left.\left._{i j}=\beta_{0 i j} \text { cons }+\beta_{1 j g 0_{i j}}+0.02562000224\right) i g 0^{\wedge} 2_{i j}+.00047000004\right) i g 0^{\wedge} 3_{i j}+ \\
& 4809),\left(0,896 \text {; 2)altura_ } C_{j}\right. \\
& \beta_{0 i j}=58.70292(0.71427)+u_{0 j}+e_{0 i j} \\
& \beta_{1 i}=0.02375(003591)+u_{1 i}
\end{aligned}
$$

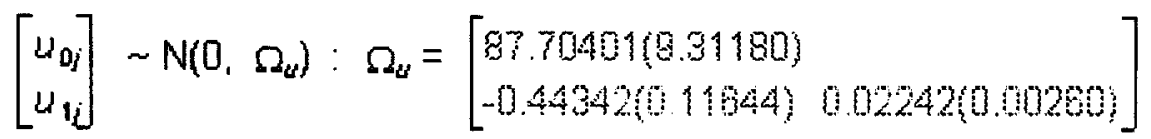

$$
\begin{aligned}
& {\left[e_{0 i j}\right] \sim N\left(0, \Omega_{e}\right): \Omega_{\mathrm{e}}=[0.50130(0,02045)]}
\end{aligned}
$$$$
-2 * \text { loglikelihood(IGLS) }=4288.38300(1133 \text { of } 6120 \text { cases in use })
$$ 
Modelo 8: Modelo 4 e variável do nível 2 - altura e termo de interação altura e idade gestacional

$$
\begin{aligned}
& \text { pesoges }_{i j} \sim N(X B, \Omega)
\end{aligned}
$$

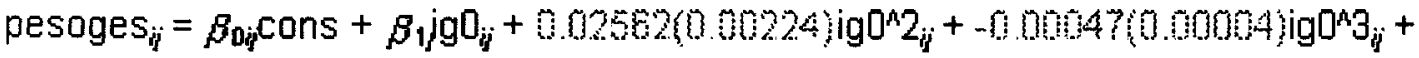

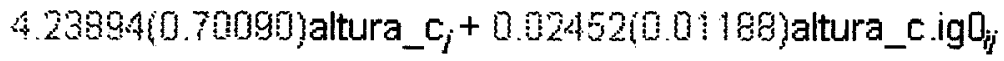

$$
\begin{aligned}
& \beta_{0 i j}=68.69918(0.71270)+u_{0 i}+e_{0 i j} \\
& \left.\beta_{1 j}=0023850003585\right)+u_{1 j} \\
& {\left[\begin{array}{l}
u_{0_{i}} \\
u_{1 i}
\end{array}\right] \sim N\left(0, \Omega_{u}\right): \Omega_{u}=\left[\begin{array}{l}
87.29002(0.26010) \\
-0.42290011400) 00217500025)
\end{array}\right]} \\
& {\left[e_{0 i j}\right] \sim N\left(0, \Omega_{e}\right): \Omega_{e}=[0.58169(0,0 \% 2040)]}
\end{aligned}
$$

$-2 *$ loglikelihood(IGLS) $=4284.19800(1133$ of 6120 cases in use $)$

Modelo 9: Modelo 4 e variável do nível 2 - altura e termo de interação altura e termo quadrático da idade gestacional

$$
\begin{aligned}
& \text { pesoges }_{i j} \sim N(X B, \Omega)
\end{aligned}
$$

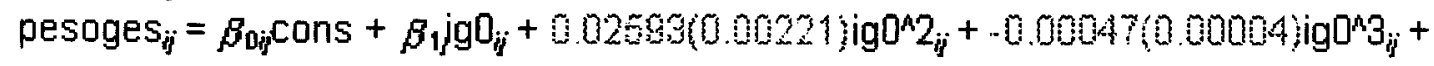

$$
\begin{aligned}
& \left.4.890710 .70093 \text { ialtura_c } c_{j}+0.02966001764\right\} \text { altura_c.igO }{ }_{i j}+ \\
& 0.0018 ?(0.00040) \text { altura_c.ig0 } 2_{i i} \\
& \left.\beta_{0 i j}=58.724180 .71075\right)+u_{0 j}+e_{\text {oij }} \\
& \beta_{1 i}=0.01855(00055)+u_{1 j} \\
& {\left[\begin{array}{l}
u_{0_{i}} \\
u_{1 i}
\end{array}\right] \sim N\left(0, \Omega_{u}\right): \Omega_{u}=\left[\begin{array}{l}
86.878910 .22201) \\
-0.40365(011917) 00160(00025)
\end{array}\right]} \\
& {\left[e_{0 i j}\right] \sim N\left(0, \Omega_{e}\right): \Omega_{e}=[0.56995(0.02805)]} \\
& -2 * \text { Joglikelihood(IGLS) }=4266.83700(1133 \text { of } 6120 \text { cases in use })
\end{aligned}
$$


Procedimento semelhante foi adotado para avaliar a influência de cada um dos demais fatores de estudo sobre o ganho ponderal (Modelos 10 a 19 no Anexo 7).

A TABELA 4 apresenta os resultados da análise multinível para cada fator de estudo (variáveis de nível 2). Somente a variável IMC inicial e altura influenciam o peso na sétima semana de gestação, intercepto do modelo $(p<0,001)$. Para as demais variáveis não foi encontrada significância estatística como termo principal.

Comparadas com mulheres com sobrepeso e obesas, as gestantes de peso adequado iniciam a gravidez em média com $15,8 \mathrm{~kg}$ a menos (estimativa do parâmetro correspondente a peso adequado igual a $-15,8$ ), entretanto apresentam ganhos semanais médios de $75 \mathrm{~g}$ por semana (estimativa da interação peso adequado e idade gestacional igual a 0,075 $\mathrm{kg} / \mathrm{semana}$ ). Observou-se comportamento semelhante para as mulheres que não residem com companheiro, estas tem em média $1 \mathrm{~kg}$ a menos no início da gestação (sétima semana) e acréscimos médios de $74 \mathrm{~g}$ semanais.

A altura tem uma influência positiva tanto no peso inicial quanto na evolução do peso gestacional.

As mulheres com alta escolaridade apresentam peso inicial superior aos das mulheres com menor escolaridade, $3,0 \mathrm{~kg}$ a mais. Inicialmente os incrementos ponderais médios semanais são negativos, sétima e oitava semana de gestação, e aumentam no decorrer da gestação (estimativa da interação escolaridade $\geq 5$ anos e idade gestacional mais a interação 
escolaridade e idade gestacional ao quadrado: $-0,00159 \mathrm{ig0}+0,01238 \mathrm{igo}^{2}$ )

Comportamento semelhante foi observado para as primíparas em relação as multíparas.

Com relação à idade, nota-se um possivel efeito dose resposta, ou seja, quanto maior a idade maior o peso inicial. Com o ganho de peso observa-se o inverso, quanto maior a idade menor o acréscimo no peso gestacional.

As gestantes que não possuem o hábito de fumar quando comparadas às gestantes que são fumantes, apresentaram na sétima semana de gestação um peso médio menor $(2,3 \mathrm{~kg}$ a menos) e incrementos médios semanais negativos durante toda a gestação. Os ganhos diminuem até a vigésima semana de gestação e a partir deste momento apresentam incrementos maiores até a quadragésima semana, entretanto ainda negativos.

Tabela 4: Análise multinivel linear para cada variável de nivel 2. Såo Paulo, março/1997 a outubro/1998

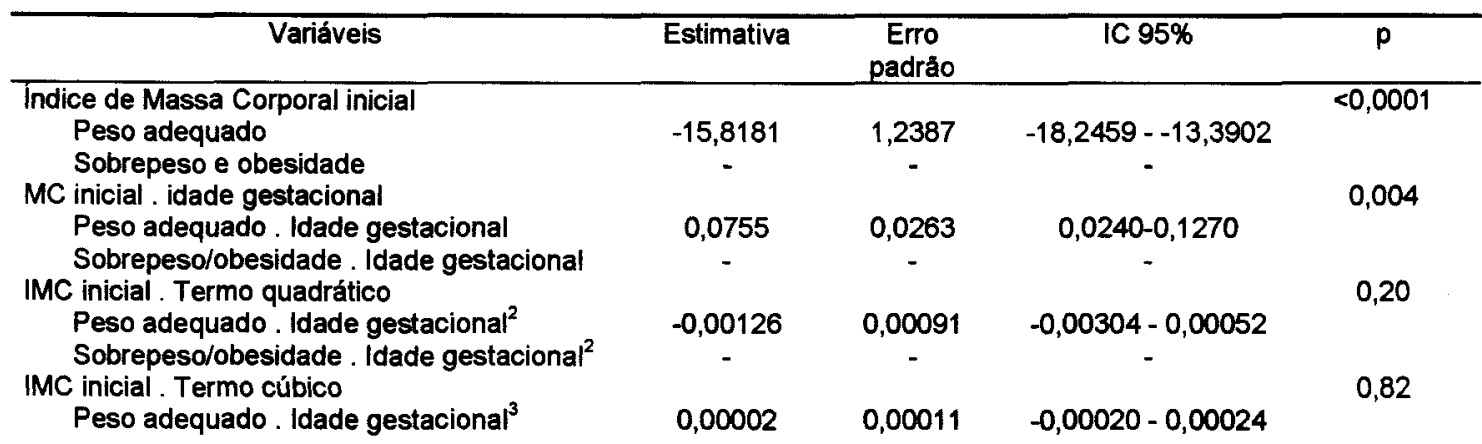


Sobrepeso/obesidade . Idade gestacional ${ }^{3}$

\section{Altura}

Altura . Idade gestacional

Altura . Idade gestacional ${ }^{2}$

Altura . Idade gestacional ${ }^{3}$

Escolaridade

$\leq 4$ anos

$>4$ anos

Escolaridade . Idade gestacional

$\leq 4$ anos . idade gestacional

$>4$ anos. idade gestacional

Escolaridade. Termo quadrático

$\leq 4$ anos. idade gestacional ${ }^{2}$

$>4$ anos . idade gestacional $^{3}$

Escolaridade. Termo cúbico

$\leq 4$ anos. idade gestacional ${ }^{3}$

$>4$ anos . idade gestacional $^{3}$

Situaçăo marital

Reside com o companheiro

Nảo reside com companheiro

Situação marital e idade gestacional

Com o companheiro . Idade gestacional

Sem companheiro . Idade gestacional

Situaçảo marital. Termo quadrático

Com o companheiro . Idade gestacional ${ }^{2}$ Sem companheiro . Idade gestacional ${ }^{2}$

Situação marital . Termo cúbico

Com o companheiro. Idade gestacional ${ }^{3}$

Sem companheiro . Idade gestacional ${ }^{3}$

Idade

$<20$ anos

20 a 29 anos

$\geq 30$ anos

Idade . idade gestacional

$<20$ anos . idade gestacional

20 a 29 anos . idade gestacional

$\geq 30$ anos . idade gestacional

Idade . Termo quadrático

$<20$ anos . idade gestacional ${ }^{2}$

20 a 29 anos . idade gestacional ${ }^{2}$

$\geq 30$ anos . idade gestacional ${ }^{2}$

Idade . Termo cúbico

$<20$ anos . idade gestacional ${ }^{3}$

20 a 29 anos . idade gestacional ${ }^{3}$

$\geq 30$ anos . idade gestacional ${ }^{3}$

Paridade

Primípara

Multipara

Paridade. Idade gestacional

Primipara . idade gestacional

Multípara . idade gestacional

Paridade. Termo quadrático

Primípara . idade gestacional ${ }^{2}$

Multipara . idade gestacional ${ }^{2}$

Paridade. Termo cúbico

Primípara . idade gestacional $\left.\right|^{3}$

Multipara . idade gestacional ${ }^{3}$

Tabagismo

Fuma

Nåo fuma

Tabagismo . idade gestacional

Fuma . idade gestacional

Năo fuma , idade gestacional
4,69911

0,02452

0,00167

0,00005

0,66512

0,01188

0,00040

0,00005

$3,39247-6,00275$

$0,00124-0,04780$

$0,00089-0,00245$

$-0,00005-0,00015$

$<0,0001$

0,04

$<0,0001$

0,28

0,06

$3,02827 \quad 1,6255$

$0,1576-6,2144$

0,10

0,0413

0,02554

$0,0086-0,0914$

0,05

$0,00159 \quad 0,00083$

$-0,00188-0,00154$

0,24

$-0,00011 \quad 0,00010$

$-0,00016-0,00024$

0,58

$-0,9 \overline{5} 588$

1,72620

$-3,4787--3,2879$

0,005

$0,07408 \quad 0,02659$

$0,0220-0,1262$

0,54

$-0,00017 \quad 0,00087$

$-0,00188-0,00154$

0,67

$0,0 \overline{0} 004 \quad 0,00010 \quad-0,00016-0,00024$

$-0,2580$

2,1607

$-4,4930--3,977$

0,8546

2,9530

$4,9333-4,9333$

0,0569

0,0339

$0,0095-0,1233$

0,09

$-0, \overline{0258}$

0,0323

$-0,0891--0,1947$

0,007

$0,00122 \quad 0,00107$

$-0,00088-0,00332$

$0,00461--0,00069$

$-0,00265$

0,00100

$-0,00017-0,00069$

0,49

$-0,00008 \quad 0,00013$

$-0,00012-0,00032$

$0,00010 \quad 0,00011$

0,86

$0,26864 \quad 1,49759$

$2,6667-3,2037$

0,0003

$0,08289 \quad 0,02282 \quad 0,0382-0,1276$

0,002

$0,00277 \quad 0,0007$

$0,00130-0,00424$

0,00002

0,00009

$-0,00016-0,00020$

1,53779

$-5,34709-0,68105$

$\begin{array}{lll}-0,00381 & 0,02439 & 0,55161-0,04399\end{array}$ 


$\begin{array}{cccc} & & & 0,001 \\ -0,00245 & 0,00077 & -0,00396-0,00094 & \\ -0,00014 & 0,00009 & -0,00032-0,00004 & 0,12\end{array}$

\subsubsection{Análise múltipla}

$\mathrm{Na}$ primeira etapa da modelagem hierarquizada introduziu-se no modelo a variável de nível 2 , estado nutricional inicial com as variáveis de nível 1 (idade gestacional e seus termos quadrático e cúbico) com variância complexa no nível 2. As demais etapas (2 a 9) consistiram da inclusão das outras variáveis de nível 2 de acordo com o modelo teórico hierarquizado apresentado na Figura 2. 
$1^{\mathrm{a}}$ etapa: inclusão da variável do nível 2/bloco hierárquico 1: IMC e altura

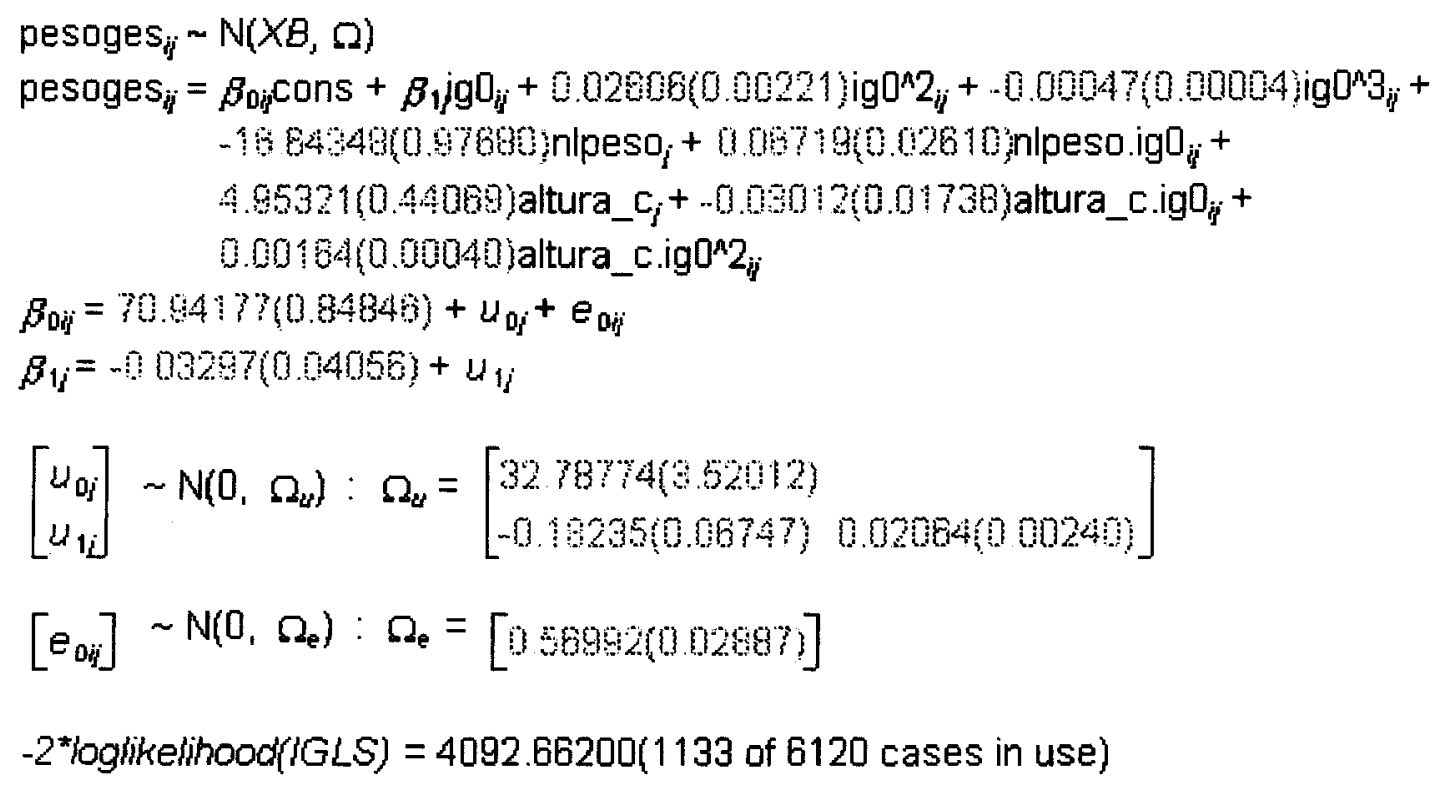

$3^{\text {a }}$ etapa: inclusão da variável de nível 2/ bloco hierárquico 2: escolaridade

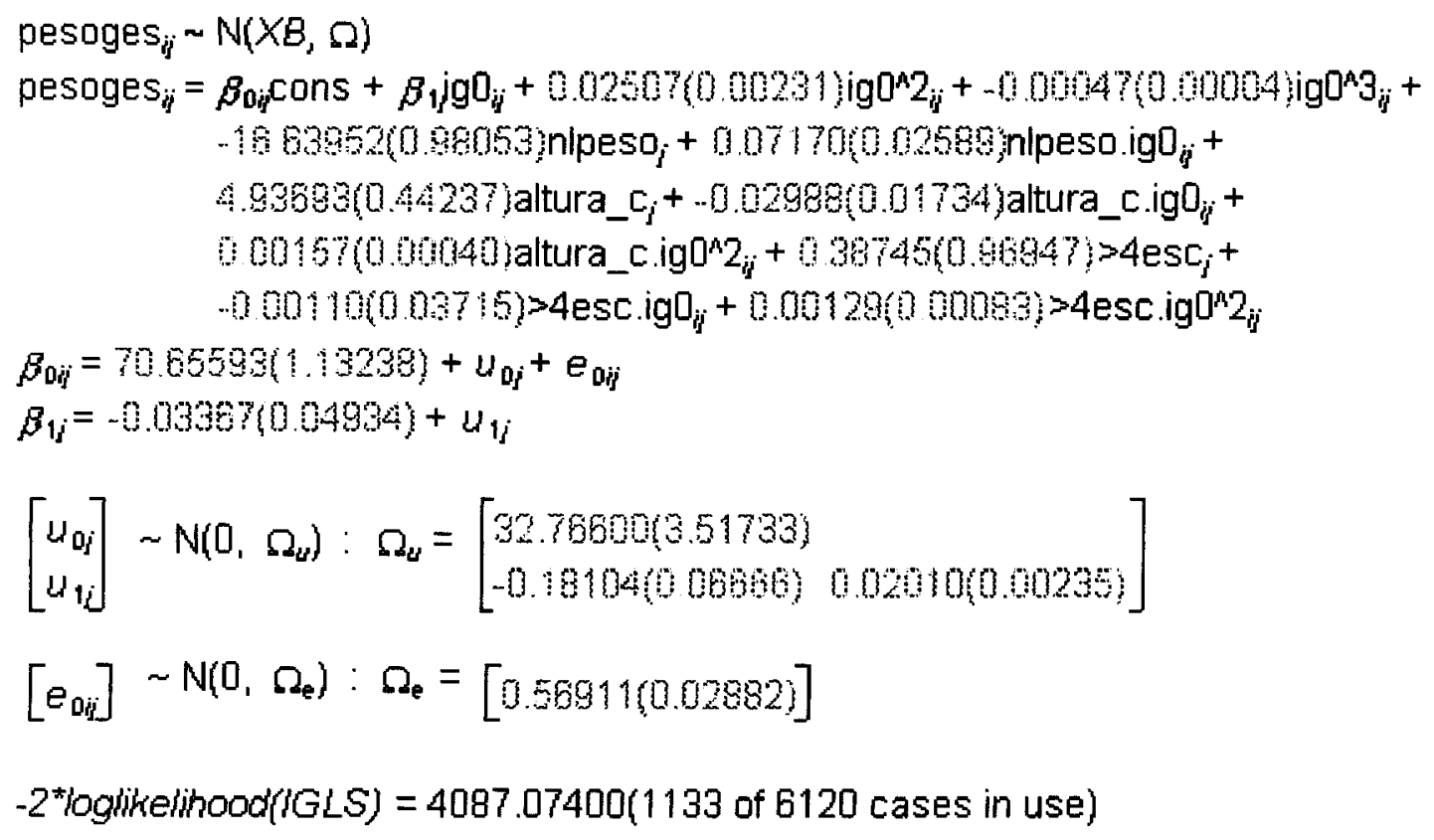


$4^{\mathrm{a}}$ etapa: inclusão da variável do nível 2/bloco hierárquico 3: situação marital

$$
\begin{aligned}
& \text { pesoges }_{i j} \sim N(X B, \Omega) \\
& \text { pesoges } \left._{i j}=\beta_{0 i j} \text { Cons }+\beta_{1 j} \mathrm{jg}_{i j}+0.02006(0.00231) \mathrm{ig}{ }^{\wedge} z_{i j}+.0000470 .00004\right) \mathrm{ig} 0^{\wedge} 3_{i j}+
\end{aligned}
$$

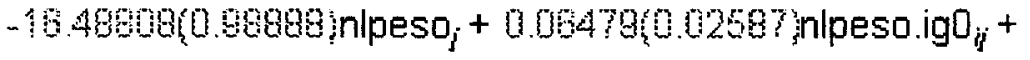

$$
\begin{aligned}
& 4.993420 .44468 \text { )altura_ } c_{j}+-000298001734 \text { )altura_c.igD } 0_{i j}+ \\
& 0.001570 .00040 \text { jaltura_c.ig0 } 2_{i j}+0.49890(0.87360)>4 \mathrm{esc}_{j}+ \\
& \left.-000570(0.08706)>4 \text { esc.ig0 } 0_{i j}+0.00125000009\right)>4 \text { esc.igon } 2_{i j}+ \\
& -107107(1.01984) \mathrm{s} / \mathrm{comp}_{j}+0.06091(002632) \mathrm{s} / \mathrm{comp} . \mathrm{igD}_{i j} \\
& \beta_{0 i j}=7073047(1.3100)+u_{0 i}+e_{0 i j} \\
& \left.\beta_{1 j}=-0.03753004919\right)+u_{1 j} \\
& {\left[\begin{array}{l}
u_{0_{j}} \\
u_{1 j}
\end{array}\right] \sim N\left(0, \Omega_{u}\right): \Omega_{u}=\left[\begin{array}{l}
32.57618(3,49788) \\
-0.17150(00666)
\end{array}\right.} \\
& {\left[e_{0 i i}\right] \sim N\left(0, \Omega_{e}\right): \Omega_{e}=[0.59901(002882)]} \\
& -2 * \text { loglikelihood(IGLS) }=4083.00900(1133 \text { of } 6120 \text { cases in use })
\end{aligned}
$$


$5^{a}$ etapa: inclusão da variável do nível 2/bloco hierárquico 4: idade e paridade

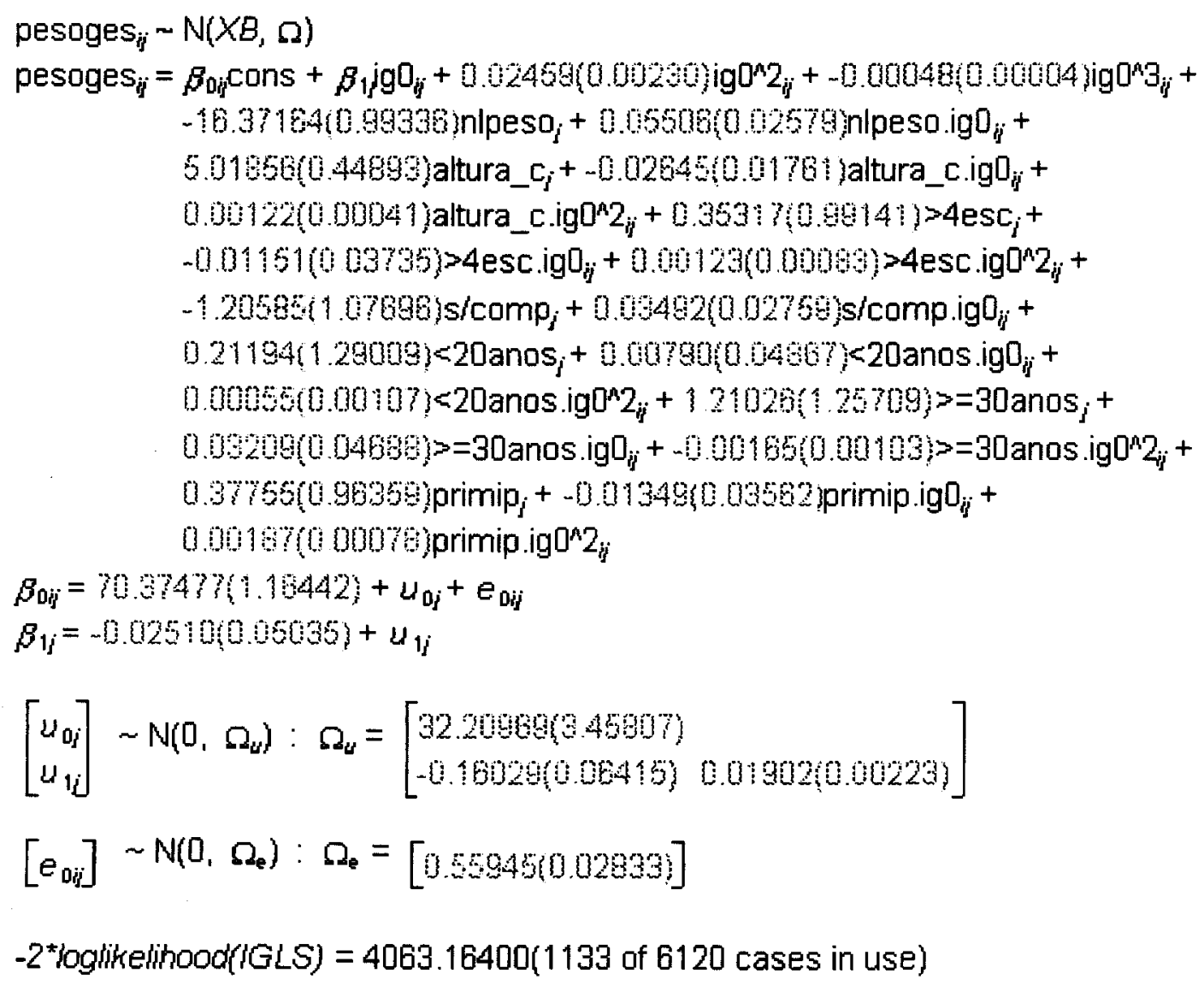


$6^{a}$ etapa: Exclusão da variável sem significância estatística: idade

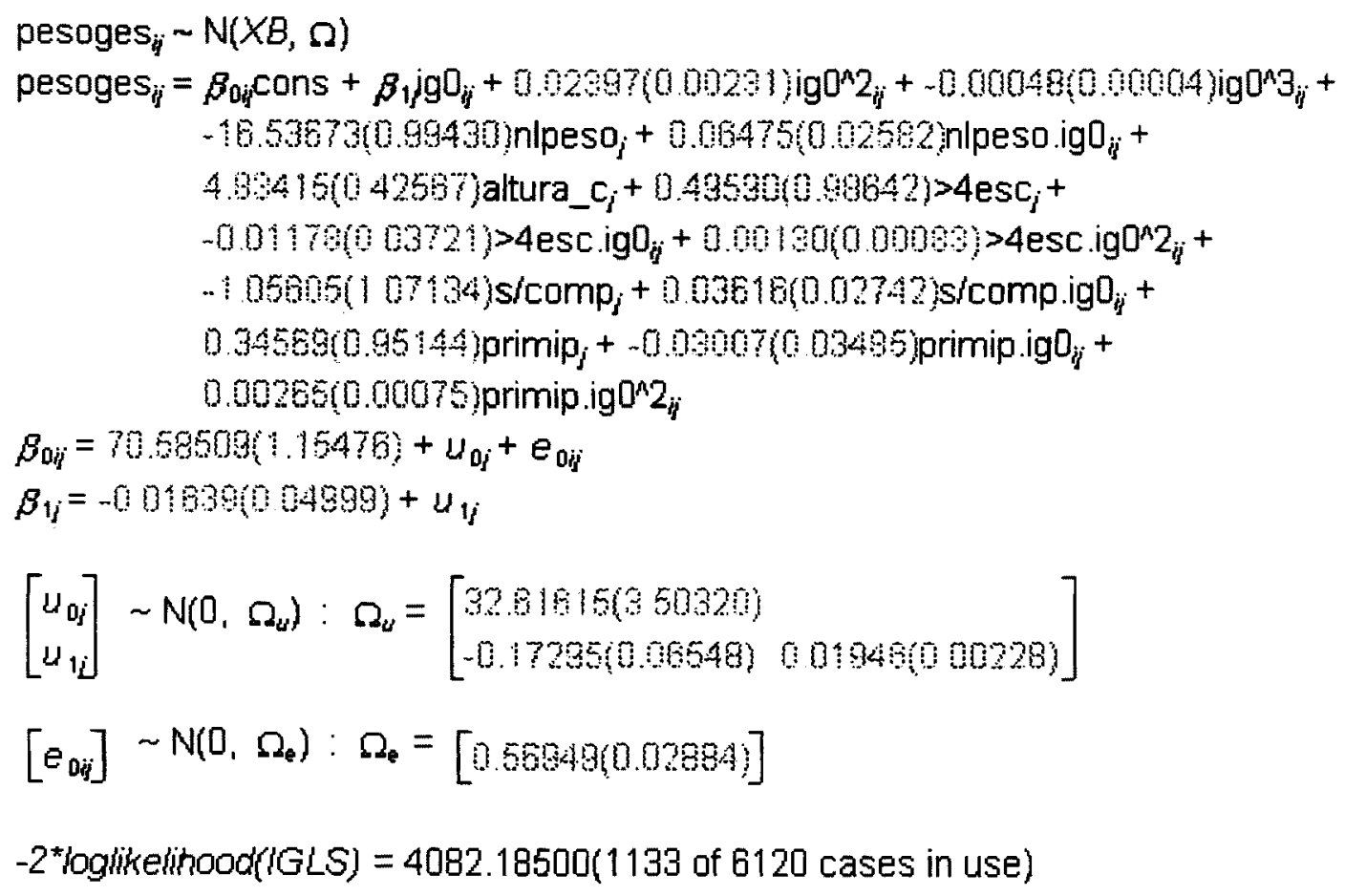


$8^{\mathrm{a}}$ etapa: inclusão da variável do nível 2/bloco hierárquico 6: Tabagismo

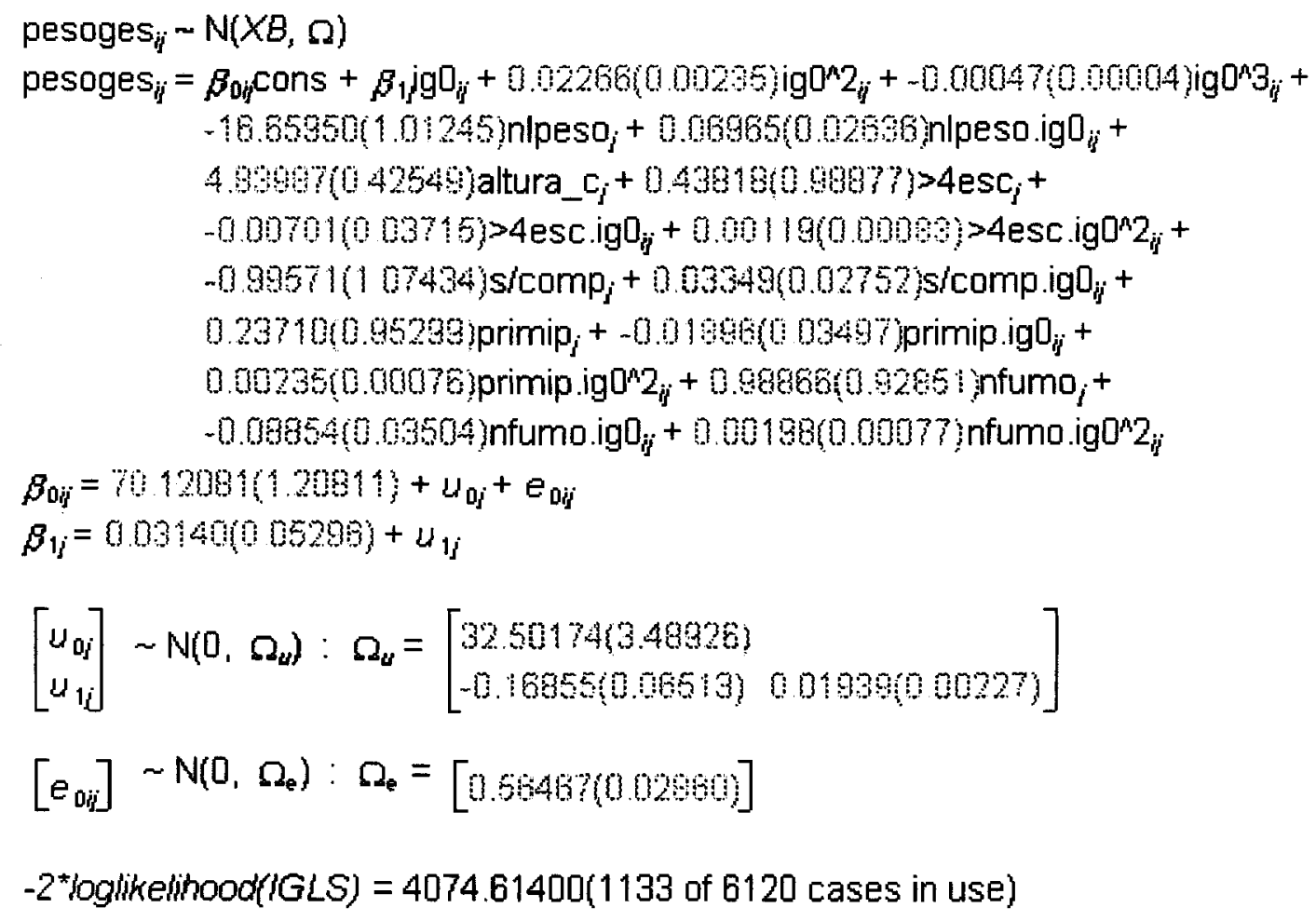

Os resultados da análise multinível estão apresentados na Tabela 5. Dentre os preditores do primeiro nivel, observou-se que a idade gestacional $(p=0,49)$ e os seus termos quadrático $(p<0,001)$ e cúbico $(p<0,001)$ associam-se com a variável resposta, indicando que durante a gestação, o ganho de peso corporal não é constante durante a gestação, isto é, o ganho de peso é mais lento no primeiro trimestre, aproximadamente constante no segundo e terceiro trimestres, mas com pequena desaceleração no último trimestre.

Com relação à influência dos demais fatores de estudo permaneceram 
estatisticamente significantes, segundo a estratégia de modelagem hierarquizada, os efeitos das variáveis: estado nutricional inicial, escolaridade, presença de companheiro, paridade e hábito de fumar. No primeiro bloco hierárquico, identificou-se que mulheres com peso adequado, segundo o IMC, iniciam a gestação com uma diferença de $16 \mathrm{~kg}$ a menos no peso corporal $(p<0,001)$ comparado com mulheres com sobrepeso ou obesas, porém as primeiras ganham semanalmente em média de $64 \mathrm{~g}$ $(p=0,004)$ a mais que gestantes sobrepesolobesas (resultados já vistos na análise bivariada).

No bloco 2, observou-se que a escolaridade apresentou uma associação direta com o peso corporal durante a gestação, assim, gestantes com quatro anos ou mais de escolaridade têm incrementos semanais médios que aumentam com a evolução da gestação, fato decorrente da interação da variável com o termo quadrático $(p=0,12)$.

Não residir com o companheiro acresce o ganho médio semanal em $51 \mathrm{~g}(p=0,03)$ em relação à mulheres que moram com seus companheiros.

A primiparidade associou-se positivamente com a evolução do peso corporal de gestantes, assim, primiparas apresentaram em ganhos semanais médios que aumentavam a cada semana de gestação $(p=0,0004)$ quando comparadas às multiparas.

As gestantes que não são tabagistas têm incrementos negativos ( $p$ $=0,011$ e $p=0,10)$ durante a gravidez em relação às fumantes. Estes incrementos não são constantes, incrementos maiores são observados na 
vigésima semana de gestação e depois eles reduzem, entretanto se mantêm negativos.

As variável idade não mostrou significância estatística $(p=0,2)$ com a variável desfecho.

Também foram introduzidas duas interações: idade e paridade; e escolaridade e situação marital. Procurou-se testar os efeitos de modificação da idade sobre a paridade e da escolaridade sobre a situação marital em relação ao ganho de peso gestacional. Porém, não foi observada significância estatística para estas interações (Anexo 7). 
TABELA 5: Análise linear multinivel hierarquizada para predição da evolução do peso durante a gestação. São Paulo, março/1997 a outubro/19981997-1998

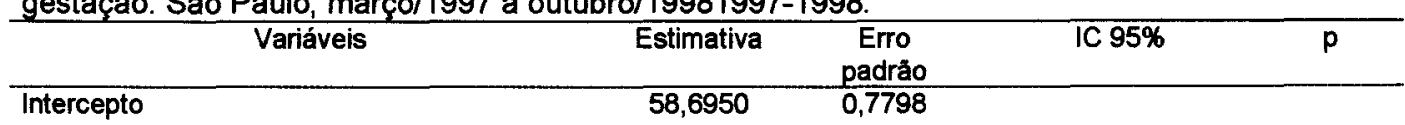

Nivel 1: Medidas

Idade gestacional (meses)

Idade gestacional ao quadrado (meses)

Idade gestacional ao cubo (meses)

Nivel 2: Gestantes

Bloco hierárquico

Indice de Massa Corporal inicial

$$
\text { Peso de adequado }
$$

Sobrepeso e obesidade

IMC . idade gestacional

Peso adequado . Idade gestacional

Sobrepeso/obesidade . Idade gestacional

Altura

Altura . Idade gestacional

Altura . idade gestacional ${ }^{2}$

\section{Escolaridade}

Bloco hierárquico 2

\section{$\leq 4$ anos}

$>4$ anos

Escolaridade . idade gestacional

$\leq 4$ anos . idade gestacional

$>4$ anos . idade gestacional

Escolaridade . termo quadrático

$\leq 4$ anos . idade gestacional ${ }^{2}$

$>4$ anos . idade gestacional ${ }^{2}$

Bloco hierárquico 3

Situação marital

Reside com o companheiro

Não reside com companheiro

Situação marital e idade gestacional Com o companheiro . Idade gestacional Semcompanheiro . Idade gestacional

Bloco hierárquico 4

Paridade

Primipara

Multipara

Paridade . idade gestacional

Primipara . idade gestacional Multípara . idade gestacional

Paridade . termo quadrático

Primípara . idade gestacional ${ }^{2}$ Multipara . idade gestacional ${ }^{2}$

Bloco hierárquico 5

Tabagismo

Fuma

Não fuma

$\begin{array}{ll}0,0245 & 0,0359 \\ 0,0256 & 0,0022\end{array}$

$-0,0005 \quad 0,00004$

$-0,04586-0,09486$

$0,00508-0,00492$

$-16,64348 \quad 0,97680 \quad-18,5580--14,7289$

$0,06719 \quad 0,0210 \quad 0,02603-0,10835$

4,95321

$-0,03012$

$-$

0,44069

0,00164

0,00040

$4,08945-5,81696$

$-0,06418-0,00394$

$0,0008-0,00394$

0,38745

0,96947

$-1,51271-2,28761$

$\begin{array}{lll}-0,00110 & 0,03715 \quad-0,07391-0,07171\end{array}$

$0,00129 \quad 0,00083 \quad-0,00034-0,00292$

$\begin{array}{lll}-1,07107 & 1,01964 \quad-3,06956-0,92742\end{array}$

$0,05091 \quad 0,02632 \quad-0,00068-0,10250$

$0,034569 \quad 0,95144 \quad-1,83025-1,89939$

$-0,03007 \quad 0,03485 \quad-0,09838-0,03824$

$0,00265 \quad 0,00075 \quad 0,00118-0,00412$

$0,098866 \quad 0,92851 \quad-1,72101-1,91875$

Tabagismo. Idade gestacional

Fuma . idade gestacional

Nåo fuma. Idade gestacional

$<0,0001$

0,01

$<0,0001$

0,08

$<0,0001$

0,69

0,97

0,12

0,29

0,05

0,72

0,38

0,0004

0,29

0,011

$-0,08854 \quad 0,03504 \quad-0,15722-0,01986$

abagismo. Termo quadrático

Fuma. Idade gestacional $^{2}$

Năo fuma . idade gestacional ${ }^{2}$

Bloco hieraracico 1 : varidiveis nivel $1+$ IMC inichal

Bloco hiertaraico 2: bloco hier rovico 1+escolaridade

Bioco hierdirquico 3: bloco hierdrquico 1 + bloco hierdrquico 2+ situagato marital

Eloco hierárquico 3: bloco hierárquico 1+ bloco hierárquico 2 + Bloco hierárquico 3 + paridade

Bloco hierárquico 5: bloco hierdrquico $1+$ bloco hierdrquico $2+$ bloco hierárquico $4+$ tabagismo 
A Tabela 6 mostra o efeito individualizado das variáveis que apresentaram associação estatisticamente significante com o peso corporal na gestação. Estes valores foram obtidos mediante substituições nas equações da análise multinivel correspondente ao respectivo bloco hierárquico.

Verificou-se que iniciar a gestação com um IMC adequado, aumenta em 2,2 kg o ganho de peso total ( $7^{\mathrm{a}}$ a $40^{\mathrm{a}}$ semana de gestação). A diferença média entre gestantes de peso adequado e com sobrepeso/obesidade é dada pela seguinte equação:-0,00110 escolaridade<4anos.ig0 $+0,00129$ escolaridade $<4$ anos.igo ${ }^{2}$ ( $3^{\mathrm{a}}$ etapa).

Independente do estado nutricional inicial, Ter no mínimo cinco anos de escolaridade leva a um ganho adicional durante a gestação de 1,4 kg. Não Ter companheiro, aumenta o peso gestacional em média $1,7 \mathrm{~kg}$. A primiparidade proporciona acréscimos médios de $1,9 \mathrm{~kg}$ no peso final da gestante. Enquanto que apresentar o hábito de fumar reduz o peso gestacional na quadragésima semana de gestação em aproximadamente $770 \mathrm{~g}$. 
Tabela 6: Acréscimo médio no ganho ponderal gestacional estimado segundo estado nutricional inicial, efeito individualizado da escolaridade, da situação marital e da paridade. São Paulo, março/1997 a outubro/1998.

\begin{tabular}{|c|c|}
\hline Variável & $\begin{array}{c}\text { Ganho de peso estimado } \\
(\mathrm{kg})\end{array}$ \\
\hline \multicolumn{2}{|l|}{ IMC inicial } \\
\hline Peso adequado & 2,2 \\
\hline Sobrepeso/Obesidade & - \\
\hline \multicolumn{2}{|l|}{ Escolaridade } \\
\hline$\leq 4$ anos & - \\
\hline$>4$ anos & 1,4 \\
\hline \multicolumn{2}{|l|}{ Situação marital } \\
\hline Reside com companheiro & - \\
\hline Não reside com companheiro & 1,7 \\
\hline \multicolumn{2}{|l|}{ Paridade } \\
\hline Primipara & 1,9 \\
\hline Multipara & \\
\hline \multicolumn{2}{|l|}{ Tabagismo } \\
\hline Fuma & \\
\hline Não fuma & $-0,770$ \\
\hline
\end{tabular}

A evolução do peso gravídico baseado no modelo com idade gestacional obtido pela análise linear hierarquizada multinivel está apresentado na FIGURA 4. Estes resultados confirmam hipótese inicial de que o peso aumenta de forma não constante no decorrer da gestação. 


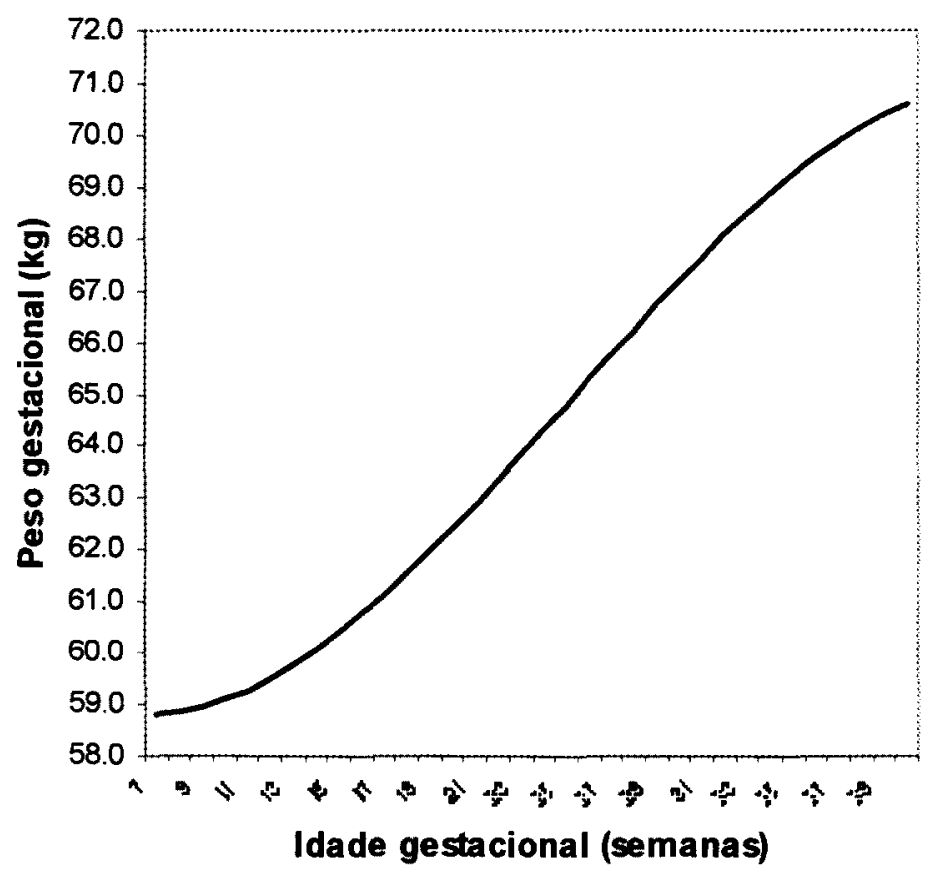

Figura 5: Evoluçăo do peso gestacional estimado segundo idade gestacional. São Paulo, março/1997 a outubro/1998. 


\section{Discussão}

\subsection{Validade}

O delineamento, do tipo coorte prospectiva, utilizado neste estudo permite incorporar informações sobre as variações individuais ao longo do tempo, produzindo estimadores mais eficientes dos parâmetros associados às medidas de tal variação, como também obter alguma informação sobre o padrão individual de variação (Bergamo, 2002).

Um aspecto importante em estudos com este delineamento é a ocorrência de viés de seleção devido à freqüência elevada de perdas durante o seguimento, seja por razões aleatórias ou por imposição do próprio estudo. As perdas referentes a este estudo foram pequenas $(0,9 \%)$ devidoA utilização de análise multinivel de medidas repetidas foi em parte responsável pelo reduzido o número de perdas deste estudo. Neste tipo de análise não é necessário seguimento completo dos indivíduos, podendo participar da análise indivíduos com apenas uma medida (Rasbash et al, 2001). Deste modo, fizeram parte da análise todas as gestantes que iniciaram o estudo.

Acredita-se que os resultados obtidos possam ser aplicáveis a gestantes semelhantes à clientela da Maternidade Amparo Maternal que 
freqüentam serviços públicos de pré-natal de outros centros urbanos de grande porte do país.

\subsection{Características das gestantes}

Verificou-se que o conjunto das 225 gestantes atendidas pelo serviço de pré-natal de baixo risco da Maternidade Amparo Maternal é constituído predominantemente por mulheres jovens, com nível de escolaridade superior a quatro anos, prímiparas e residindo com o compaßumi melação à escolaridade, foi constatado que $68,3 \%$ das mulheres apresentam nível de escolaridade igual ou superior a 5 anos. Porcentagem maior $(79,9 \%)$ foi encontradas em coorte de 312 mães do Município de Pelotas/RS (Gigante et al, 2000).

A freqüência de gestantes que residem com o companheiro $(74,4 \%)$ é semelhante à encontrado por Ribeiro et al (2000) em 282 gestantes de 18 a 19 anos de Ribeirão Preto/SP: 77,3\% possuem companheiro. Porém, Barbieri et al (2000) e Gigante et al (2000) observaram freqüências maiores de gestantes nestas condições, $85,2 \%$ e $84,0 \%$, respectivamente.

As gestantes têm em média 23 anos de idade, sendo que $14,8 \%$ encontram-se na faixa etária de 18 a 19 anos e $71,7 \%$ entre 20 a 29 anos. A 
coorte estudada é mais jovem que o total de gestantes que deu a luz no Município de São Paulo em 1998: 10,5\% tinham entre 18 e 19 anos, e 39,4\% entre 20 e 29 anos (Monteiro et al, 2000). É igualmente mais jóvem do que as gestantes de Pelotas $(66,0 \%$ têm 30 anos ou mais).

Mais da metade das gestantes é de primíparas, porcentagem superior à observada em Pelotas $(36,5 \%)$ por Gigante et al (2000) e no Município de São Paulo (43,9\%) por Monteiro et al (2000).

Constatou-se uma freqüência de $35,3 \%$ de fumantes na coorte, porcentagem semelhante foi encontrada por Horta et al (1997). Entretanto, Monteiro et al (2000) e Ribeiro et al (2000) verificaram uma prevalências inferiores no município de São Paulo e Pelotas: $28,3 \%$ e 20,6\%, respectivamente.

No presente estudo, as gestantes na primeira consulta de pré-natal encontravam-se com 11,4 semanas de gestação em média. As gestantes ( $n=77$ ) estudadas por Soltani \& Fraser (2000) realizaram sua primeira consulta de pré-natal com idade gestacional ligeramente superior, 13,2 semanas de gestação.

O estado nutricional com que as mulheres iniciam o pré-natal, avaliado segundo categorias de IMC propostas pela OMS (1995) para a população adulta, apresenta a seguinte distribuição: $4,4 \%$ baixo peso; $68,4 \%$ peso adequado; $17,3 \%$ sobrepeso; e $9,8 \%$ obesidade. Nucci et al 
(2000) em estudo com gestantes atendidas pelo Sistema Único de Saúde (SUS) de seis capitais brasileiras, encontraram porcentagens semelhantes para mulheres com baixo peso $(5,6 \%)$ e eutróficas $(65,5 \%)$, porém a freqüência de mulheres com sobrepeso $(22,3 \%)$ foi superior e de obesas foi inferior $(6,6 \%)$.

A porcentagem de gordura observada $(28,9 \%)$ é semelhante as relatadas por Villar et al (1992) (28,9\%) e Lindsay et al $(1997)(24,4 \%)$.

Quanto às características antropométricas, as grávidas apresentam peso médio no início da gestação igual a 63,7 , estatura média de $158,5 \mathrm{~cm}$ e IMC médio na primeira consulta de pré-natal de $23,7 \mathrm{~kg} / \mathrm{m}^{2}$. A análise de dados da Pesquisa Nacional sobre Demografia e Saúde (PNDS) de 1996 mostrou médias de peso inferiores $(59,0 \mathrm{~kg})$ e estaturas médias menores $(156,0 \mathrm{~cm})$ e IMC de $24,0 \mathrm{~kg} / \mathrm{m}^{2}$ para mulheres brasileiras de 15 a 49 anos (Coitinho, 2001).

\subsection{Mudanças longitudinais nas medidas gordura corporal e de prega cutâneas}

O padrão para as variações longitudinais de gordura corporal observado neste estudo: incrementos positivos nos dois primeiros trimestres, com maior magnitude no segundo trimestre, em relação ao 
terceiro trimestre de gestação, segue padrão observado por Van Raaij et al (1989) em estudo longitudinal com 57 gestantes alemãs saudáveis. Entretanto, as mudanças na gordura corporal estimadas por este estudo: $+0,5,2,0$ e 0,3 kg para os três trimestres de gestação, respectivamente, são inferiores aos encontrados para esta coorte de gestantes (incrementos de $+1,3,2,7,-0,3 \mathrm{~kg}$ por trimestre). Estudo com 27 mulheres não obesas verificou que 0 acúmulo de gordura ocorre predominantemente na primeira metade da gestação, ou seja, no final da gestação há uma redução da contribuição da gordura no ganho de peso (Lindsay et al, 1997). Estes achados estão de acordo com a constatação que os produtos da gestação representam $10,20,30$, e $40 \%$ do total de ganho de peso na $10^{a}, 20^{a}, 30^{a}$ e $40^{a}$ semana de gestação, respectivamente (Lindsay et al ,1997). No último trimestre, o feto pode requerer uma maior proporção da energia materna disponível, de maneira que não ocorrerá qualquer adição a gordura corporal (Koop-Hoolihan et al, 1999).

O ganho total de gordura corporal varia em função do método utilizado para sua determinação, como também o período em que foi estimado. Observou-se que o ganho médio de gordura foi de $4,2 \mathrm{~kg}$ durante a gestação. Resultados semelhantes (deposição média de $4,1 \mathrm{~kg}$ de gordura) foram encontrados por Koop-Hoolihan (1999), em estudo de coorte de avaliou 10 gestantes saudáveis com o objetivo de determinar a 
deposição de gordura durante a gestação. O total de gordura corporal foi estimado a partir da avaliação de quatro compartimentos corporais (água total, peso, densidade e massa mineral óssea) e os ganhos de gordura a partir da diferença da gordura na $36^{\mathrm{a}}$ semana de gestação e da gordura anterior a concepção. Os dois estudos citados anteriormente (Van Raaij et al, 1989; Lindsay et al, 1997) referem ganhos de gordura menores: 2,0 e 3,5 kg respectivamente. Paxton et al (1998) estimaram a gordura gestacional na $14^{a}$ e na $37^{a}$ semana de gestação por meio de três equações que utilizam medidas de pregas cutâneas e circunferências e um modelo de quatro compartimentos, e obtiveram as seguintes variações da gordura: $4,2,4,3,5,4,5,2$ e 3,3 kg; as duas primeiras são semelhante aos resultados deste estudo. Um estudo com 77 gestantes encontrou resultado similar, ganho total de gordura igual a 4,6 kg (Soltani et al, 2000).

A evolução das pregas cutâneas subescapular e triciptal ao longo da gestação,identificados no presente estudo, mostrou aumentos lineares até o segundo trimestre, e uma redução no terceiro trimestre. A dobra cutânea subescapular apresenta maiores acréscimos em relação a do tríceps. Villar et al (1997) e Sidebotton (2001) descrevem padrões semelhantes de mudanças destas duas pregas durante a gestação.

Aumentos médios de $2,8 \mathrm{~mm}$ na prega cutânea subescapular foram observados para esta coorte de gestantes. Variação semelhante foi 
verificada por estudo já citado (Paxton et al, 1998), 3,1 mm. Sidebottom et al (2001) encontrou ganho médio da pré-concepção até a $37^{\mathrm{a}}$ semana de gestação igual a $4,2 \mathrm{~mm}$.

O valor médio da prega cutânea triciptal no primeiro mês de gestação e no nono são similares. Os estudos de Paxton et al (1998) e Sidebottom et al (2001) registram variações pequenas nesta dobra cutânea: 1,0 e 1,5 mm, nesta ordem.

Identificou-se que a deposição de gordura subcutânea ocorre principalmente na região subescapular. Estudo de coorte com 105 gestantes residentes na Guatemala mostrou maiores acréscimos na prega cutânea subescapular do que na região do tríceps (Villar et al, 1992). Stevens-Simon et al (2001) estudaram 28 adolescentes primíparas e verificaram que os estoques subcutâneos de tecido adiposo aumentam significativamente mais rápido no tronco do que nas extremidades. Achados que estão de acordo com resultados encontrados por Taggart e Forsum: as mulheres grávidas depositam a maior parte da gordura no tronco.

5.4. Influência de fatores socioeconômicos, reprodutivos e comportamentais sobre a evolução do peso gestacional 
A análise de fatores que influenciam o ganho ponderal gestacional identificou associação estatisticamente significante com as variáveis: estado nutricional inicial, escolaridade, situação marital, paridade e fumo.

O padrão de ganho de peso observado neste estudo, ganhos menores no primeiro trimestre, aumentos mais acentuados no segundo e discretamente mais lento no último trimestre, são condizentes com que é descrito por Villar et al (1992) e Abrams et al (1995).

As mulheres que iniciam a gravidez com estado nutricional eutrófico, têm maiores incrementos de peso. No final deste período apresentam em média $2,5 \mathrm{~kg}$ a mais do que as gestantes com sobrepeso/obesidade. Estes resultados estão de acordo com os achados de Lederman et al (1997) e Nucci et al (2001). Esses autores observaram que o ganho de peso tende a ser menor no grupo de IMC muito elevado quando comparado ao grupo de IMC normal e baixo. Olson \& Strawderman (2003) observaram que a média de ganho de peso varia segundo a categoria de IMC. As gestantes obesas ganham menos peso e as gestantes de IMC normal ganham mais. Achados que estão de acordo com recomendação de ganho de peso gestacional proposta pelo IOM, na qual mulheres de baixo peso devem ganhar mais peso e as obesas ganhar menos peso durante a gestação. Idealmente, assim aumentaria os estoques de gordura das primeiras e minimizaria o ganho de gordura das 
mulheres obesas. O coeficiente de correlação entre a porcentagem de gordura inicial e o IMC da primeira consulta de pré-natal foi igual 0,70 . Lindsay et al (1997) ao encontrarem um coeficiente de correlação de 0,72 para as mesmas variáveis, concluem que o IMC precoce pode ser adotado como substituto da porcentagem de gordura em gestantes, uma vez que os resultados são consistentes aos reportados pela literatura para mulheres não grávidas

Ao comparar as gestantes de maior escolaridade ( $\geq 5$ anos) com as gestantes de menor escolaridade ( $<5$ anos), nota-se que as primeiras apresentam ganhos de peso maiores $(+1,4 \mathrm{~kg})$. Hickey $(2003)$ em revisão da literatura sobre fatores demográficos e psicossociais associados com o ganho de peso durante a gestação cita resultado da análise de dados americanos de 1992, que indica que existe uma relação direta entre a escolaridade e os ganhos ponderais gravídicos. Quanto maior a escolaridade maior o ganho de peso durante a gestação. No presente estudo, o nivel de escolaridade pode estar expressando mais o acesso aos alimentos do que conhecimento, assim mulheres com maior escolaridade teriam maior disponibilidade (variedade e qualidade) de

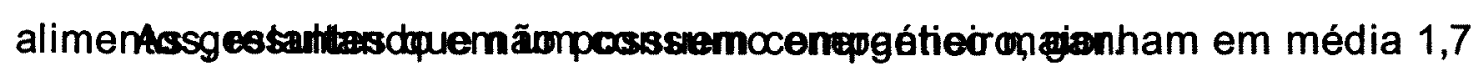
$\mathrm{kg}$ a mais em relação às gestantes que residem com seus companheiros. Entretanto, estudo realizado por Taffel (1986), citado em publicação do 
IOM (1990), verificou que gestantes americanas com companheiro ganham cerca de $1,0 \mathrm{~kg}$ a mais do que as gestantes sem companheiro. Uma possível explicação para o resultado do presente estudo é o fato da ausência de companheiro indicar um apoio psicossocial inadequado. Gestantes nesta situação estariam mais sujeitas à ansiedade, que seria compensada com um aumento no consumo de alimentos. Freqüentemente, esta variável está relacionada ao nível socioeconômico, uma vez que as mulheres que são chefes de família tendem a ter uma renda menor, como é o caso do estudo de Taffel. Estudo com 547 gestantes observou o efeito do apoio psicossocial no ganho de peso gestacional, mostrando que o apoio apoio psicossocial inadequado está associado a maiores ganhos de peso (Olson \& Strawderman, 2003).

As prímiparas $(53,8 \%$ das mulheres) têm ganho de peso superior ao das multíparas (em média $+1,9 \mathrm{~kg}$ ). Kleinnan (1990), em análise de regressão linear ajustada pela idade, também observou que as primíparas ganham mais do que as multíparas, porém o ganho das primíparas é metade do encontrado neste estudo. Olson \& Strawderman (2003) também verificaram ganhos maiores para as primíparas. A primeira gestação, por ser uma experiência completamente nova, poderia gerar uma certa ansiedade que poderia se expressar como a sensação de fome e/ou desejos, levando estas mulheres aumentar o consumo calórico. 
Observou-se que as mulheres que não fumam têm incrementos menores no peso gravídico $(-770 \mathrm{~g})$ em relação às fumantes. A literatura é controversa com relação à associação entre tabagismo e ganho de peso gestacional. Estudo realizado por Olson \& Strawderman (2003) encontraram que mulheres que fumam de meio pacote a um pacote de cigarros por dia ganham significantemente menos peso quando comparadas a gestantes que não fumam. A publicação Nutrition during Pregnancy (IOM, 1990) faz referência a cinco estudos (Rush, 1974; Davies et al, 1976; Carruth, 1981; Meyer, 1978; Picone et al, 1982) que observaram a associação do tabagismo com o ganho de peso gravídico. Os dois primeiros estudos mostraram que mulheres não fumantes ganham menos peso que as fumantes, entretanto outros estudos verificaram que não há diferença no ganho de peso gestacional segundo hábito de fumar. Hillersteadt et al (1997) avaliou o ganho de peso em fumantes e não fumantes segundo o estado nutricional inicial. Mostrou que entre as mulheres obesas, o ganho de peso não varia significantemente segundo o hábito de fumar. Entretanto fumantes com peso adequado ganham menos peso do que as gestantes não fumantes. Fumar durante a gestação, ato amplamente condenado, pode estar expressando inadequação do cuidado e atenção que a mulher tem com a gestação e consigo mesma. Como os cuidados que as fumantes parecem dispensar a gravidez são mínimos, o 
ganho de peso apresentado por elas é maior. O peso no início também é superior ao das não fumantes.

Vale destacar que neste estudo foi elevada a freqüência de gestantes que apresentaram as características positivamente associadas ao ganho de peso, estado nutricional inicial eutrófico $(68,4 \%)$, nível de escolaridade superior a 4 anos $(68,3 \%)$, primiparidade $(53,8 \%)$ e não ter

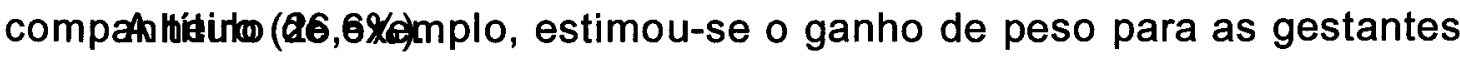
com IMC inicial adequado e altura igual a mediana $(158,5 \mathrm{~cm})$ : em média $13,2 \mathrm{~kg}$, no período que compreende da $7^{a}$ a $40^{a}$ semana de gestação. Caso elas possuam maior nível de escolaridade $\left(5^{\mathrm{a}}\right.$ série do $1^{\circ} \mathrm{grau}$ ou mais) o ganho médio para o mesmo período é de $14,6 \mathrm{~kg}$. Se além disso, forem primíparas o ganho de peso médio é de $16,5 \mathrm{~kg}$. Para gestantes sem companheiro, o ganho de peso médio estimado é de $18,2 \mathrm{~kg}$. Nota-se que o ganho médio estimado nestas duas últimas situações é superior à recomendação de ganho de peso para gestantes eutróficas $(11,5$ a $16,0 \mathrm{~kg})$ segun®o aOpjusto dos resultados obtidos ressalta a importância do monitoramento do peso durante a gestação, o qual expressa a evolução da deposição de gordura, e deve priorizar as gestantes primíparas, as com maior escolaridade e as sem companheiro.

O monitoramento do peso constitui uma estratégia fundamental Jara o aconselhamento nutricional com vistas a saúde e nutrição da jestante e do feto. 


\section{CONCLUSÕES}

- A coorte de gestantes estudada é constituída em sua maior parte por mulheres jovens (20 a 29 anos), com escolaridade maior que 4 anos e primíparas, e com companheiro.

- As mudanças longitudinais observadas para a gordura corporal e para as pregas cutâneas triciptal e subescapular durante a gestação são similares, ou seja, apresentaram aumentos até o segundo trimestre e uma ligeira redução no último trimestre de gestação.

- A evolução do peso e da gordura corporal apresentaram padrões semelhantes nos dois primeiros trimestres, incrementos positivos neste período. Porém, no terceiro trimestre, o peso mantém o padrão ascendente, enquanto que a gordura reduz moderamente.

- A gordura corporal apresentou ganhos médios de $4,2 \mathrm{~kg}$ ao longo da gestação.

- A prega cutânea do tríceps praticamente não apresentou alterações. O valor médio observado no final é similar ao do início da gestação. Entretanto, 
verificou-se um acréscimo médio de $2,8 \mathrm{~mm}$ na prega cutânea subescapular, indicando uma deposição de gordura nesta região.

- Conforme o esperado, as gestantes eutróficas no início da gravidez apresentaram maiores incrementos de peso quando comparadas com as gestantes com sobrepeso/obesidade.

- As mudanças longitudinais de peso foram positivamente associadas com o nível superior de escolaridade ( $\geq 5$ anos), não ter companheiro e paridade. Vale destacar a elevada freqüência de gestantes com estas características na coorte estudada. 


\section{Referências Bibliográficas}

1. Abrams B \& Selvin S. Maternal weight gain pattern and birth weight. Obstet Gynecol 1995; 86(2): 163-169.

2. Abrams et al. Factors associated with the pattern of maternal weight gain during pregnancy. Obstetr Gynecol 1995; 86(2): 170-176.

3. Barbieri MA et al. Risk factors for the increasing trend in low birth weigth among live birthss born by vaginal delivery, Brazil. Rev Saúde Públ 2000; 34(6): 596-602.

4. Barros AJD. Modelos Multinivel - Uma introdução à teoria e à pratica. Departamento de Medicina Social, Faculdade de Medicina da Universidade de Pelotas, 2001. [mimeo].

5. Bergamo GC. Aplicação de modelos multiniveis na análise de dados de medidas repetidas no tempo. São Paulo, 2002. [Dissertação de Mestrado - Escola Superior de Agricultura "Luiz de Queiroz" da USP].

6. Butte NF et al. Composition of gestational weight gain impacts maternal fat retetion and infant birth weigth. Am J Obstet Gynecol 2003; 189(5): 1423-1432.

7. Carmichael S, Abrams B \& Selvin S. The pattern of maternal weight gain in women with good pregnancy outcomes. Am J Public Helth 1997; 87(12): 1984-1988.

8. Coitinho DC et al. Obsesity and weight change relate to parity and breast-feeding among parous women in Brazil. Public Health Nutrition 2001; 4(4): 856-870..

9. Feig DS \& Naylor CD. Eating for two: are guidelines for weight gain during pregnancy too liberal? The Lancet 1998; 351:1054-55.

10. Gigante DP et al. Breast-feeding has a limited long-tem effect on Antropometry and body compositin of brazilian mothers. Journal Nutrition 2000; 131: 78-84; 
11. Gunderson EP \& Abrams B. Epidemiology of gestational weight gain and body weight changes after pregnancy. Epidemiol Reviews 1999; 21:261-75.

12. Habicht JP. Estandarizacion de metodos epidemiologicos cuantitativos sobre el terreno. Bol Of Sanit Panam 1974; May: 375-384.

13. Harris $\mathrm{HE}$ et al. The impact of pregnancy on the long-term weight gain of primiparous women in England. Int J Obes Relat Metab Disord 1997; 21 (9):747755.

14. Hellerstedt WL et al. The effects of cigarrete smoking and gestational weight chance on birth outcomes in obese and normal-weight woman. Am J Public Health 1997; 87(4): 591-596.

15. Hickey CA. Sociocultural and behavioral influences on weight gain during pregnancy. Am J Clin Nutr 2000; 71(Suppl): 1364S-1370S.

16. Horta BL et al. Baixo peso ao nascer em duas coortes de base populacional no sul do Brasil. Cad Saúde Publ 1996; 12(Supl 1): 27-31.

17. Institute of Medicine. Subcommitee on Nutritional Status and Weight Gain during Pregnancy. Nutrition during pregnancy. Washington, DC: National Academy of Sciences, National Academy Press. 1990.

18. Jelliffe Db \& Jelliffe EFP. The arm circuference as a public health index of proteincalorie malnutrition of early childhood. Background. J Trop Pediatr 1969; 15:179188.

19. -Jelliffe Db \& Jelliffe EFP. Community nutritional assessment with special reference to less technically develop countries. $2^{\text {nd }}$ ed., London: Oxford University Press, 1989.

20. Kac G. Fatores determinantes da retenção de peso no pós-parto: uma revisão da literatura. Rev Saúde Públ 2001; 17(3):455-466. 
21. Kopp-Hoolihan, LE et al. Fat mass deposition during pregnancy using a fourcomponent model. J Appl Physiol 1999; 87(1): 196-202.

22. Lederman SA et al. Body fat and water changes during pregnancy in women with different body weight and weight gain. Obstet Gynecol 1997; 90: 483-488.

23. Lindsay CA et al. Longitudinal changes in relationship between body mass index and percent body fat in pregnancy. Obstet Gynecol 1997; 89(3): 377-382.

24. Lohman TG et al. Anthropometric standardization reference manual. Abridged edition. Human Kinetics Books, 1988.

25. Martorell $R$ et al. Obesity in latin american women and children. Am Soc Nut Sci $1998 ; 1464-73$.

26. Monteiro CAEpidemiologia da obesidade. In: Obesidade (A. Halpern, AFG Matos, HL Suplicy, MC Manzini \& MT Zanela, org). Porto Alegre: Lemos Editorial, pp. 1520, 1998.

27. Monteiro CA. et al. Shifting obesity trends in Brazil. Eur J Clin Nut 2000a; 54: 342346.

28. Monteiro CA , Benício MHD'A, Ortiz LP. Tendência secular do peso ao nascer na cidade de São Paulo (1976 - 1998). Rev Saúde Públ 2000b; 34(6S): 26-40.

29. Muscati Sk, Gray-Donald K, Koski KG. Timing of weight gain during pregnancy: promoting fetal growth and minimizing maternal weight retention. Int $\mathrm{J}$ Obes 1996; 20: 526-532.

30. Nousis MJ. SPSS for Windows Advanced Statistics, Release 11.0, Eglewood Cliffs, New Yok, N.J.: Prentice-Hall; 2001.

31. Nucci LB et al. Assesment of weight gain during pregnancy in general prenatal care services in Brazil. Cad Saúde Públ 2001; 17: 1367-1374. 
32. Olson CM \& Strawderman MS. Modifiable behavioral factors in a biopsychosocial model predict inadequate and excessive gestational weight gain. Journal Am Diet Assoc 2003; 103(1): 48-54.

33. Parker JD \& Abrams B. Differences in postpartum weight retention between black and white mothers. Obstet Gynecol 1988; 71:701-7.

34. Paxton A et al. Anthropometric equations for study body fat in pregnanct women. Am Clin Nutr 1998; 67: 104-110.

35. Picone at al. Pregnancy outcome in North American women. I. Effects of diet, cigarret smoking, and psychological stress on maternal weigth gain. Am J Clin Nutr 1982; 36: 1205-1213 .

36. Popkin BM. The nutrition transition in low-income countries: na emerging crisis. Nutr Reviw 1994; 52:285-298.

37. Ribeiro ERO et al. Comparação entre duas coortes de mães adolescentes em município do Sudeste do Brasil. Rev Saúde Públ 2000; 34(2): 136-142.

38. Schieve LA, Cogswell ME, Scanlon KS. Maternal weight gain and preterm delivery: differential effects by body mass index. Epidemiology 1999; 10: 141-147,.

39. Scholl TO et al. Gestational weight gain, pregnancy outcome, and postpartum weight retention. Obstet Gynecol 1995; 86(3): 423-427.

40. Sebire NJ et al. Maternal obesity and pregnancy outcome: a stydy of 287213 pregnancies in London. Int J Obes Relat Metab Disord 2001; 25(8):1175-82.

41. Segal KR et al. Lean body mass estimation by bioelectrial impedance analysis: a four-seti cross-validation study. Am J Clin Nutr 1988; 47:7-14.

42. Sidebotton $A B$ et al. Pregnancy-related changes in body fat. Eur J Obst \& Gynecol and Reprod Biol 2001; 94: 216-223. 
43. Smith DE et al. Longitudinal changes in adiposity associated with pregnancy. The CARDIA Study. JAMA 1994; 271(22): 17471751.

44. Snijders T \& Bosker R. Multinivel analysis. An introduction to basic and advanced multilevel modeling. London: Sage Publications Ltda.; 1999.

45. Sohlström A \& Forsum E. Changes in adipose tissue volume and distribution during reproducyion in Swedish women as assessed by magnetic resonance imang. Am J Clin Nutr 1995; 61: 287-295.

46. Soltani H \& Fraser RB. A longitudinal study of maternal anthropometric changes in normal weight, overweight and obese women during pregnancy and postpartum. British J Nutr 2000; 84: 95-101.

47. Steven-Simon $C$ et al. Skinfold caliper and ultrsound assesssments of change in the distribution of subcutaneous fat during adolescent pregnancy. Int J Obes 2001; 25 : $1340-1345$

48. Strychar et al. Psychosocial and lifestyle factors associated with insufficiente and excessive maternal weight gain during pregnancy. J Am Diet Assoc 2000; 100(3): 353-356.

49. Stubalch TE. Determinantes do ganho ponderal excessivo durante a gestação em um serviço público de pré-natal de baixo risco. São Paulo, 2003. [Dissertação de Mestrado - Faculdade de Saúde Pública da USP].

50. Van Raaij JMA et al. Body fat mass and basal metabolic rate in Dutch women begore, during, and after pregnancy: a reappraisal of energy cost of pregnancy. Am J Clin Nutr 1989; 49: 765-772.

51. Van Raaij JMA et al. New equations for estimating body fat mass in pregnancy from body density or total body water. Am Clin Nutr 1988; 48: 24-29. 
52. Victora, CG et al. The role conceptual frameworks in epidemiological analysis: a hierarchical approach. International Jornal of Epidemiology 1997; 26: 226-227.

53. Villar MD et al. Effect of fat and fat-free mass deposition during pregnancy on birth weigth. Am J Obstet Gynecol 1992; 167(5): 1344- 1352.

54. World Health Organization. Obesity, Preveting and Managing the global Epidemicc. Report of a WHO Consulation on Obesity. Geneva: WHO/Nut/NCD/98.1.

55. World Health Organization. Physical status: the use and interpretation of antropometry. Geneva [WHO-Technical Reports Series, 854], 1995.

56. Yang $\mathrm{M}$ et al. MlwiN Macros for advanced multinivel modelling. London, Institute of Education, 1999.

57. Young TK \& Woodmansee B. Factors that are associated with cesarean delivery in a large private practice: the importance of prepregnancy body mass index and weight gain. Am J Obstet Gynecol 2002; 187:312-320. 
ESTADO NUTRICIONAL MATERNO E CRESCIMENTO

FETAL: INDICADORES ANTROPOMÉTRICOS DE PREDIÇAO

Questionário 1

\section{IDENTIFICAÇÃO DA GESTANTE}

SERVIÇO DE SAÚDE: (1) Amparo Maternal

(2)

código

n.o do prontuário :

NOME:

ENDEREÇO:

TELEFONE PARA CONTATO:

ENTREVISTADOR:

hora início:

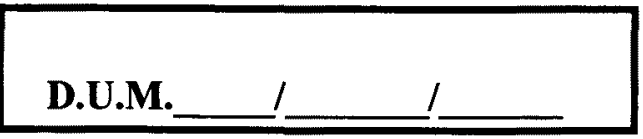
hora término:

\begin{tabular}{|c|c|c|c|c|c|c|c|c|c|c|c|c|c|c|c|c|}
\hline \multicolumn{17}{|l|}{ data } \\
\hline \multirow{3}{*}{$\begin{array}{l}\text { idade } \\
\text { gestacional }\end{array}$} & um & us & um & us & um & us & um & us & um & us & um & us & um & us & um & us \\
\hline & & & & & & & & & & & & & & & & \\
\hline & & & & & & & & & & & & & & & & \\
\hline
\end{tabular}

controle

retorno

critica 


\section{PARTE 2: A MULHER}

Q1. Qual é a sua idade? anos data de nascimento

Q2. Estado onde nasceu? ( coloque o nome inteiro do Estado)

( )

(49) estrangeiro

Q3. Tempo de residência em São Paulo:
(1) nasceu em São Paulo
(2) menos de 1 ano
(3) 1 ano
(4) 2 a 4 anos
(5) 5 a 9 anos
(6) 10 anos ou mais
(9) não sabe

Q4. Raça
(1) Branca
(2) Negra
(3) Mulata
(4) Amarela

Q5. Qual o seu estado civil?
(1) solteira
(2) casada
(3) separada
(4) viúva
(5) outro

Q6. Atualmente mora com o seu marido/companheiro?
(1) Sim
(2) Não $\Rightarrow$ (siga Q8)

Q7. Há quanto tempo está com o seu companheiro?
(1) - de 3 meses
(2) de 3 a 5 meses
(3) de 6 a 11 meses
(4) de 1 a 2 anos
(5) + de 2 anos

Q8. Com quem mora ? ( somente para as mulheres sem companheiro)
(1) mora com os pais/familiares
(2) mora sozinha
(3) mora com os amigos
(4) mora com os filhos
(5) mora no local de trabalho
(6) Amparo Maternal
(7) outro:

Q9. Freqüentou escola?

Sim (1)

Não (2)_— $\Rightarrow$ (siga Q13)

Q 10.Até que ano/série cursou?

(9) não sabe série/ano

Q11. De que grau?
(1) $1^{\circ}$ grau
(2) $2^{\circ}$ grau
(3) $3^{\circ}$ grau
(4) antigo primário
( 5 ) antigo ginásio
(6) antigo científico/normal
( 7 ) outro
(9) não sabe

Q12. Fez supletivo?
(1) não
(2) de $1^{\circ}$ grau completo
(3) de $2^{\circ}$ grau completo

Apenas para quem tem menos de 4anos de escolaridade ou nunca frequentou escola

Q13. Sabe ler e escrever?

(1) $\operatorname{Sim}$ (2) Não 
MORBIDADE (FICHA CLÍNICA)

código

Q1. Quantas vezes você já engravidou? (incluir gestação atual) gestações

Q2. Quantos filhos (nascidos vivos) teve até hoje no total? filhos

Q3.Você teve anteriormente e qual foi o número dos seguintes eventos?

\begin{tabular}{|l|l|l|l|}
\hline Evento & Sim & Não & $\begin{array}{l}\text { Quantas } \\
\text { vezes? }\end{array}$ \\
\hline Q4. aborto (< de 28 semanas ) & & & Q5. \\
\hline Q6 natimorto (bebê nasceu morto) $\left(^{*}\right)$ & & & Q7. \\
\hline
\end{tabular}

Códigos

1X (1)

$2 \mathrm{X}(2)$

somente para nascidos vivos

\begin{tabular}{|l|l|l|l|}
\hline Q8. morte neonatal (óbito antes de 28 dias) $\left(^{*}\right)$ & & & Q9 \\
\hline Q10. baixo peso ao nascer (<de 2500 g) $\left(^{*}\right)$ & & & Q11. \\
\hline Q12. prematuro (<37 semanas) (*) & & & Q13. \\
\hline
\end{tabular}

(*) checar os dados com a gestante

Q14. Quando foi o seu último parto?
( 8 ) não se aplica ( $1^{\circ}$ gestação)
(1) menos de 1 ano
(2) 1 ano $-1,5$ anos
(3) 1,5 anos -- 2 anos
(4) mais que 2 anos

Q15. Onde ocorreu o seu último parto?
( 8 ) não se aplica $\left(1^{\circ}\right.$ gestação)
( 1 ) em casa
(2) no hospital
Qual 
Você já teve alguns desses problemas de saúde?

\begin{tabular}{|l|l|l|l|}
\hline \multicolumn{1}{|c|}{ Problema } & \multicolumn{3}{c|}{ Ocorrência } \\
\hline & (1) sim & (2) não & (9) não sabe \\
\hline Q16 cardiopatia & & & \\
\hline Q17 hipertensão arterial & & & \\
\hline Q18 diabetes & & & \\
\hline Q19 endocrinopatias & & & \\
\hline Q20 infecção urinária e pielonefrite & & & \\
\hline Q21 tuberculose & & & \\
\hline Q22 rubéola & & & \\
\hline Q23 m.Chagas & & & \\
\hline Q24 cervicite, vaginite(corrimento) & & & \\
\hline Q25 esquistossomose & & & \\
\hline Q26 hepatite & & & \\
\hline Q27 AIDS & & & \\
\hline Q28 outros $\left.{ }^{*}\right)$ & & & \\
& & & \\
& & & \\
& & & \\
& & & \\
& & & \\
\end{tabular}

${ }^{*}$ ) incluir infecções genitais especificadas nos antecedentes ginecológicos da Ficha Clínica 


\section{código}

\section{data}

\begin{tabular}{|c|c|c|c|c|c|}
\hline & 1.a & 2.a & 3.a & medida final & $\begin{array}{l}\text { grau de } \\
\text { diticuldade }\end{array}$ \\
\hline $\begin{array}{c}\text { Q3. peso atual ( kg) } \\
(\mathrm{cm})\end{array}$ & & & & & \\
\hline $\begin{array}{c}\text { Q5. prega tricipital ( mm) } \\
(\mathrm{mm})\end{array}$ & & & & & \\
\hline $\begin{array}{c}\text { Q6. Prega sub-escapular } \\
(\mathrm{cm})\end{array}$ & & & & & \\
\hline $\begin{array}{c}\text { Q7. Circunferência da coxa } \\
\text { Q8. Prega da coxa ( mm) }\end{array}$ & & & & & \\
\hline $\begin{array}{c}\text { Q9. Circunferência da } \\
\text { panturilha (cm) }\end{array}$ & & & & & \\
\hline $\begin{array}{c}\text { Q10. BIOIMPEDANCIA } \\
\text { resistência }\end{array}$ & & & & & \\
\hline
\end{tabular}

\section{ATENCẼO}

Diferenças aceitas entre duas medidas : peso $<100 \mathrm{~g} /$ estatura e circunferência $<0,5 \mathrm{~cm} /$ pregas $<1 \mathrm{~mm}$

classificar o grau de dificuldade na realização das medidas antropométricas, utilizando os seguintes códigos: (1) sem dificuldade (2) com dificuldade, realizou a medida (3) com dificuldade, não foi possível realizar a medida. 
ESTADO NUTRICIONAL MATERNO E CRESCIMENTO FETAL: INDICADORES ANTROPOMÉTRICOS DE PREDIÇAO

Ouestionário 3

\section{IDENTIFICAÇÃO DA GESTANTE}

SERVIÇO DE SAÚDE: (1) Amparo Maternal

(2)

codigo

n.o do prontuário :

NOME:

ENDEREÇO:

TELEFONE PARA CONTATO:

ENTREVISTADOR:

hora início:

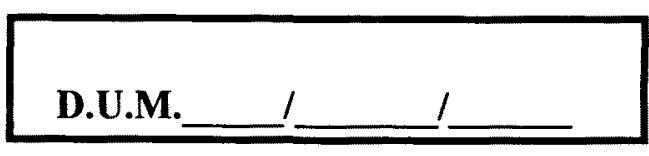
hora término:

\begin{tabular}{|c|c|c|c|c|c|c|c|c|c|c|c|c|c|c|c|c|}
\hline \multicolumn{17}{|l|}{ data } \\
\hline \multirow{3}{*}{$\begin{array}{l}\text { idade } \\
\text { gestacional }\end{array}$} & um & us & um & us & um & us & um & us & $\mathrm{um}$ & us & um & us & um & us & um & us \\
\hline & & & & & & & & & & & & & & & & \\
\hline & & & & & & & & & & & & & & & & \\
\hline & & & & & & & & & & & & & & & & \\
\hline
\end{tabular}

controle

\begin{tabular}{|l|l|l|l|l|l|l|l|l|}
\hline retorno & & & & & & & & \\
\hline critica & & & & & & & & \\
\hline
\end{tabular}




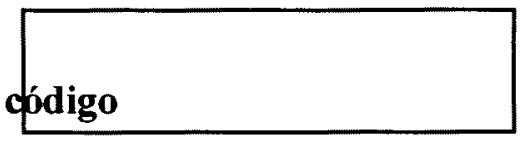

Q1. Número de pessoas no domicílio? pessoas

Q2. Enumerar as pessoas que moram no domicílio:

\begin{tabular}{|c|l|l|l|l|}
\hline Pessoa & Idade (anos ou meses) & sexo & Parentesco & Renda indiv. \\
\hline 1 & & & & \\
\hline 2 & & & & \\
\hline 3 & & & & \\
\hline 4 & & & & \\
\hline 5 & & & & \\
\hline 6 & & & & \\
\hline 7 & & & & \\
\hline 8 & & & & \\
\hline
\end{tabular}

Q3. A família tem algum outro ganho que contribui para renda familiar? (pensão, aluguel e etc.) (1) Sim

(2) Não (segue Q5)

Q4. Valor mensal aproximado de outras rendas? reais

Q5. A família recebe cesta básica/vale refeição/vale alimentação?

(1) Sim, regularmente

(2) Sim, irregularmente $=>$ especificar quantas vezes no último ano

(3) Não vezes 
PARTE 10: O CIGARRO

E OUTRAS DROGAS

nome

código

Q1. Você fuma?

(1) $\mathrm{Sim}$

(2) Não $\quad \Rightarrow$ (siga questão 5)

(3) Fumava antes de ficar grávida $\Rightarrow$ (siga questão 3)

Q2. Quantos cigarros você fuma, em média, por dia? cigarros $\Rightarrow$ (siga questão 5)

Q3. Há quanto tempo você parou de fumar?

(especificar tempo)

Q4. Quantos cigarros você fumava, em média, por dia? cigarros

Você já fez uso de algumas dessas drogas?

E desde o início da gravidez até agora, você já fez uso de algum deles?

\begin{tabular}{|l|l|l|}
\hline Droga & Sim & Não \\
\hline Q5. remédio para emagrecer & & \\
\hline Q6. remédio para dormir & & \\
\hline Q7. calmantes & & \\
\hline Q8. maconha & & \\
\hline Q9. crack & & \\
\hline Q10. cocaína & & \\
\hline Q11. LSD & & \\
\hline Q12. heroína & & \\
\hline Q13. outros & & \\
\hline Quais? & & \\
\hline
\end{tabular}


PARTE 5: A ANTROPOMETRIA (A) data nome

\section{código}

Q1. Peso pré-gestacional:

Q2. Altura : $\mathrm{cm}$
$\mathrm{Kg} \quad$ (8) não sabe

(8) não sabe

\begin{tabular}{|c|c|c|c|c|c|}
\hline & 1.a & 2.a & 3.a & medida final & $\begin{array}{l}\text { grau de } \\
\text { dificuldade }\end{array}$ \\
\hline Q3. peso atual ( $\mathrm{kg}$ ) & & & & & \\
\hline $\begin{array}{l}\text { Q4. circunferência do bra } \\
(\mathrm{cm})\end{array}$ & & & & & \\
\hline $\begin{array}{l}\text { Q5. prega tricipital } \\
(\mathrm{mm})\end{array}$ & & & & & \\
\hline $\begin{array}{l}\text { Q6. Prega sub-escapular } \\
(\mathrm{mm})\end{array}$ & & & & & \\
\hline $\begin{array}{l}\text { Q7. Circunferência da cos } \\
(\mathrm{cm})\end{array}$ & & & & & \\
\hline Q8. Prega da coxa $(\mathrm{mm})$ & & & & & \\
\hline $\begin{array}{l}\text { Q9. Circunferência } \\
\text { da panturilha }(\mathrm{cm})\end{array}$ & & & & & \\
\hline $\begin{array}{r}\text { Q10. BIOIMPEDANCIA } \\
\text { resistência }\end{array}$ & & & & & \\
\hline reactância & & & & & \\
\hline
\end{tabular}

\section{ATENCẼO}

Diferenças aceitas entre duas medidas : peso $<100 \mathrm{~g} /$ estatura e circunferência $<0,5 \mathrm{~cm} /$ pregas $<1 \mathrm{~mm}$

classificar o grau de dificuldade na realização das medidas antropométricas, utilizando os seguintes códigos: (1) sem dificuldade (2) com dificuldade, realizou a medida (3) com dificuldade, não foi possível realizar a medida. 


\section{Anexo 3}

\section{Análise multinível}

A análise multinivel trabalha com o conceito de que os dados encontram-se estruturados de forma hierárquica, ou seja, unidades agrupadas em um nivel mais baixo, as quais estão agrupadas dentro de outras unidades de um nivel mais alto e assim sucessivamente (Bergamo, 2002).

É muito comum que os indivíduos estejam organizados de forma hierárquica nos estudos. Por exemplo, ao se estudar crianças que freqüentam creches, elas se organizam em classes, que por sua vez estão agrupadas nas creches, formando uma hierarquia de três niveis (3-creches, 2-classes e 1crianças).

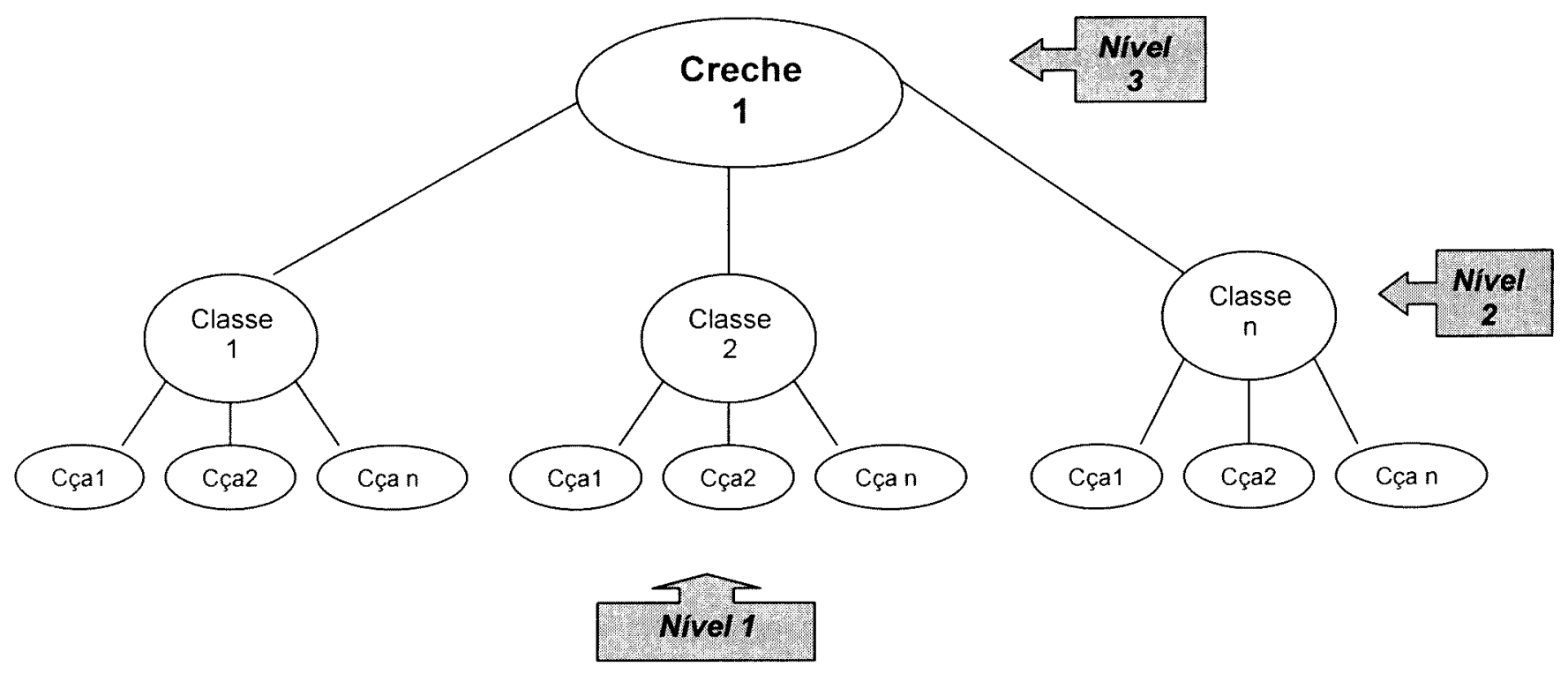


Quando os dados são estruturados em hierarquia, as unidades de um mesmo nível pertencentes a uma unidade de nivel mais alto, raramente são independentes. Uma vez que essas unidades compartilham de um mesmo ambiente ou apresentam características semelhantes, passando a existir uma correlação entre essas unidades. Este fato não está de acordo com uma das suposições dos modelos de regressão tradicionais, de independência entre os indivíduos (Barros, 2001).

Ignorar a estrutura hierárquica pode implicar na subestimação da variância dos coeficientes do modelo, levando a intervalos de confianças mais estreitos e, consequentemente à falsa significância estatística (Barros, 2001).

Os modelos multinível contemplam a estrutura hierárquica dos dados, considerando todas as correlações existentes entre as observações nos diferentes niveis de hierarquia (Bergamo, 2002).

Dados de medidas repetidas em uma mesma unidade são passiveis de ser em analisados por modelo multinível. Para tanto, não é necessário ter o mesmo número de ocasião de medidas para cada indivíduo. Os estudos de medidas repetidas apresentam uma estrutura básica de 2 níveis hierárquicos: no nível1 temos a ocasião das medidas e no nível 2 os indivíduos.

O estudo longitudinal, na qual as observações de um conjunto de indivíduos são classificados em diferentes tratamentos segundo um ou mais fatores ao longo de diversas ocasiões de medida, não apresenta total independência entre as observações, uma vez que as miedidas são feitas em um mesmo indivíduo, assim espera-se encontrar alguma correlação entre as observações realizadas no mesmo indivíduo (Barros, 2001; Bergamo, 2002). 
Grande parte do esforço para analisar dados longitudianis, está relacionada com a modelagem dessa estrutura de variância, uma vez que o número de parâmetros para descrever essa estrutura de covariância torna-se grande, principalmente se o número de ocasiões de medida é desbalanceado (Bergamo, 2002).

Uma outra vantagem que os modelos multinivel apresentam em relação às técnicas tradicionais, é a possibilidade de modelar a estrutura de variância de cada nível da hierarquia em função de variáveis explanatórias. Por exemplo, no caso de ajuste de curvas de crescimento (medidas repetidas) sabe-se que a variância muda com a idade, o modelo multinivel permite que se modele a variabilidade ao nível do indivíduo em função da idade (Barros, 2001). 


\section{Anexo 4}

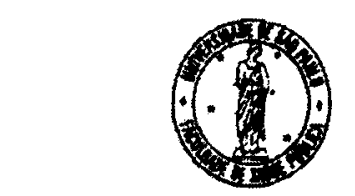

\section{Universidade de São Paulo}

Faculdade de Saúde Pública COMITE DE ÉTICA-CORP

Av. Dr. Arnaido, 715 - CEP 01246-904 - Sto Paulo - Brasil Telefones: (55-11) 3066-7734 - fone/fax (55-11) 3064 -7314 - o-mail: mdgracas@usp.br

\section{Of.COEP/050/03}

12 de março de 2003

Pelo presente, informo que o Comitè de Ética em Pesquisa da Faculdade de Saúde Páblica da Universidade de São Paulo-COEP, analisou e aprovou, em sua 02." $/ 03$ Sessảo Ordinária, realizada em 11.03.03, de acordo com os requisitos da Resolução CNS/196/96, o Protocolo de Pesquisa ${ }^{\circ}{ }^{\circ} 926$, intitulado: "EVOLUÇÃO PONDERAL DE GESTANTES DE BAIXA RENDA: INFLUÉNCLA DO ESTADO NUTRICIONAL. INICIAL E DE FATORES DEMOGRÁFICOS, REPRODUTIVOS E COMPORTAMENTAIS", apresentado pela pesquisadora Silvia Cristina Konno.

Atenciosamente,

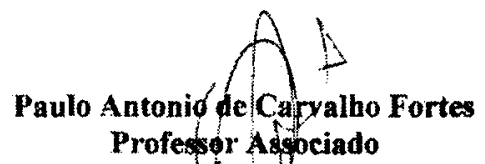

Coordenador do Comitê de Eticalem Pesquisa da FSP-COEP

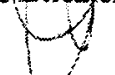




\section{Anexo 5}

Tabela: Distribuição das gestantes segundo número de medidas de peso durante a gestação.

\begin{tabular}{cccc} 
N medidas por gestante & Gestantes & Total de medidas \\
& $\mathrm{n}$ & $\%$ & \\
\hline 1 & 15 & 6,7 & 15 \\
\hline 2 & 11 & 4,9 & 22 \\
\hline 3 & 8 & 3,6 & 24 \\
\hline 4 & 12 & 5,3 & 48 \\
\hline 5 & 27 & 12,0 & 135 \\
\hline 6 & 45 & 20,0 & 270 \\
\hline 7 & 56 & 24,9 & 392 \\
\hline 8 & 31 & 13,8 & 248 \\
\hline 9 & 15 & 6,7 & 135 \\
\hline 10 & 4 & 1,8 & 40 \\
\hline 11 & 1 & 0,1 & 1 \\
\hline Total & 225 & 100 & 1340 \\
\hline
\end{tabular}


Tabela:Número de medidas de peso segundo idade gestacional em semanas.

\begin{tabular}{|c|c|}
\hline $\begin{array}{c}\text { Idade gestacional } \\
\text { (semanas) }\end{array}$ & $\begin{array}{c}\mathrm{N}^{\circ} \\
\text { medidas }\end{array}$ \\
\hline 1 & 1 \\
\hline 2 & 1 \\
\hline 3 & 1 \\
\hline 4 & 2 \\
\hline 5 & 1 \\
\hline 6 & 3 \\
\hline 7 & 13 \\
\hline 8 & 24 \\
\hline 9 & 28 \\
\hline 10 & 31 \\
\hline 11 & 30 \\
\hline 12 & 33 \\
\hline 13 & 46 \\
\hline 14 & 41 \\
\hline 15 & 42 \\
\hline 16 & 56 \\
\hline 17 & 41 \\
\hline 18 & 38 \\
\hline 19 & 39 \\
\hline 20 & 55 \\
\hline 21 & 50 \\
\hline 22 & 47 \\
\hline 23 & 38 \\
\hline 24 & 47 \\
\hline 25 & 37 \\
\hline 26 & 37 \\
\hline 27 & 40 \\
\hline 28 & 39 \\
\hline 29 & 44 \\
\hline 30 & 41 \\
\hline 31 & 48 \\
\hline 32 & 39 \\
\hline 33 & 49 \\
\hline 34 & 44 \\
\hline 35 & 53 \\
\hline 36 & 65 \\
\hline 37 & 39 \\
\hline 38 & 25 \\
\hline 39 & 22 \\
\hline 40 & 7 \\
\hline 41 & 1 \\
\hline 42 & 2 \\
\hline Total & 1340 \\
\hline
\end{tabular}




\section{Anexo 6}

Resíduo do Modelo 3

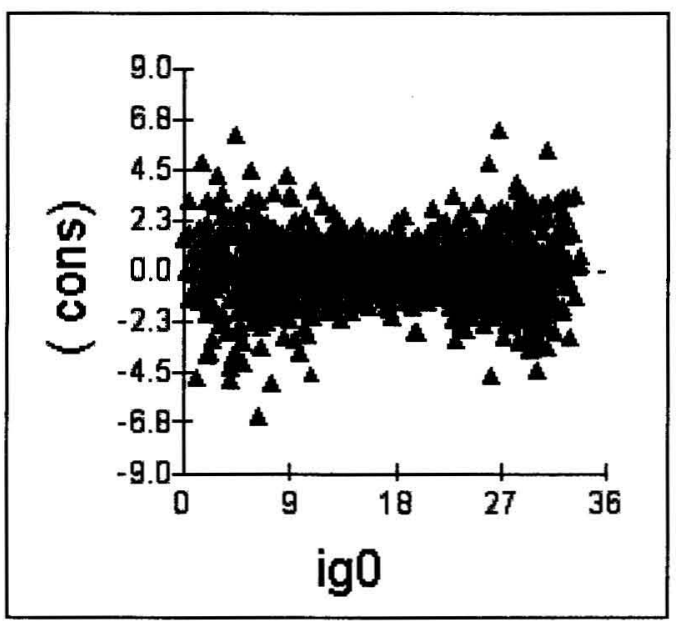

Resíduo do Modelo 5

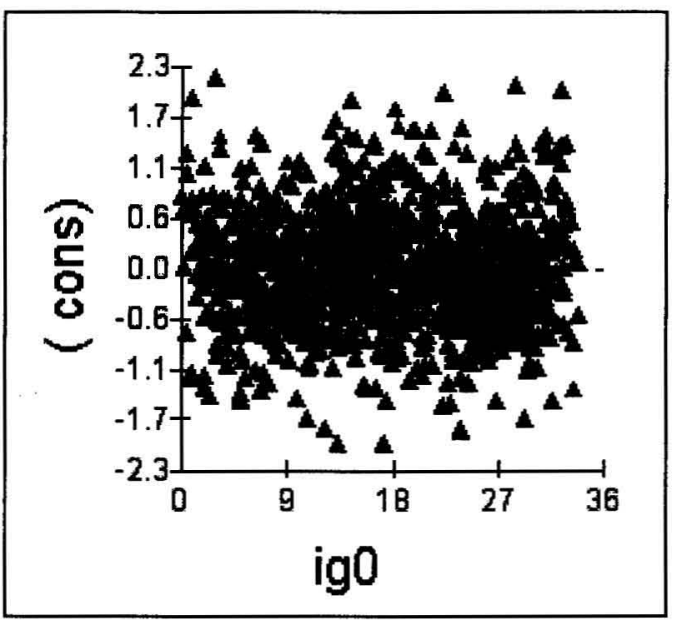




\section{Anexo 7}

Modelo 4a: Modelo com variância do nível 1 dependendo da idade gestacional

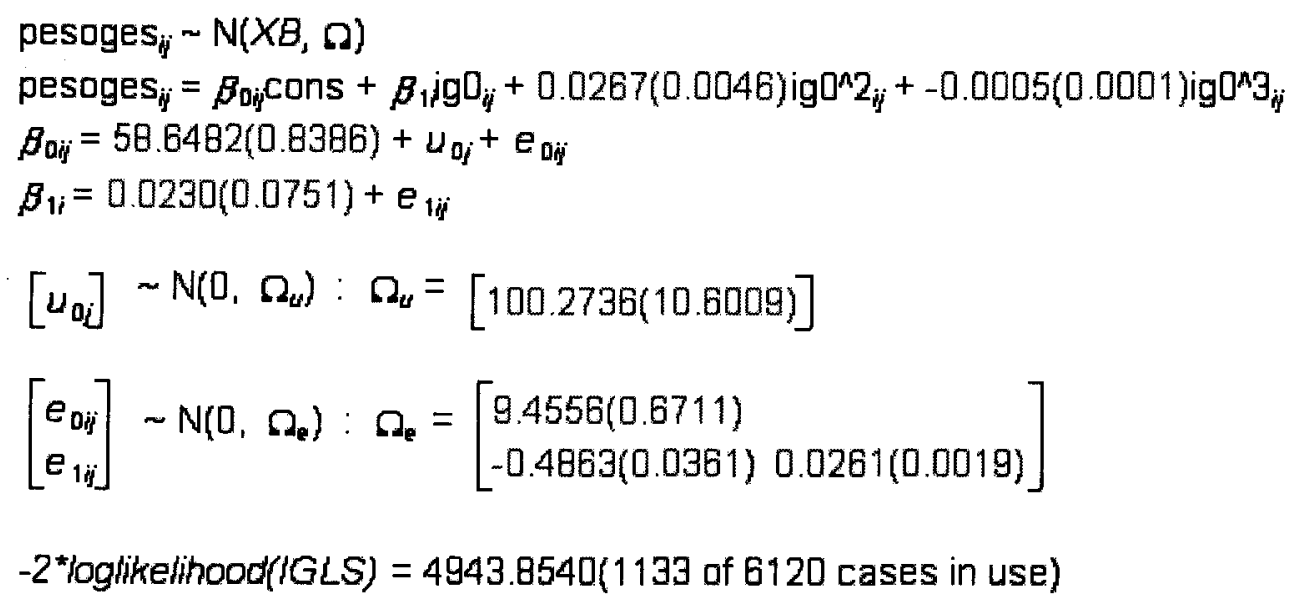

Modelo 6a: Modelo 6 e termo de interação IMC inicial e termo quadrático da idade gestacional

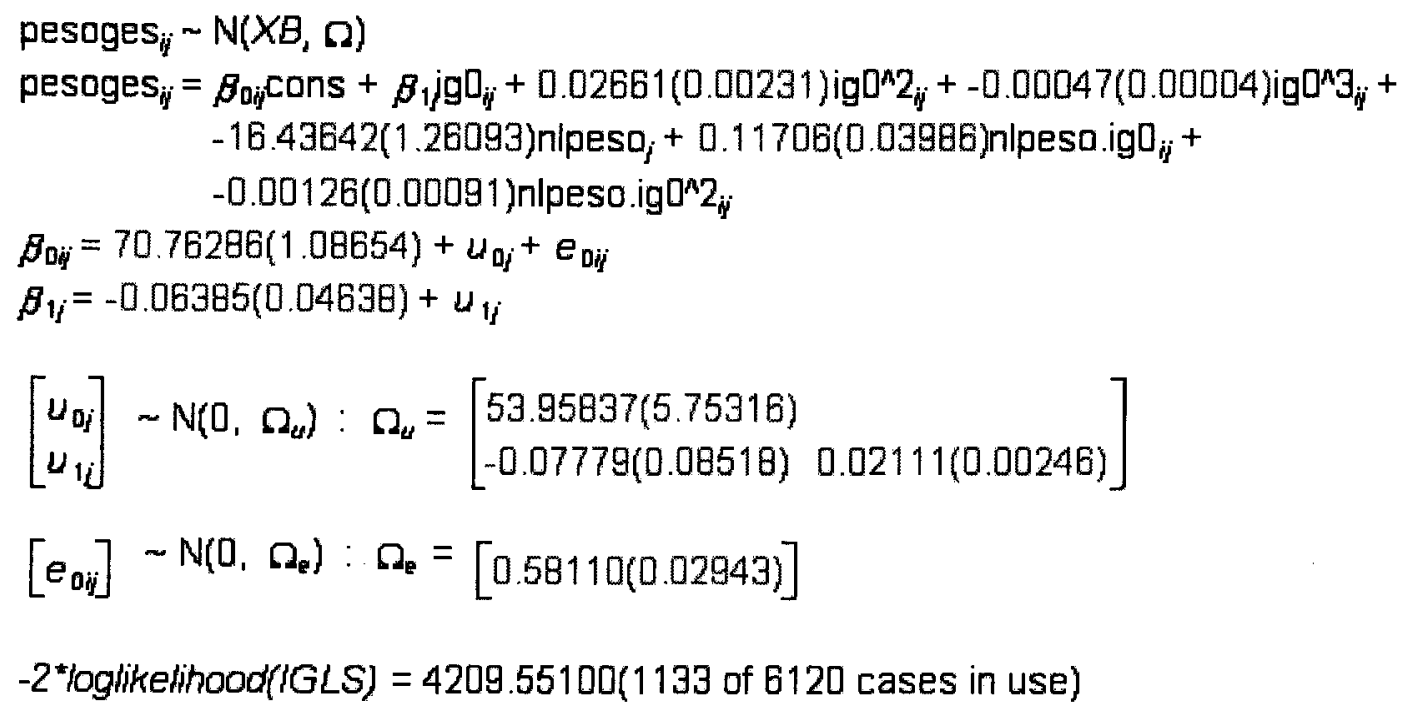


Modelo 6b: Modelo 6a e termo de interação IMC inicial e termo cúbico para idade gestacional

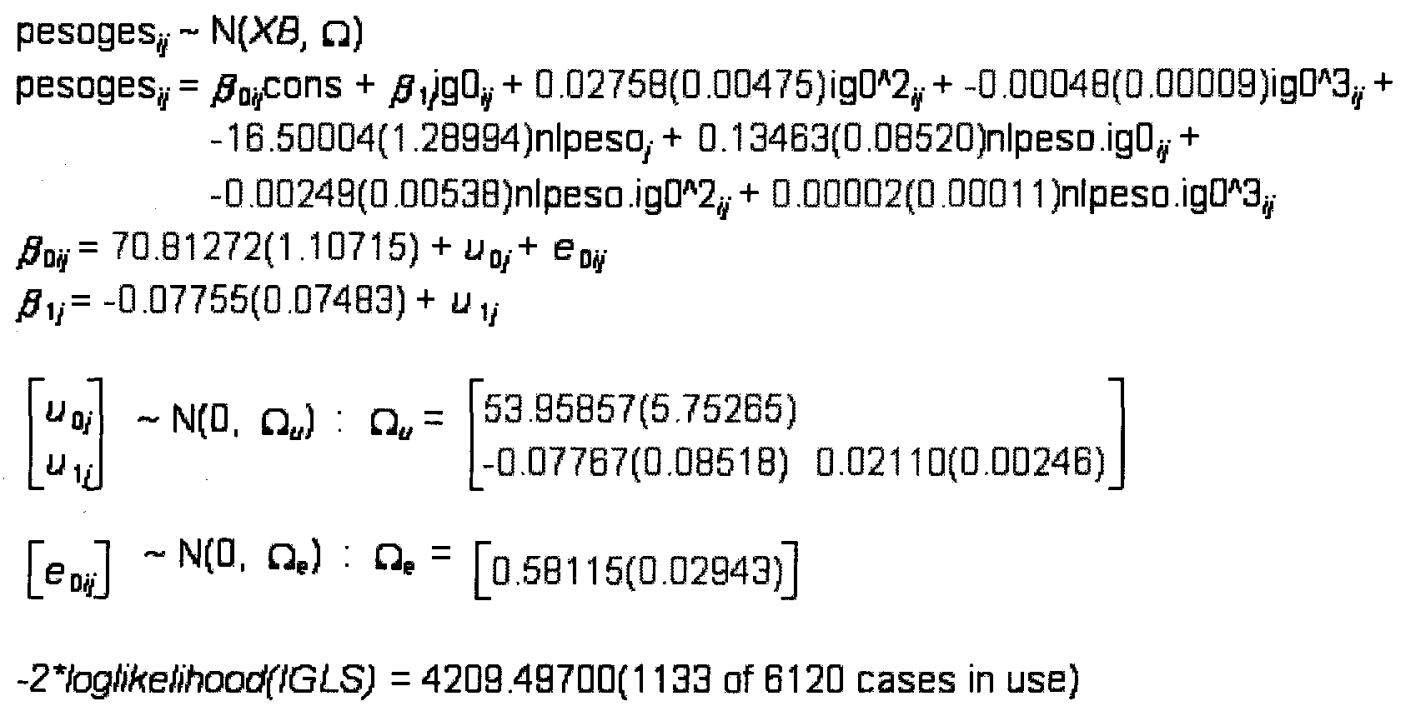

Modelo 9a: Modelo 9 e termo de interação altura e termo cúbico da idade gestacional

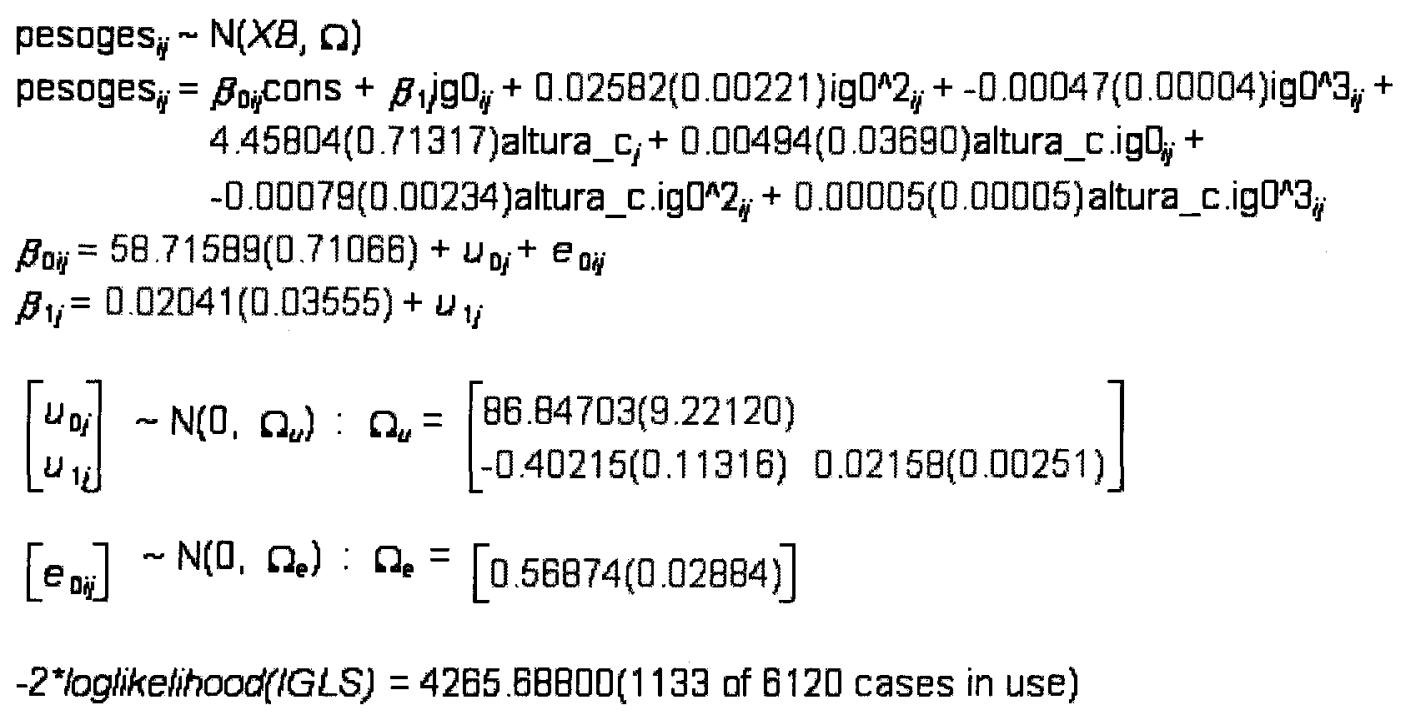


Modelo 10: Modelo 4 e variável do nivel 2 - escolaridade

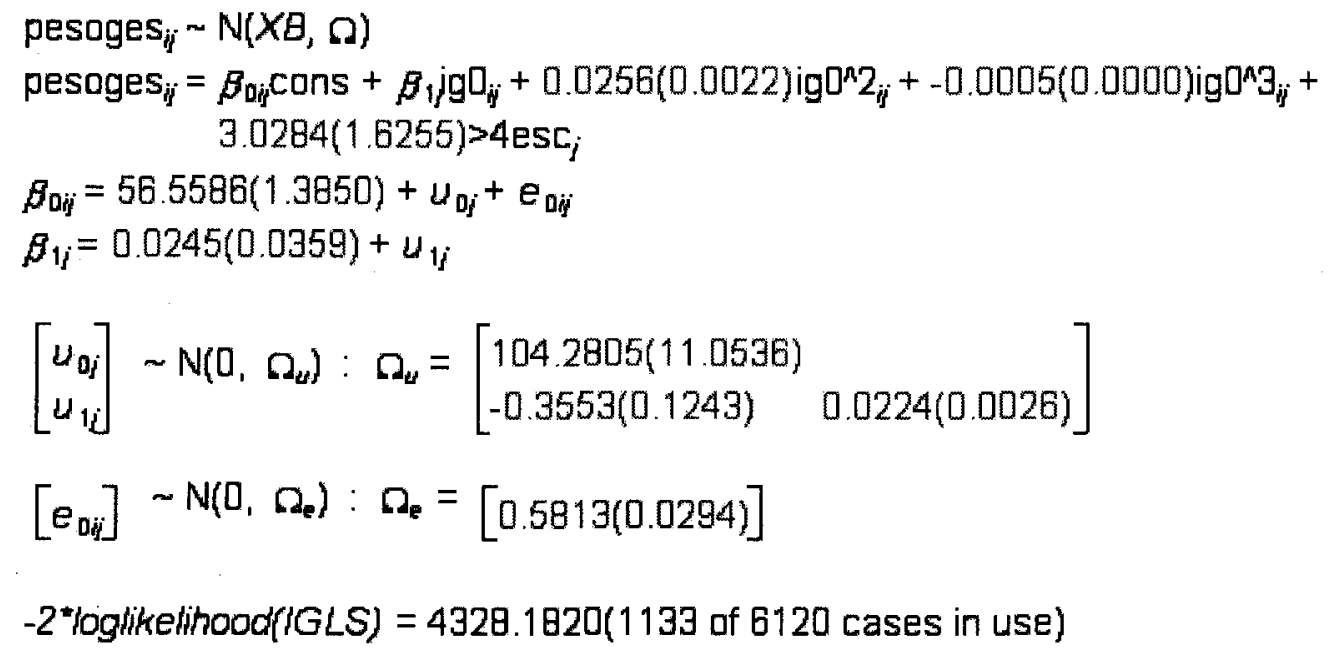

Modelo 11: Modelo 10 e termo de interação escolaridade e idade gestacional pesoges $_{i j} \sim N(X \theta, \Omega)$ pesoges $_{i j}=\beta_{0 j}$ Cons $+\beta_{i j} \mathrm{jO}_{i j}+0.0256(0.0022) \mathrm{igO}^{\wedge} 2_{i j}+-0.0005(0.0000) \mathrm{ig}^{\wedge} 3_{i j}+$ $2.3802(1.6736)>4 \mathrm{esc}_{j}+0.0414(0.0255)>4 \mathrm{esc} . \mathrm{ig} \mathrm{D}_{i j}$

$\beta_{0 i j}=57.0175(1.4131)+u_{0 j}+e_{0 i j}$ $\beta_{1 i}=-0.0050(0.0402)+u_{1 j}$

$\left[\begin{array}{l}u_{\mathrm{D} j_{j}} \\ u_{1 j}\end{array}\right] \sim \mathrm{N}\left(\mathrm{O}, \Omega_{u}\right): \Omega_{u}=\left[\begin{array}{ll}104.1256(11.0430) & \\ -0.3464(0.1231) & 0.0220(0.0026)\end{array}\right]$

$\left[e_{0 i j}\right] \sim N\left(D, \Omega_{e}\right): \Omega_{e}=[0.5816(0.0295)]$

$-2 *$ loglikelihood(IGLS) $=4325.5750(1133$ of 6120 cases in use $)$ 
Modelo 12: Modelo 11 e termo de interação escolaridade e termo quadrático da idade gestacional

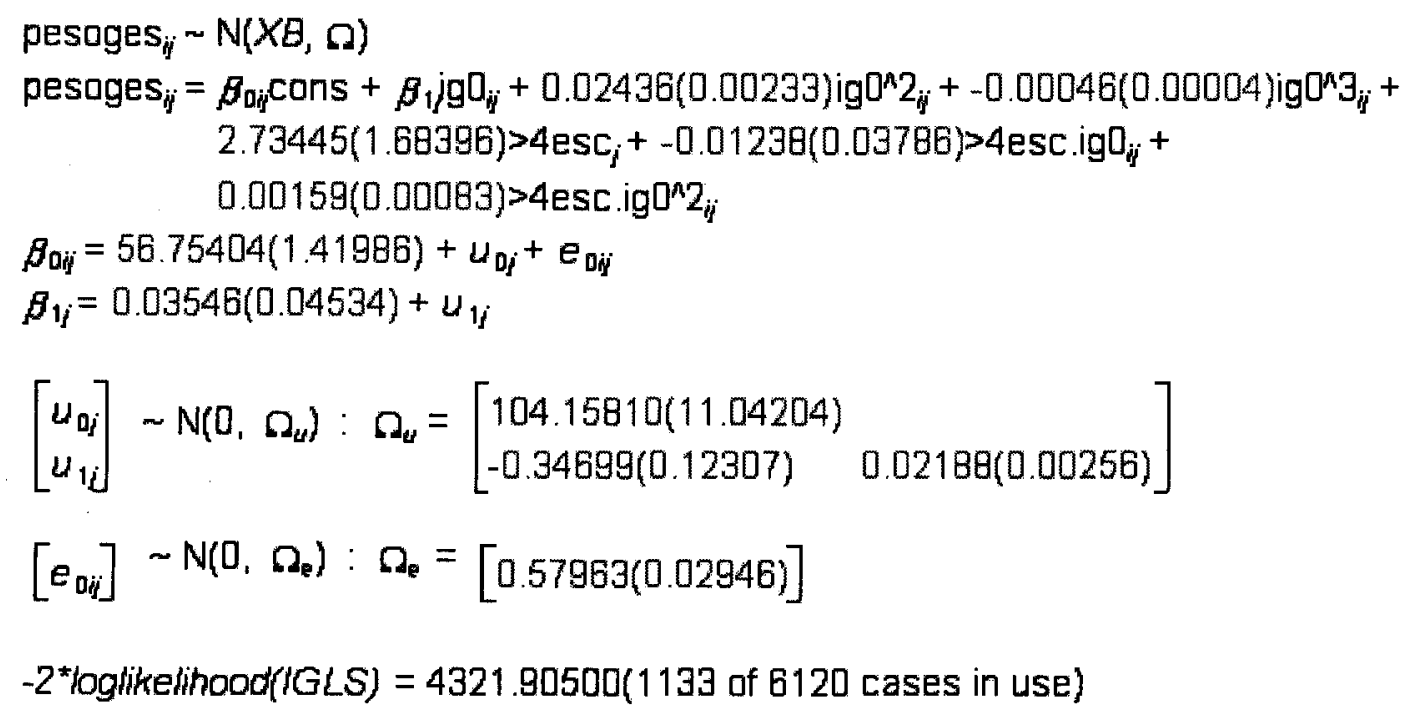

Modelo 12a: Modelo 12 e termo de interação escolaridade e termo cúbico da idade gestacional

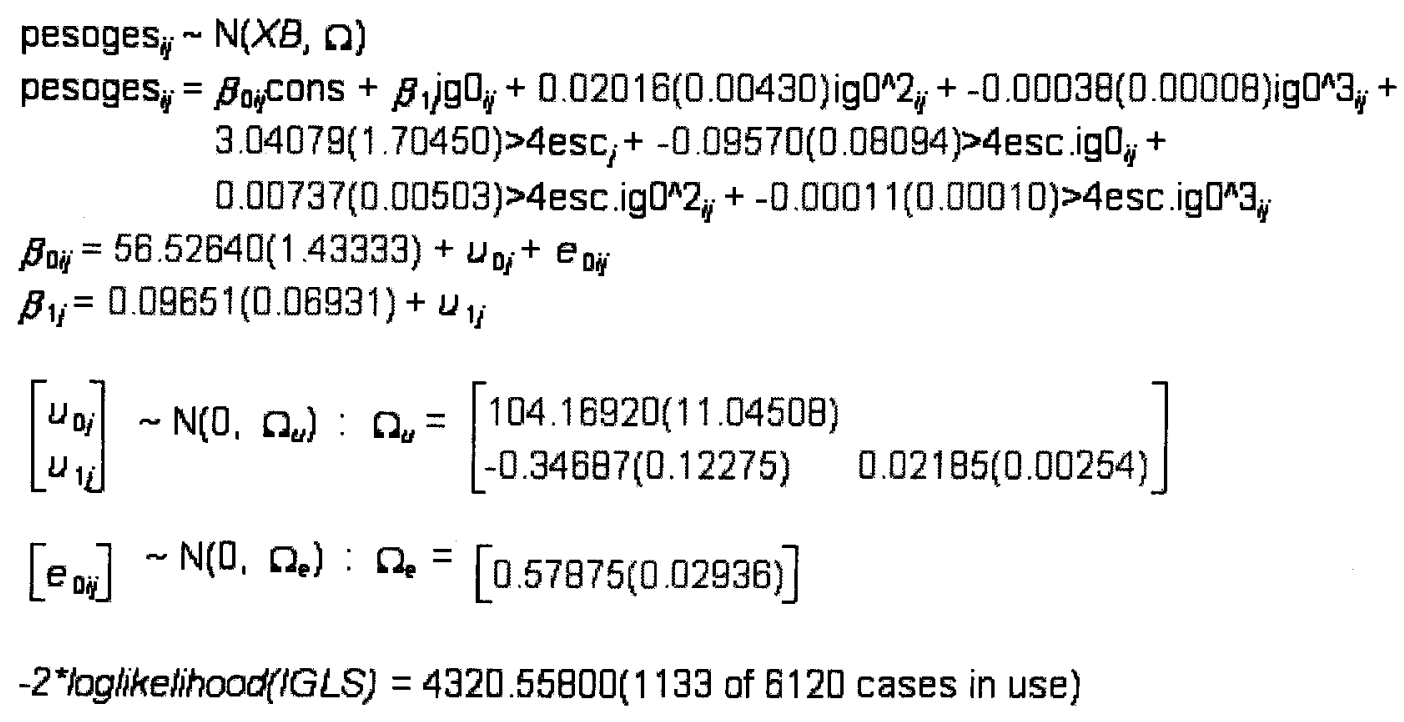


Modelo 13: Modelo 4 e variável do nível 2 - situação marital

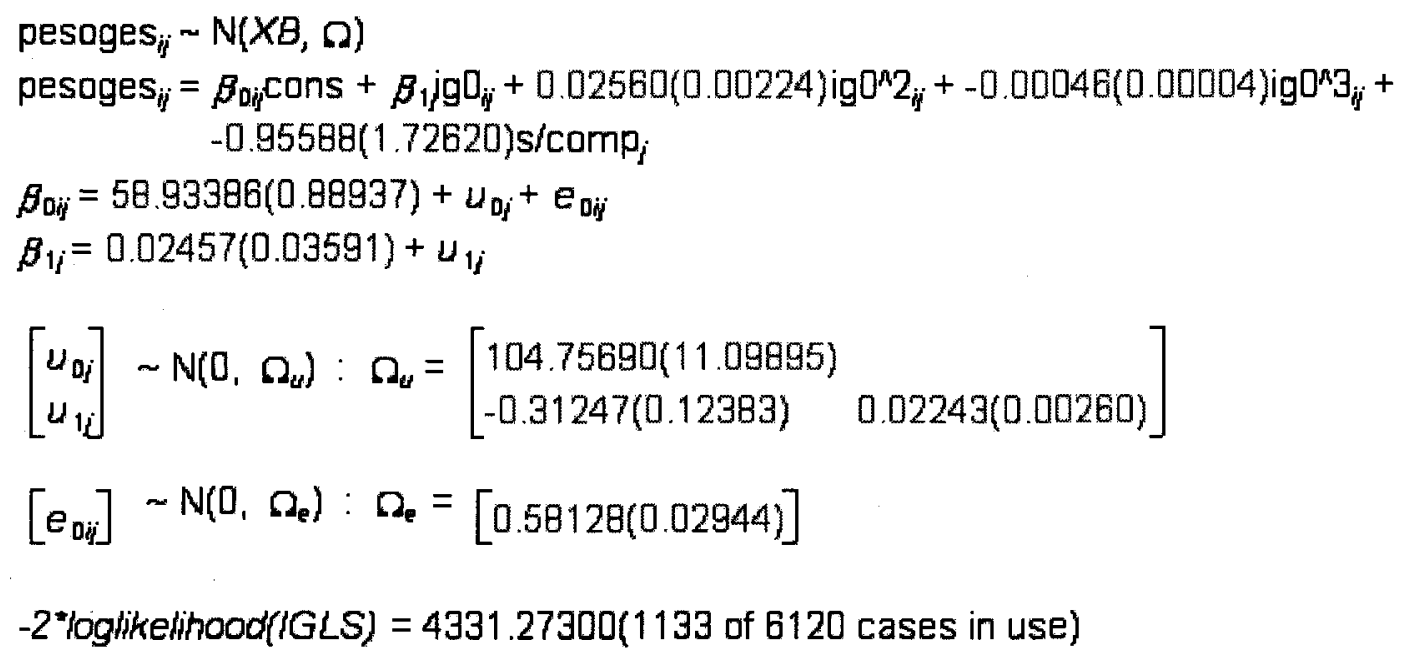

Modelo 14: Modelo 13 e termo de interação situação marital e idade gestacional

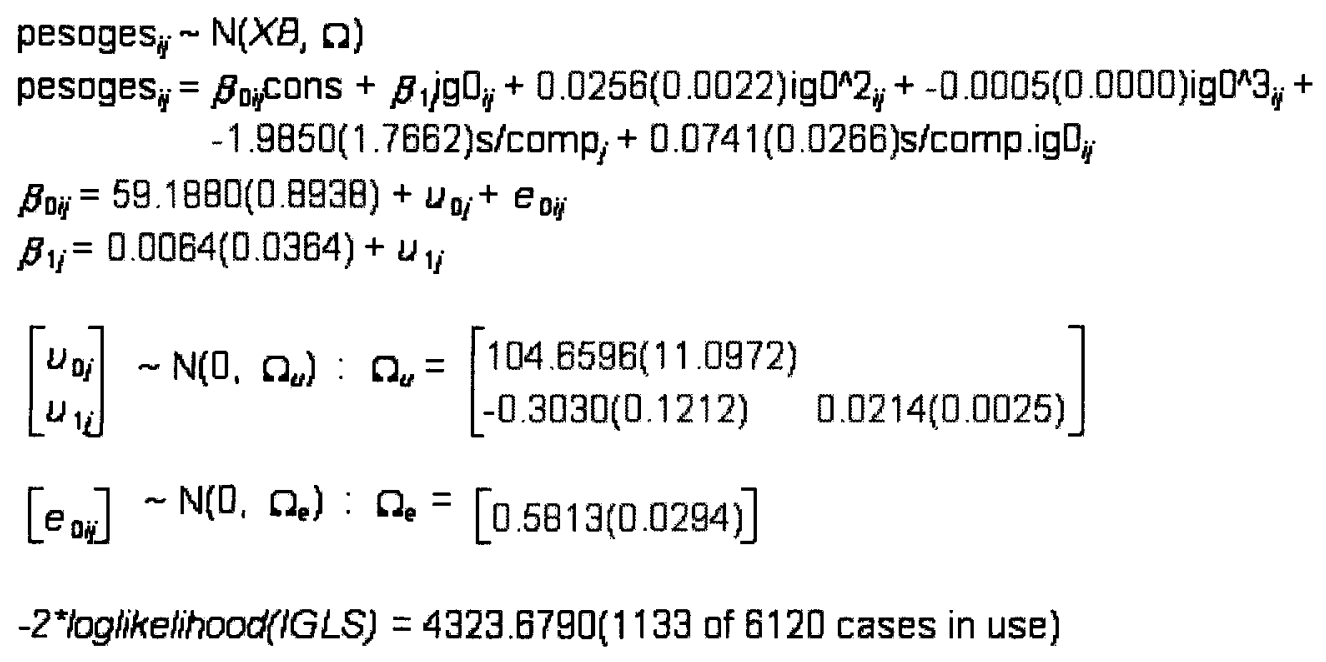


Modelo 15: Modelo 14 e termo de interação situação marital e termo quadrático da dade gestacional

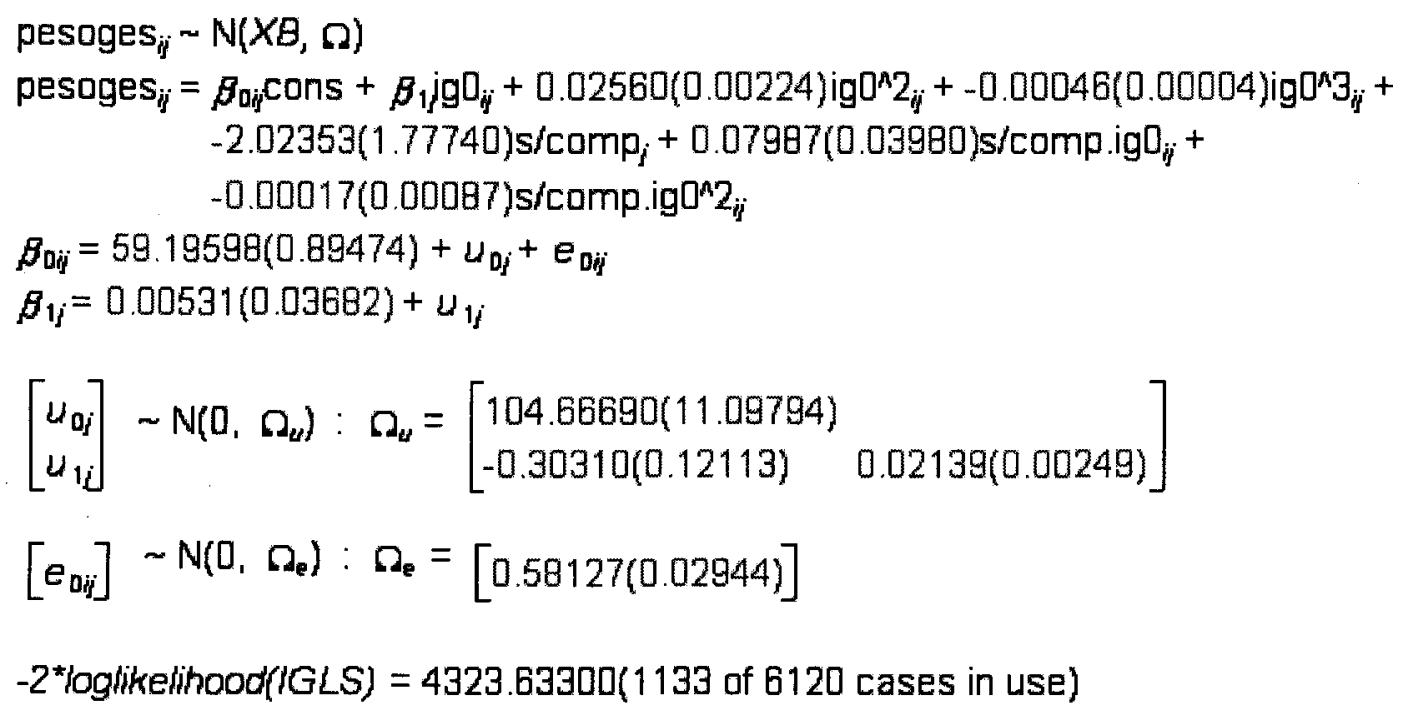

Modelo 15a: Modelo 15 e termo de interação situação marital e termo quadrático da dade gestacional

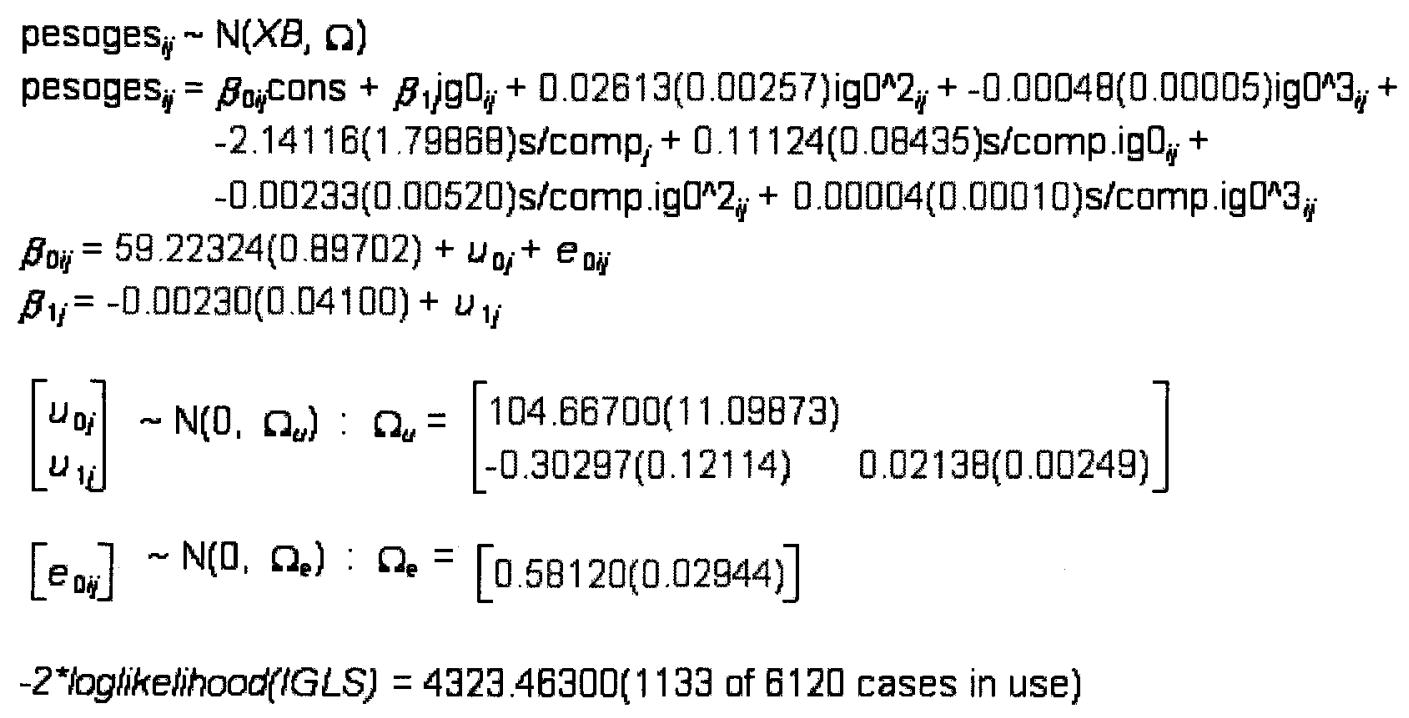


Modelo 16: Modelo 4 e variável do nível 2 - idade

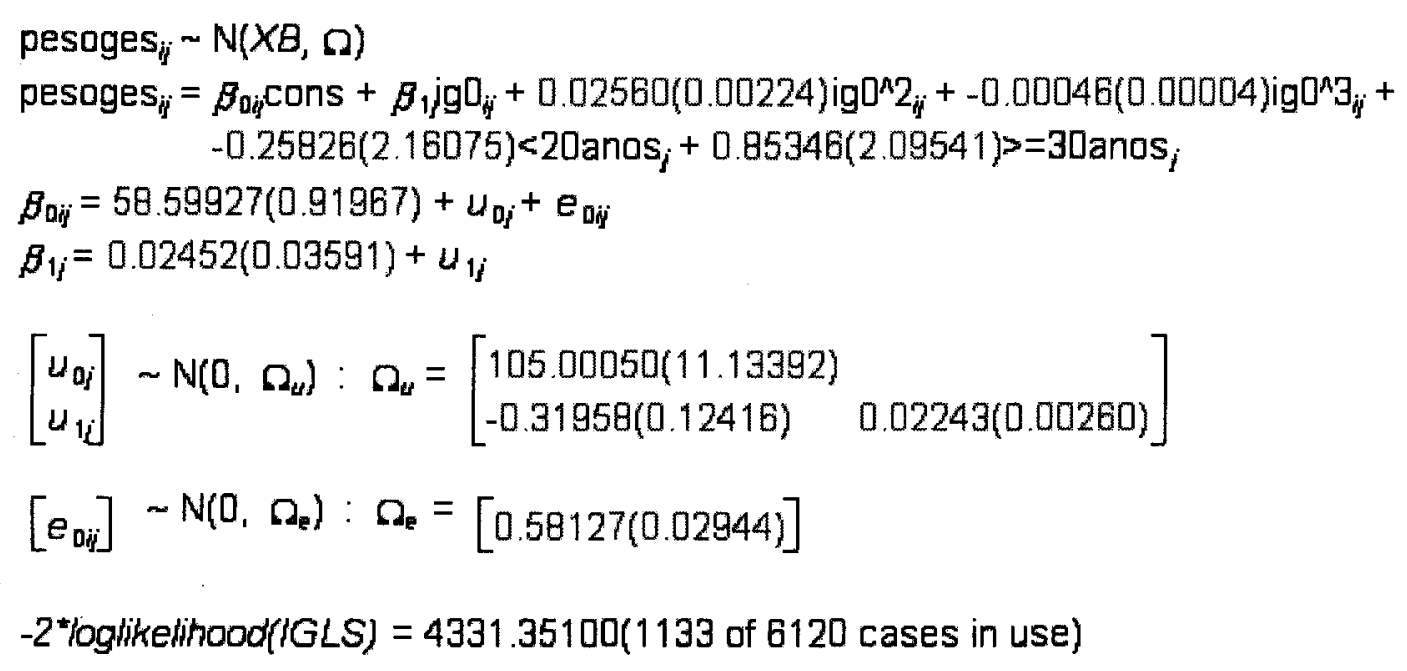

Modelo 16a: Modelo 16 e termo de interação idade e idade gestacional

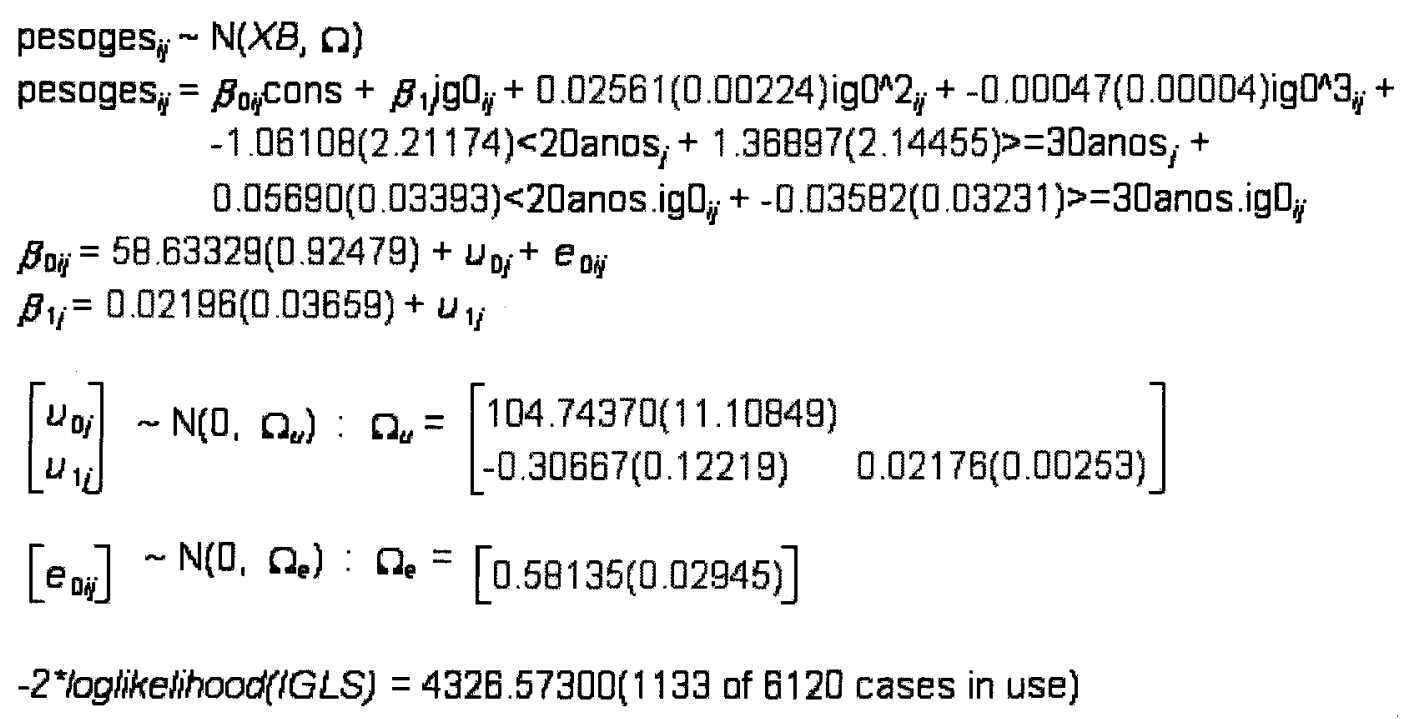


Modelo 17: Modelo 16 e termo de interação idade e termo quadrático da idade gestacional

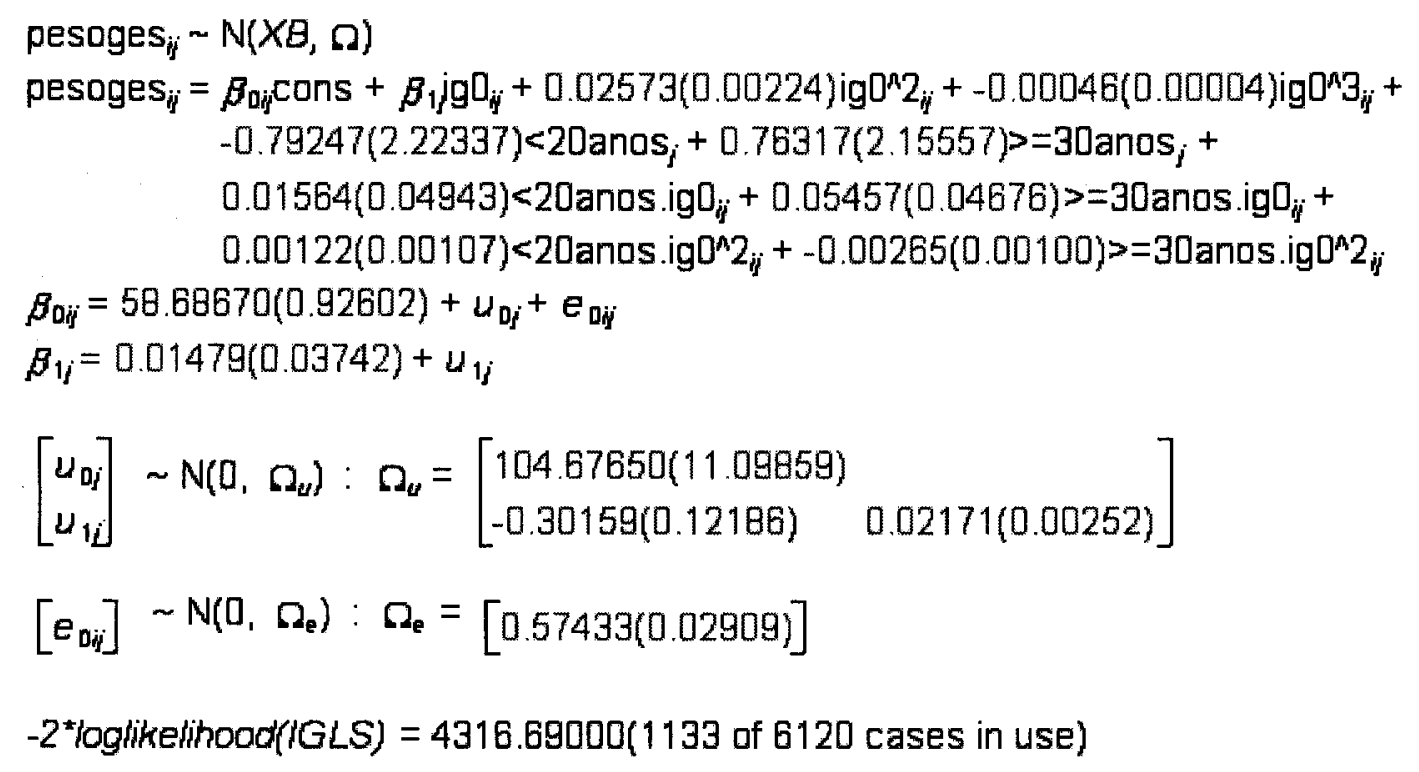

Modelo 17a: Modelo 17 e termo de interação idade e termo cúbico da idade gestacional

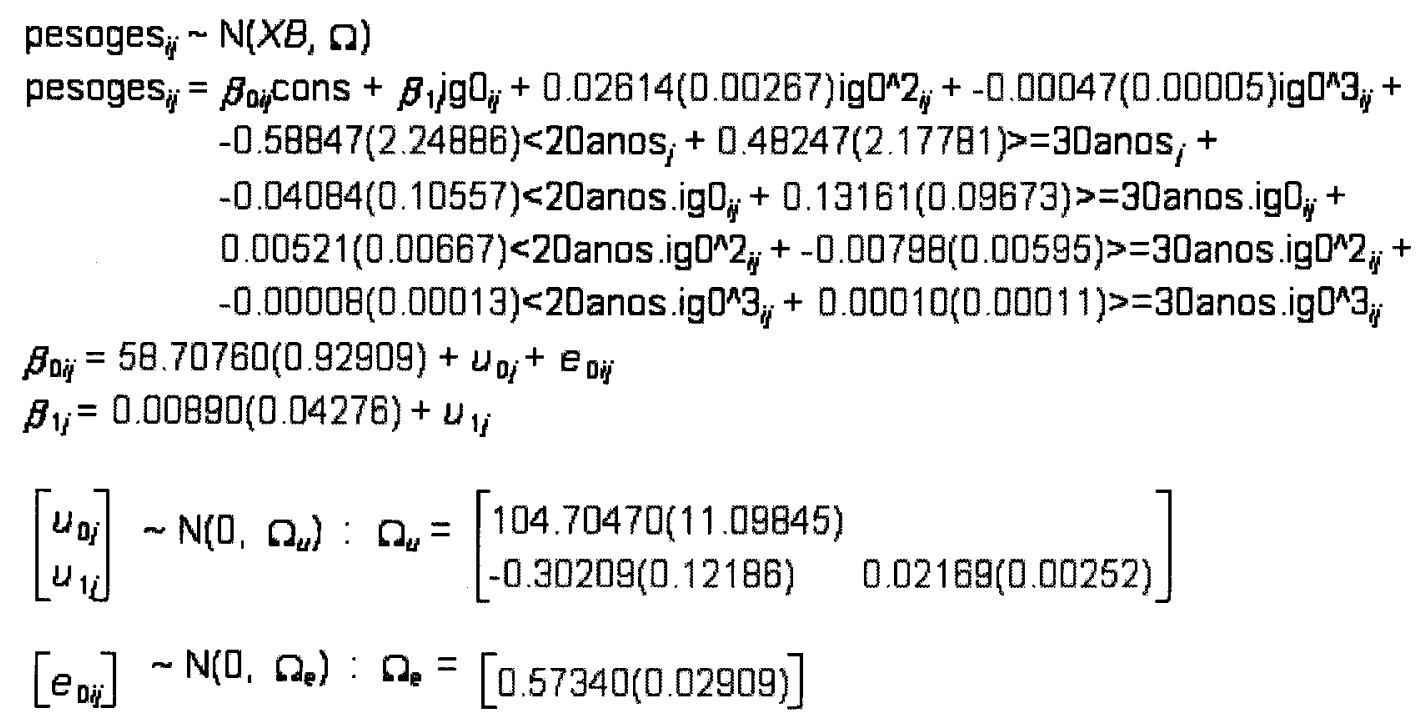


Modelo 18: Modelo 4 e variável do nível 2: paridade

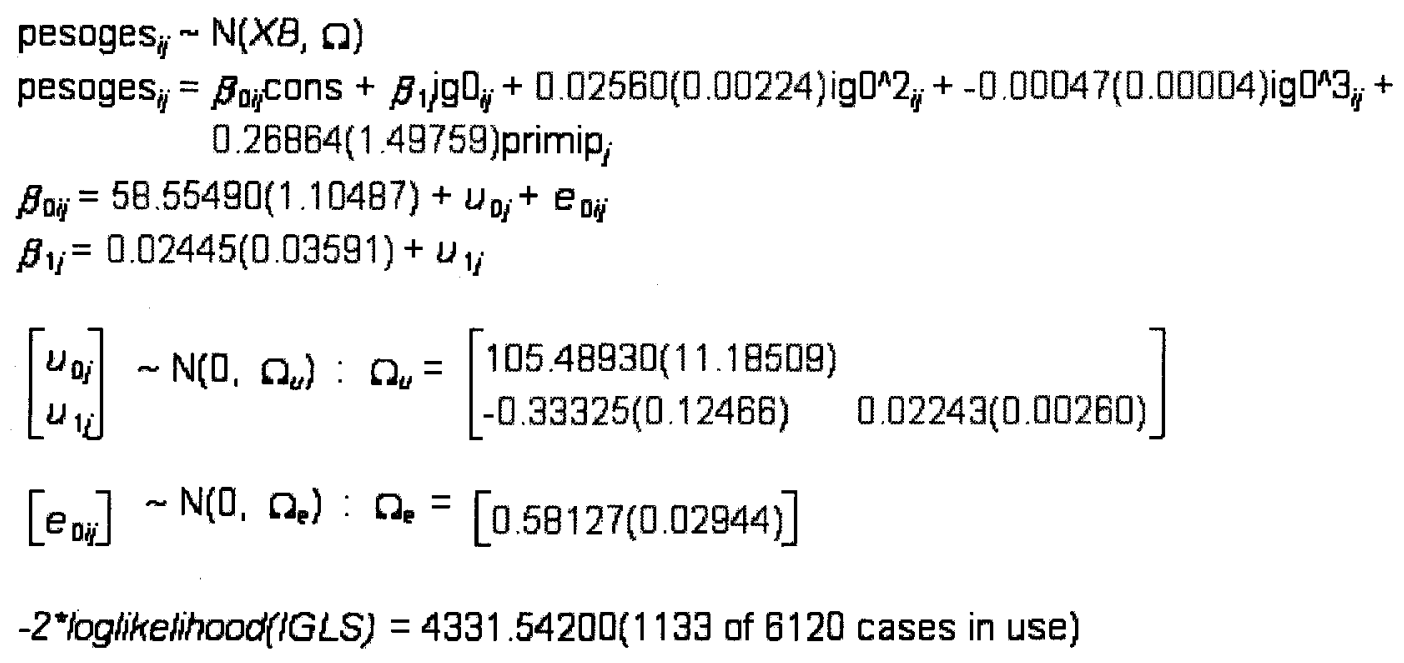

Modelo 19: Modelo 18 e termo de interação paridade e idade gestacional

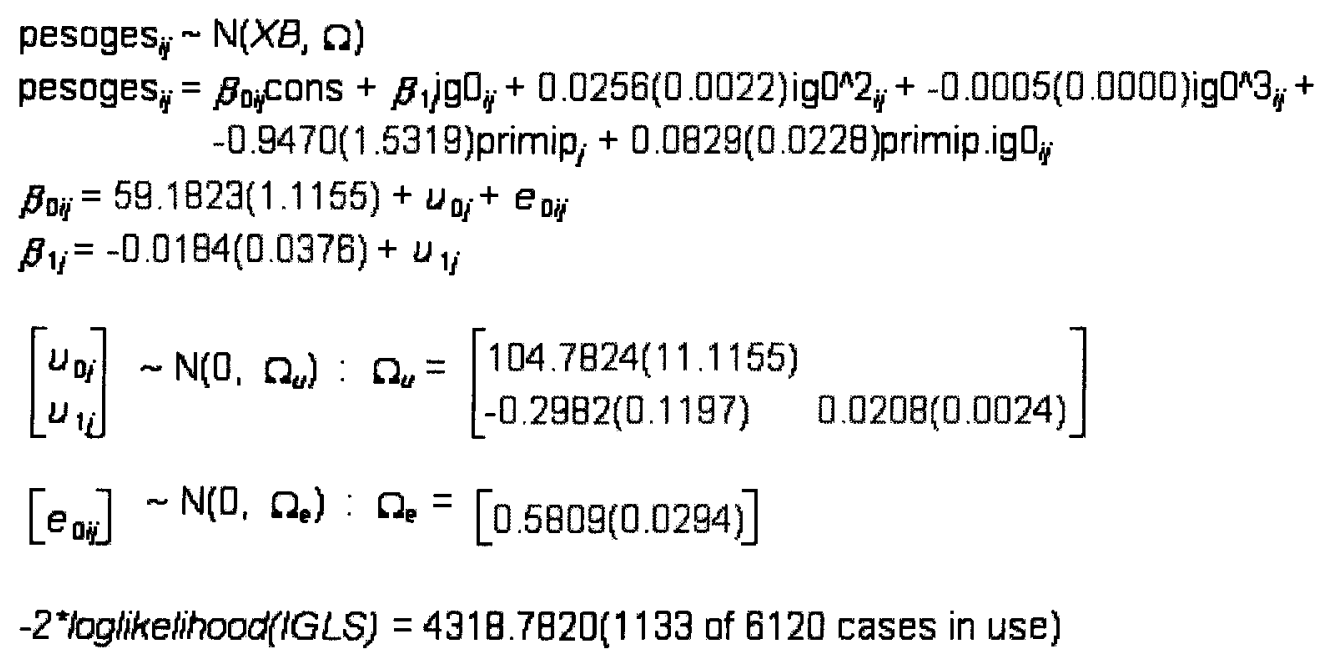


Modelo 20: Modelo 19 e termo de interação paridade e termo quadrático da idade gestacional

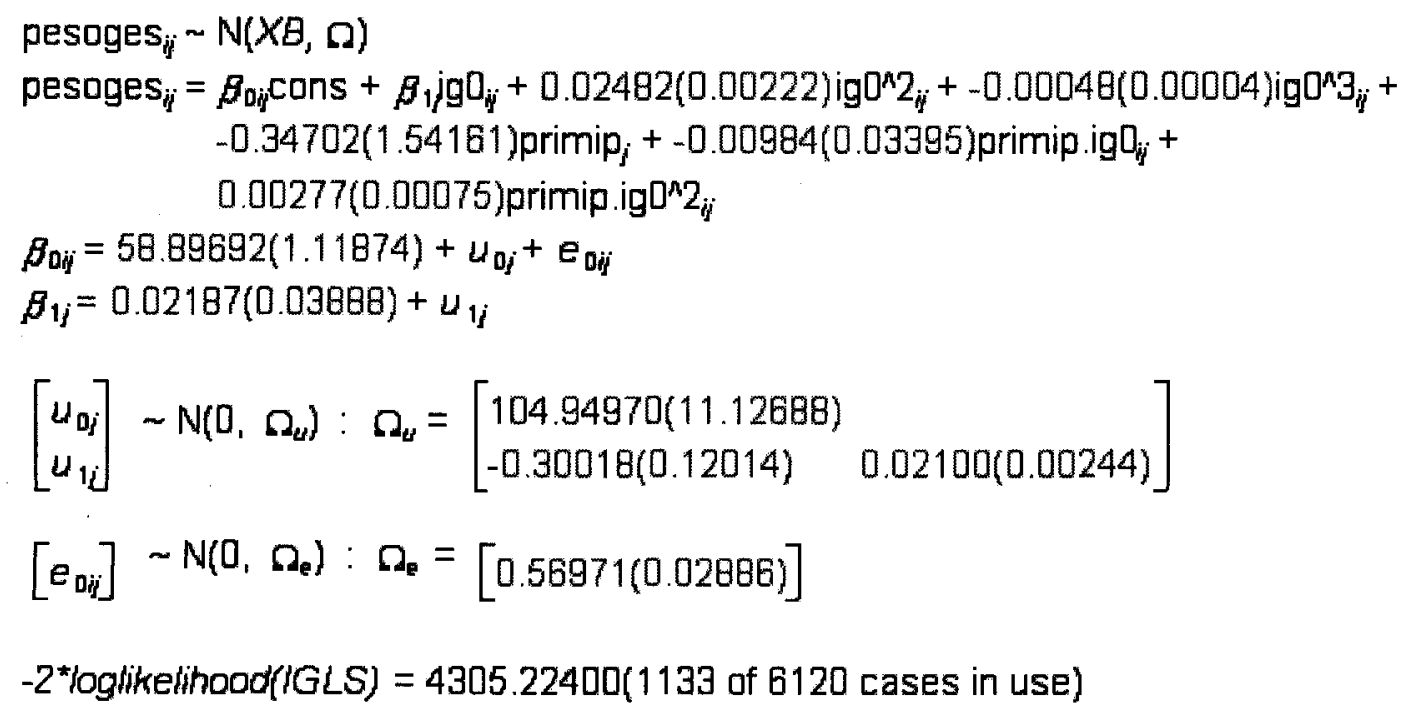

Modelo 20a: Modelo 20 e termo de interação paridade e termo cúbico da idade gestacional

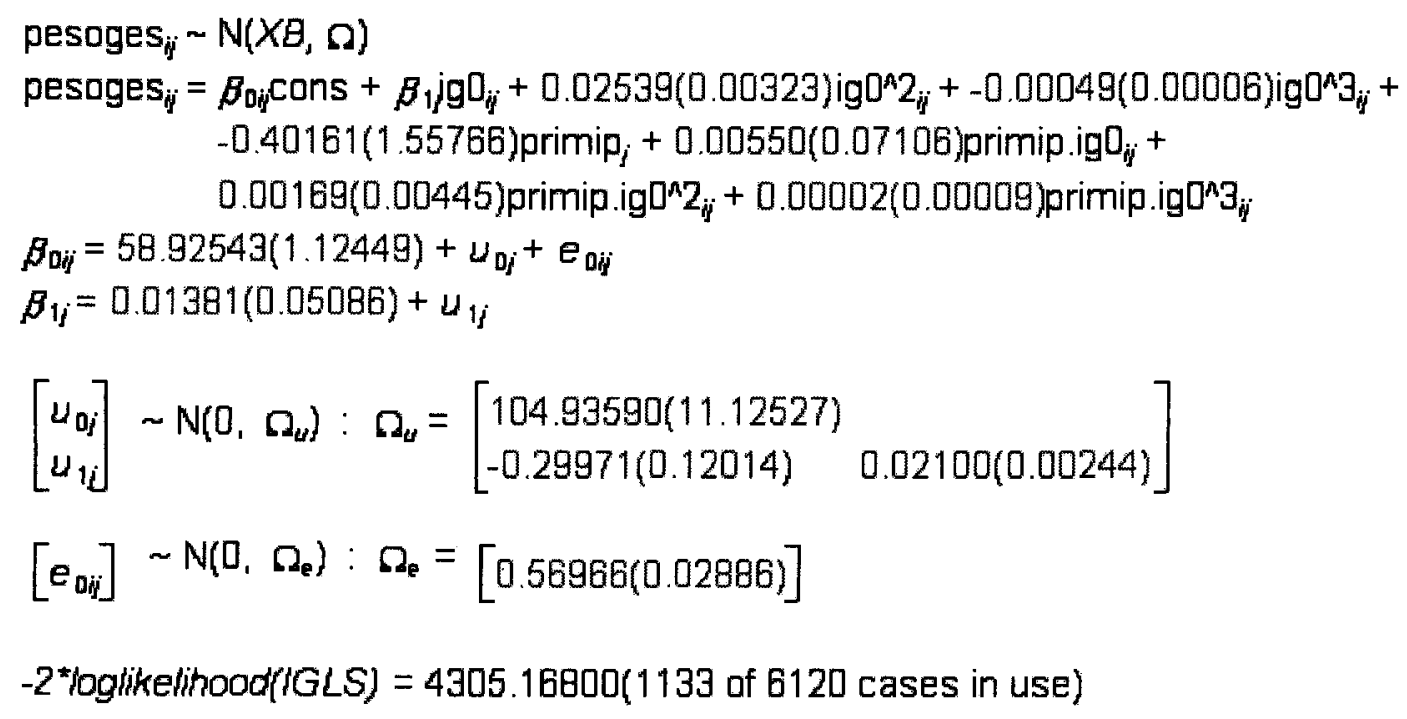


Modelo 21: Modelo 4 e variável do nível 2 - tabagismo

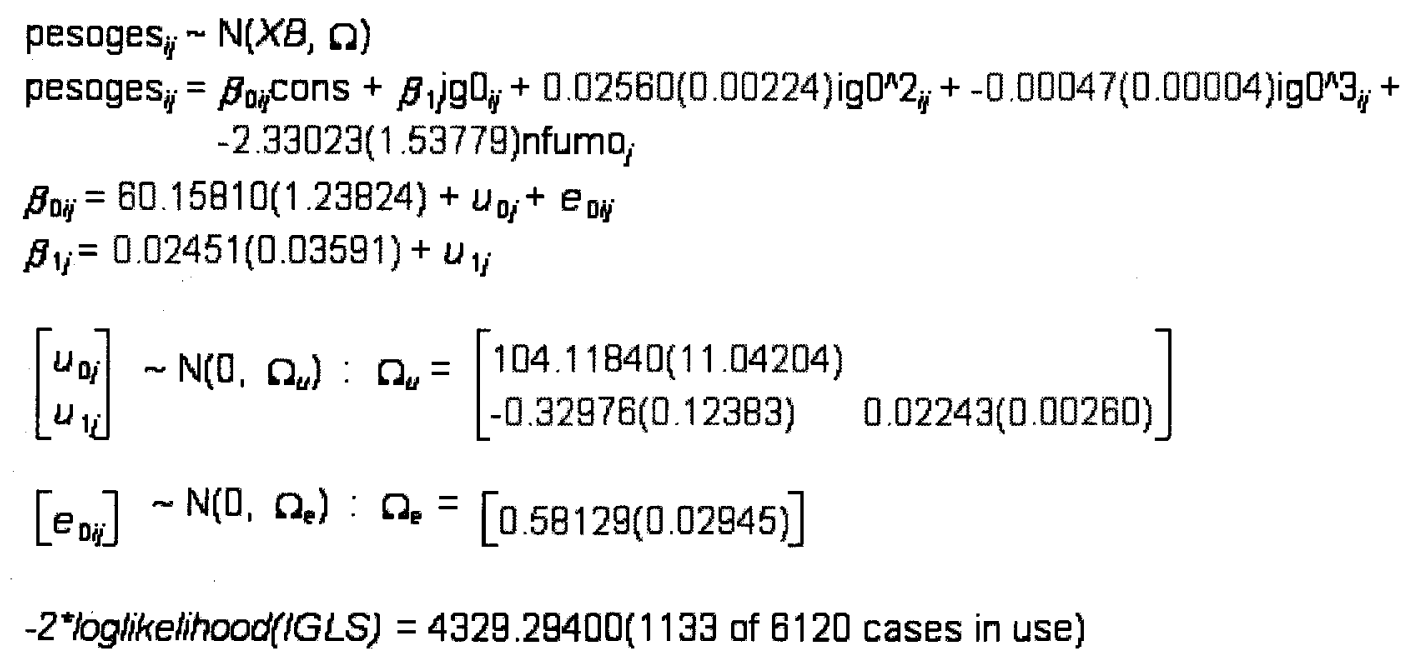

Modelo 21a: Modelo 21 e interação tabagismo e idade gestacional

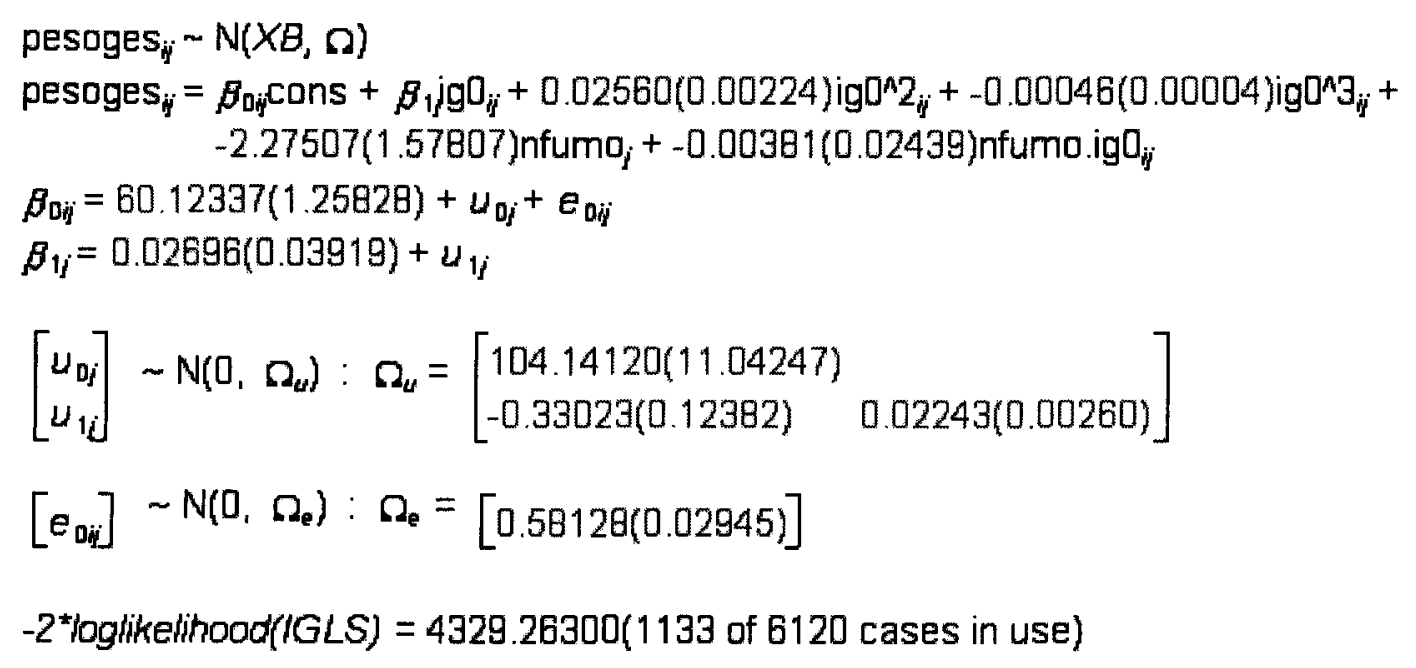


Modelo 22: Modelo 21 e termo de interação tabagismo e termo quadrático da idade gestacional

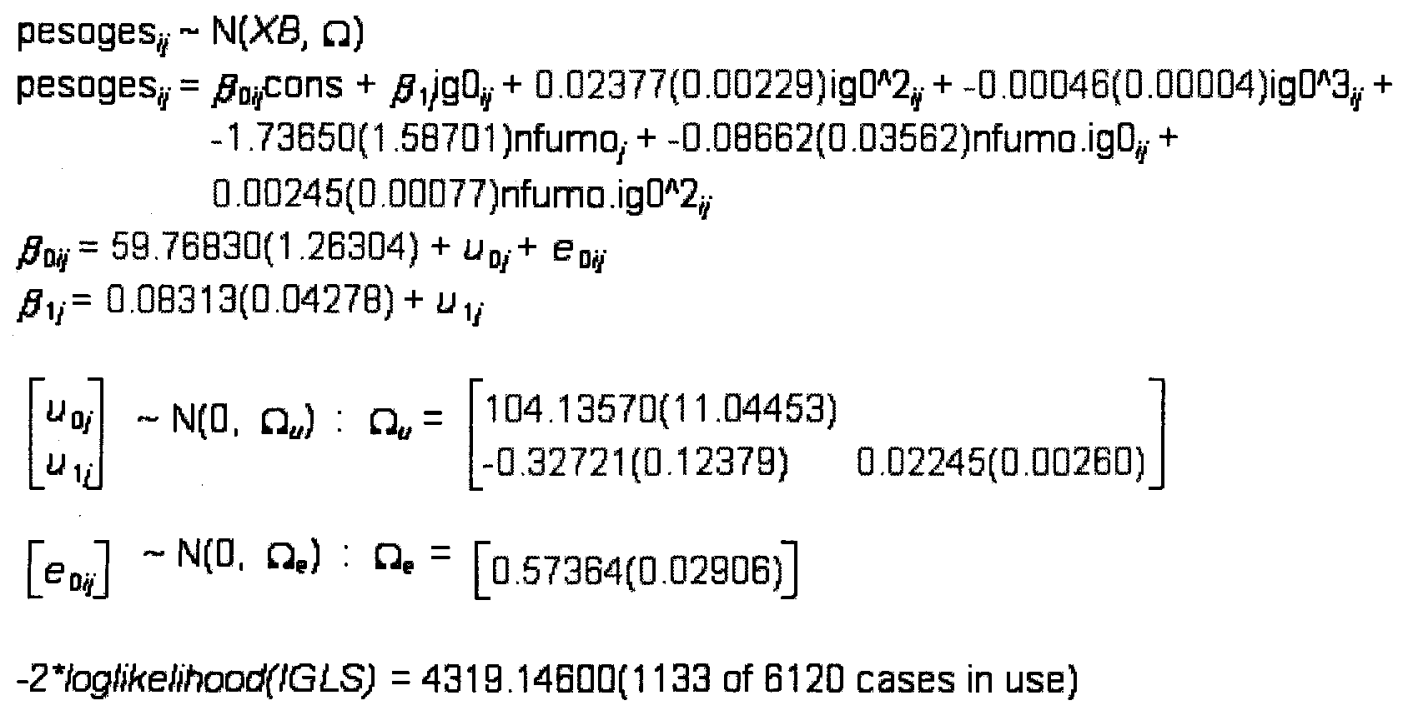

Modelo 22a: Modelo 22 e termo de interação tabagismo e termo cúbico da idade gestacional

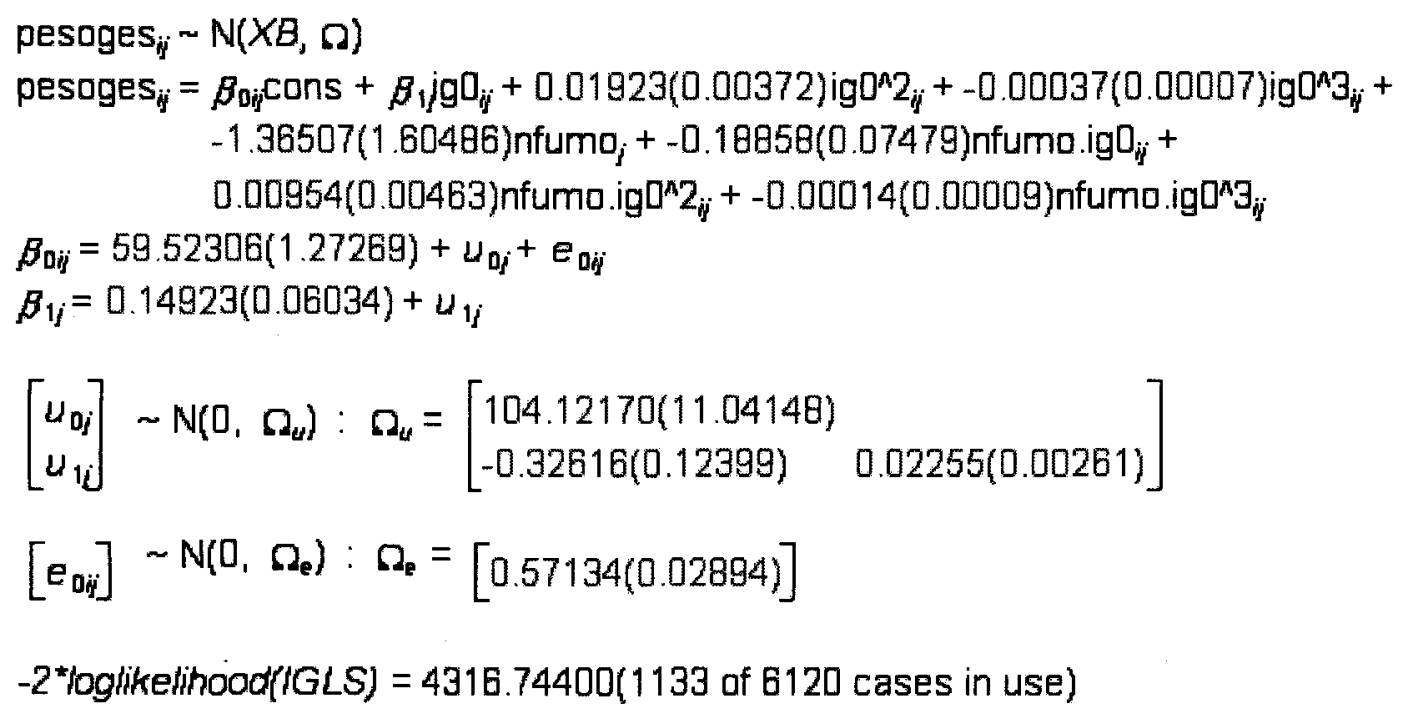




\section{Anexo 8}

Modelo final e interação com idade e paridade

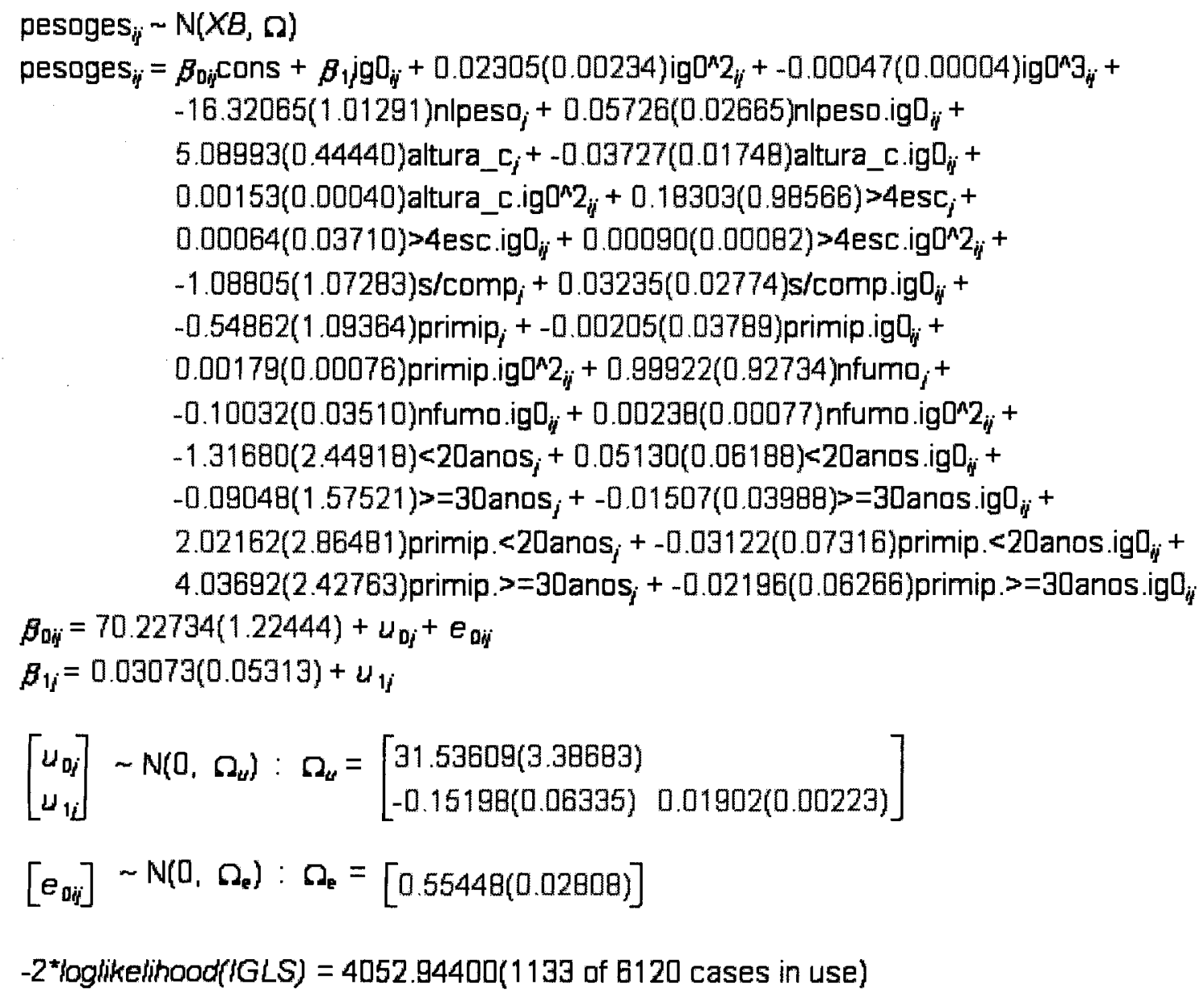




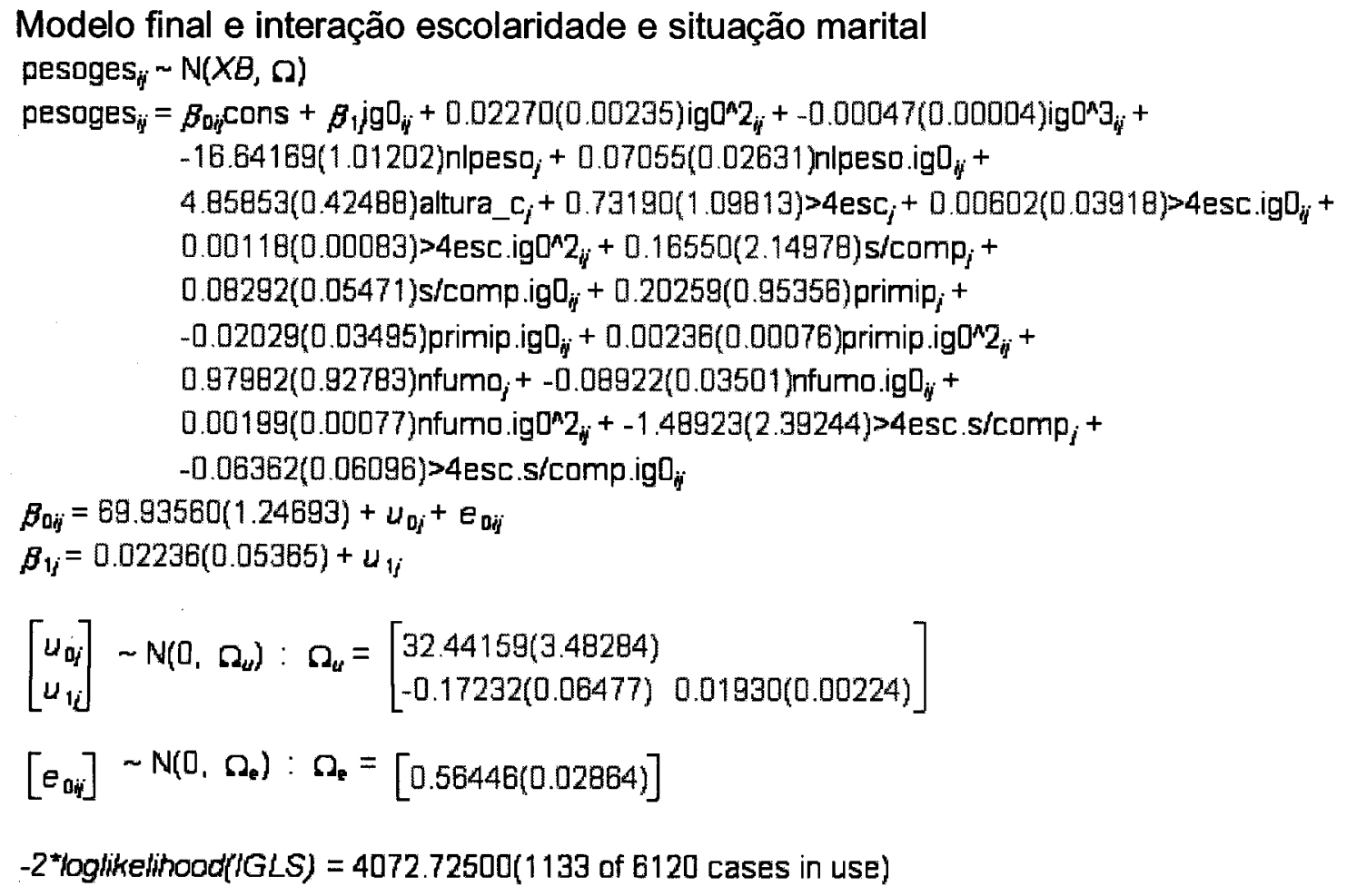




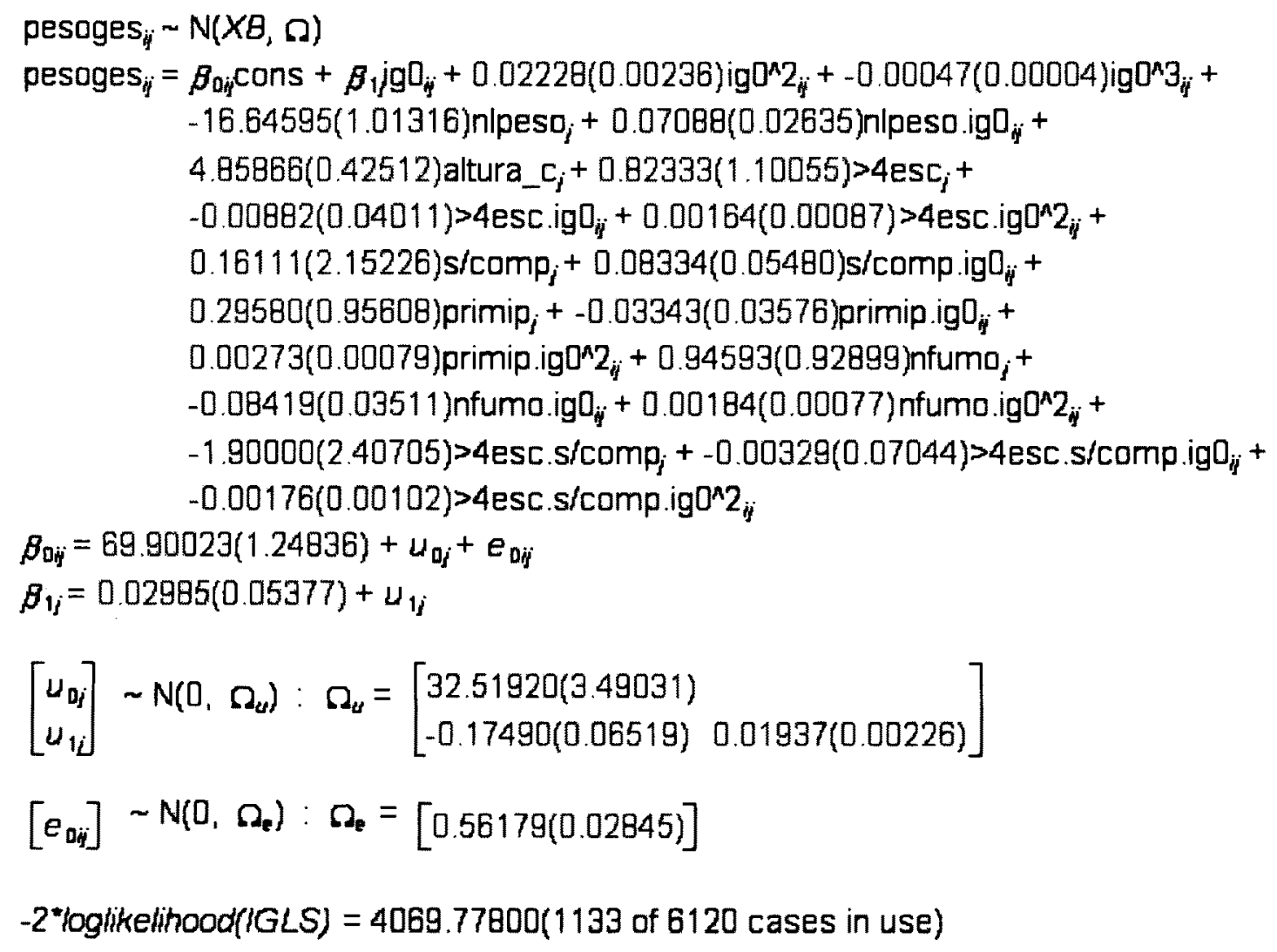

